\title{
THE ANATOMY OF HEALTH INSURANCE
}

\author{
David M. Cutler \\ Richard J. Zeckhauser \\ Working Paper 7176 \\ http://www.nber.org/papers/w7176
NATIONAL BUREAU OF ECONOMIC RESEARCH
1050 Massachusetts Avenue
June 1999 \\ Cambridge, MA 02138
}

This paper was prepared for the Handbook of Health Economics. We are grateful to Dan Altman for research assistance, to Jon Gruber, Tom McGuire, and Joe Newhouse for helpful comments, and to the National Institutes on Aging for research support. All opinions expressed are those of the authors and not those of the National Bureau of Economic Research.

(C) 1999 by David M. Cutler and Richard J. Zeckhauser. All rights reserved. Short sections of text, not to exceed two paragraphs, may be quoted without explicit permission provided that full credit, including $\mathbb{C}$ notice, is given to the source. 
The Anatomy of Health Insurance

David M. Cutler and Richard J. Zeckhauser

NBER Working Paper No. 7176

June 1999

JEL No. I1

\section{ABSTRACT}

This article describes the anatomy of health insurance. It begins by considering the optimal design of health insurance policies. Such policies must make tradeoffs appropriately between risk sharing on the one hand and agency problems such as moral hazard (the incentive of people to seek more care when they are insured) and supplier-induced demand (the incentive of physicians to provide more care when they are well reimbursed) on the other. Optimal coinsurance arrangements make patients pay for care up to the point where the marginal gains from less risk sharing are just offset by the marginal benefits from less wasteful care being provided. Empirical evidence shows that both moral hazard and demand-inducement are quantitatively important. Coinsurance based on expenditure is a crude control mechanism. Moreover, it places no direct incentives on physicians, who are responsible for most expenditure decisions. To place such incentives on physicians is the goal of supply-side cost containment measures, such as utilization review and capitation. This goal motivates the surge in managed care in the United States, which unites the functions of insurance and provision, and allows for active management of the care that is delivered.

The analysis then turns to the operation of health insurance markets. Economists generally favor choice in health insurance for the same reasons they favor choice in other markets: choice allows people to opt for the plan that is best for them and encourages plans to provide services efficiently. But choice in health insurance is a mixed blessing because of adverse selection -- the tendency of the sick to choose more generous insurance than the healthy. When sick and healthy enroll in different plans, plans disproportionately composed of poor risks have to charge more than they would if they insured an average mix of people. The resulting high premiums create two adverse effects: they discourage those who are healthier but would prefer generous care from enrolling in those plans (because the premiums are so high), and they encourage plans to adopt measures that deter the sick from enrolling (to reduce their overall costs). The welfare losses from adverse selection are large in practice. Added to them are further losses from having premiums vary with observable health status. Because insurance is contracted for annually, people are denied a valuable form of intertemporal insurance -- the right to buy health coverage at average rates in the future should they get sick today. As the ability to predict future health status increases, the lack of intertemporal insurance will become more problematic.

The article concludes by relating health insurance to the central goal of medical care expenditures -- better health. Studies to date are not clear on which approaches to health insurance promote health in the most cost-efficient manner. Resolving this question is the central policy concern in health economics.

David M. Cutler

Department of Economics

Harvard University

Cambridge, MA 02138

and NBER

dcutler@fas.harvard.edu
Richard J. Zeckhauser

Kennedy School of Government

Harvard University

Cambridge, MA 02138

and NBER

richard_zeckhauser@harvard.edu 
Insurance plays a central role in the health care arena. More than 80 percent of health care expenditures in the United States are paid for by insurance, either public or private, with an even greater percentage supported in most other developed nations. Insurance thus provides the money that motivates and supports the health care system.

This paper describes the anatomy of health insurance. At the micro level, it details why individuals seek insurance, and the challenges in structuring insurance policies. At the macro level, it explains the role of health insurance in the medical care sector. The medical care triad (figure 1) depicts that sector in a fundamental fashion. Insurers mediate between individuals ${ }^{1}$ and their providers. Often times, the flow of funds is more roundabout: governments or employers nominally pay insurers, but these costs are then passed on to individuals, via increased taxes or lower wages.

The insurer intermediary must design a policy to pay for (and possibly provide) care. This is a treacherous task. Designing a health insurance policy is not nearly so challenging technologically as, say, designing a personal computer system, but it must still overcome some distinct and substantial economic obstacles. The most important of these obstacles are agency problems. Insurers cannot get relevant parties to do what efficiency requires. Thus, people with generous insurance spend more on medical care than people with less generous insurance (moral hazard), and providers paid on a fee-for-service (piece-rate) basis may provide more care due to supplier-induced demand than they would if they were not paid per task. In a situation where agency relationships are imperfect, insurance is necessarily second-best. Insurers must trade off the benefits from more generous insurance - primarily the reduction in risk it affords - against the costs of more

${ }^{1}$ Throughout the paper, to facilitate exposition, we mostly refer to patients or insureds as individuals, although most health insurance is purchased on behalf of families. 
generous insurance - moral hazard or supplier-induced demand. Throughout this chapter, we highlight central lessons about health insurance, which are then collected in Table 10. This clash between risk sharing and incentives is Lesson 1 about health insurance.

Agency problems in health care can be alleviated in two ways. The demand-side approach discourages excessive utilization by making people pay something when they consume medical care. Demand-side rationing is epitomized in the traditional indemnity insurance plan, which prevailed in the United States for a half century. The supply-side approach discourages utilization by monitoring providers carefully, penalizing them if they are profligate, and giving them financial incentives to provide only essential care. Increasingly, supply-side limitations are fostered by integrating insurance and provision. Some HMOs, for example, are both insurers and providers of care. Integration of the insurance and provision functions is unique to medical care, and results from the fundamental difficulties with just demand-side rationing. The integration of health insurance and provision of medical services is Lesson 2 about health insurance. Sections III through V of the chapter lay out the issues involved in demand- and supply-side rationing.

We then move from these micro relationships to the broader arena of the market for health insurance. People have preferences for different types of health insurance, and those preferences should be accommodated to the extent possible. In addition, competition in health insurance can encourage production efficiency, driving down overall costs. But competition in health insurance produces results unlike competition in other markets, for a fundamental reason: the costs of providing insurance, as opposed to say computers or food, depend on the characteristics of the buyer. People with a poor medical history will benefit more from and cost more to insure than those with a healthy past. Thus, the sick will sort themselves into more generous plans than will the healthy. 
This process, called adverse selection, can substantially limit the benefits of health plan choice. Individuals will have incentives to choose less generous policies over more generous ones (to pool with the healthy instead of the sick) and insurers will have incentives to reduce the generosity of their benefits (to attract the healthy instead of the sick). Lesson 3 describes the consequences of competition when buyer identity affects costs. Section VI discusses adverse selection and approaches to deal with it.

The natural tendency of insurers to charge the sick greater premiums than the healthy presents a further challenge to health insurance: lack of coverage against the long-term risk of becoming sick and having higher expected costs in the future. Using the thought experiment of individuals making choices behind the veil of ignorance, they would choose to insure their risk of becoming sicker than average, a multi-year risk, just as individuals in any year wish to insure their medical costs that year. Markets for multi-year insurance do not exist, however, for understandable reasons, and in practice individuals are left without this insurance. The kernel of the problem is that information on risk levels becomes available before insurance contracts can be drawn. Lesson 4 is that early information dries up insurance markets. Long-term insurance is taken up in Section VII of the chapter.

However effectively health insurance controls costs or spreads risks, the focus of most of this chapter, its key goal is to promote health. In Section VIII we examine the relationship between health insurance and health. Variations in insurance generosity have relatively little impact on health among those with insurance. This finding is consistent with the idea that insurance generally restricts care offering relatively low value. But the time frame over which these issues has been examined is not large. We know less about the long-run effect of different health insurance arrangements on health than we should. We mark the centrality of health as opposed merely to 
financial transfers and the lack of clear evidence on the relative benefits of different systems as Lesson 5 about health insurance.

At the outset, it is important to take account of the distinctive role health insurance plays in society. Economists traditionally measure value by willingness to pay, and the value of health insurance, or its byproduct medical care, is calibrated in dollar terms, the same as apples or television sets. In much of the world, however, particularly outside the United States, medical care and medical insurance are treated differently. Medical care is often viewed as a right, for which marketbased allocation is not appropriate. For some, the right is absolute; markets should play no role in the allocation of medical services. More moderate positions assign government a special responsibility for medical care, which leads to a government insurance system or set of subsidies. Rights-oriented sentiments show up even in the United States. The United States subsidizes medical insurance directly for poor people and old people, and indirectly for the working-age population (through the exclusion of health insurance from individual taxable income). While some such subsidies may be justified on externality grounds (when people get medical care, they are less likely to spread infectious diseases to others), merit good arguments, or fiscal externality arguments (when people are healthier, they earn more, pay more in taxes, and receive less in public benefits), we suspect that a right to medical care is the more basic motive.

But the rationale for subsidizing health insurance, as opposed to medical care, is less clear. The government could promote consumption of medical care through direct delivery of services or by subsidizing inputs, without intervening in the medical insurance market. We thus focus primarily on the economic analysis of health insurance, leaving aside normative views about access to basic medical services [CITE OTHER CHAPTERS]. We come back to the access issue in the last section. 
In this essay, we follow common parlance by [primarily] using the terms health care and health insurance, although the terms medical care and medical care insurance might be better descriptors. Health status cannot be insured. The costs of medical care can be, and are, albeit often bearing the label health insurance.

We begin in the first section by discussing the provision of health insurance around the world and in the second with a review of the principles of insurance. We then examine the micro and macro issues in health insurance.

\section{Health Insurance Structures in Developed Nations}

Health insurance is common to all developed countries, but the mechanism for obtaining insurance differs from country to country. In most countries, health insurance is universal; everyone is entitled to coverage and is required to purchase it. ${ }^{2}$ In some nations, such as Canada, the financing is through taxation; people pay an income or payroll tax, and the proceeds are used by the government to purchase or provide health insurance. In other nations, the financing is through private insurance; individuals or their employers contribute to health insurance companies, which then provide insurance for the population. While the payment for any individual may differ in these two systems (a tax financed system generally imposes relatively more on the rich), the implications for the provision of health insurance are generally slight. Governments in both systems are intimately involved in determining what services are covered, the cost sharing that patients face, and

2 In some countries, such as Germany, temporary workers do not receive health insurance, but they comprise a small part of the population. All citizens are entitled to insurance. 
the restrictions imposed on providers.

The specifics of health insurance structures differ significantly across developed nations. Countries like England and Italy finance health insurance through general taxation and (at least historically) provide services publicly. ${ }^{3}$ Countries such as Canada and Germany finance insurance publicly but contract for services through private providers.

\section{I.1 Health Insurance in the United States}

Describing the detailed structures for health insurance in different nations would take an entire volume. We focus our attention primarily on the United States. The United States is distinctive among OECD countries because health insurance is not universal. ${ }^{4}$ Table 1 shows the sources of health insurance in the United States. About one-quarter of the United States population is insured through the public sector. The primary public programs are Medicare, which mostly insures the elderly, along with the disabled and people with kidney failure; and Medicaid, which insures younger women and children, the elderly (for services not covered by Medicare such as nursing home care), and the blind and disabled. Other public programs, primarily for veterans and dependents of active duty military personnel. insure another 1 percent of the population.

Another 60 percent of the population has private health insurance. Most of this insurance is provided by employers; less than 10 percent of the population purchases insurance privately. The

${ }^{3}$ Countries like the U.K. have moved to more of a decentralized provision system in recent years. Hospitals have been set up as private trusts, for example, and physicians are no longer salaried.

${ }^{4}$ Health insurance coverage is not required in Switzerland but it is subsidized so heavily that essentially everyone purchases it. 
predominance of employer-provided insurance results from the favorable tax treatment of that method of payment. Compensation to employees in the form of wages and salaries is taxed through Federal and state income taxes, and through the Federal Social Security tax. Compensation paid as health insurance, in contrast, goes untaxed. Since marginal tax rates range from 15 to 40 percent for most employees, ${ }^{5}$ the subsidy to employer-provided insurance, as opposed to individually-purchased insurance, is substantial. The subsidy to employer-provided health insurance generally does not extend, however, to out-of-pocket payments made by employees. As a result, there are incentives to have generous insurance, paid for by employers, with few individual copayments. We return to the effects of this subsidy structure below.

The remaining 15 percent of the United States population is uninsured. The implications of being uninsured are a subject of vigorous debate (Weissman and Epstein, 1994). Some of the uninsured (perhaps 4 percent) are eligible for public insurance (particularly Medicaid) but have chosen not to take up that insurance. Presumably, if these people become sick they will enroll in Medicaid. ${ }^{6}$ Others will receive "uncompensated" care if they become sick-they will get emergency care if they need it, but they will not pay for it. The costs of uncompensated care then get shifted to people with insurance, for whom payments made exceed the cost of services provided. In this sense, the United States has a form of universal insurance coverage for catastrophic care, although the patchwork nature of that coverage is undoubtedly suboptimal. It also limits primary and preventive care for those without health insurance.

\footnotetext{
${ }^{5}$ Income tax rates can range as high as 40 percent, but the income level at which these rates are reached are past the cap on earnings subject to the payroll tax.

${ }^{6}$ Since it is difficult to deny treatment, providers have a strong interest to enroll eligible people in Medicaid, so that they can receive some payment for them.
} 
The last column of Table 1 shows the share of total payments that each group makes. As in any insurance policy, people may use more or less of the service than they pay for. This is particularly true for the uninsured, whose out-of-pocket payments are much lower than the cost of services they receive. The table reports the share of total payments made by each group; the share of services that is used by each group will be somewhat different. Because people insured through the public sector are older and sicker than people insured privately, and because some of the costs of the uninsured are passed on to the public sector, the public sector accounts for much more of medical spending than its demographic share of insurance coverage. Close to half of medical spending in the United States is paid for publicly. While this amount is extremely high relative to most goods and services in society, it is low by international standards for medical care. In OECD nations, governments generally pay for 75 to 90 percent of medical care.

Whether run publicly or privately, health insurance encounters fundamental problems that any insurer must face. Adverse selection, though diminished for government since some of its programs are so heavily subsidized that the vast majority choose to participate, still exists, and moral hazard affects governments no less than private insurers. Thus, when we discuss the optimal design of health insurance policies, we do not distinguish between public or private insurers. We return to public versus private insurance issues in the conclusion.

\section{The Principles of Insurance}

In this section and the next three, we discuss the optimal design of health insurance policies. Our perspective is that of an insurer -- public or private -- wanting to optimally insure its enrollees 
against the costs of treating adverse health outcomes.

The value of health insurance is rooted in the unpredictability of medical spending. While individuals know something about their need for medical services, the exact amount they will spend on medical care is to a significant degree uncertain. Medical spending is extremely variable. Table 2 shows the distribution of medical spending in the United States in 1987 (Berk and Monheit, 1992). The top 1 percent of medical care users consume an average of nearly $\$ 50,000$ each in a year (in 1987 dollars), and account for 30 percent of medical spending. The top 10 percent of users account for nearly three-quarters of total medical spending. The shorter the time period, of course, the greater is the percentage disparity in medical spending among individuals. But even looking over several years, the skewness of medical spending is substantial (Roos et al., 1989; Eichner, McClellan, and Wise, 1998). In such a situation, insurance can significantly spread risks.

Risk averse individuals will want to guard against the potential of requiring a substantial amount of medical care. One way to do this is to wait, borrow money for treatment should they get sick, and then repay the money when well. But borrowing when debilitated is difficult, since the individual may not live long enough or be healthy enough to repay the loan. The borrowing process, moreover, may also take more time than the sick individual has available. A reasonable alternative might be for individuals to save money when they are healthy to pay for medical care should they get sick. But some sicknesses are significantly more expensive than others. The substantial expenses of very severe illness make saving prior to illness impractical as a protective measure. All of us would have to significantly curtail consumption to save up for expenses that would be borne by only a few. The natural solution is to insure against the possibility of medical illness by pooling risks with others in the population. Annual consumption would be reduced only by the premium, 
the average cost of care.

Risks to health have always been with us, but health insurance is a relatively new phenomenon, only becoming economically significant in the postwar era. Fire and life insurance were well developed by the end of the 19th century, and marine insurance was already being written in the 12th century. There was little role for health insurance in earlier eras, however, since expensive medical treatments could accomplish little for health. Insurers also feared they could not control individual use of medical services if the services were insured. Once effective hospital care -- an extremely expensive commodity -- became possible, significant health insurance became desirable and inevitable.

\section{II.I Insurance with fixed spending}

The simplest insurance situation is one where sickness entails a fixed cost and insurance is priced at its actuarial cost. Imagine a situation where initially identical individuals are either healthy or sick in a period of one year. There is one disease. People are healthy with probability 1-p, in which case they require no medical care. People get sick with probability $p$. Let $d=0$ or $d=1$ indicate whether absent medical care the person is healthy or sick. Treatment of a person who is sick requires medical spending of $m$. The after-expenditure health of a sick person is $h=H[d, m]$. To simplify exposition, we assume that medical spending restores a person to perfect health, so that $\mathrm{H}[1, \mathrm{~m}]=\mathrm{H}[0,0]$.

Before proceeding, we alert the reader to our use of mathematics. We use mathematics to derive statements precisely. We also endeavor to explain all of our results intuitively. Thus, readers who wish to skip the mathematical portions of the chapter can still follow the central arguments. 
Individuals receive utility, $\mathrm{u}$, which depends on their consumption, $\mathrm{x}$, and their aftertreatment health, $h$. Thus we have $u=U(x, h)$. Assume. for simplicity, that people have exogenous income endowments, $y$; and that they can neither borrow or lend. Thus, an individual's consumption is what is left over after paying medical expenditures, or if insured, his insurance premium, $\pi$. Thus, for uninsured people, $x=y$ when healthy and $x=y-m$ when sick. For insured people, $x=y-\pi$ whether healthy or sick. We use the subscripts I and $\mathrm{N}$ to indicate whether the individual is insured or not insured.

Let $U(x) \equiv U(x, H[0,0])$; i.e., it is the reduced form utility function for consumption given perfect health. In the absence of insurance, an individual's expected utility is given by:

$$
\begin{aligned}
\mathrm{V}_{\mathrm{N}} & =(1-\mathrm{p}) \mathrm{U}(\mathrm{y}, \mathrm{H}[0,0])+\mathrm{pU}(\mathrm{y}-\mathrm{m}, \mathrm{H}[1, \mathrm{~m}]), \\
& =(1-\mathrm{p}) \mathrm{U}(\mathrm{y})+\mathrm{p} \mathrm{U}(\mathrm{y}-\mathrm{m}),
\end{aligned}
$$

where the second equality follows from the assumption that medical care restores the person to perfect health. ${ }^{7}$ We assume that $U$ has the standard property that utility is increasing in consumption albeit at a declining rate: $U^{\prime}>0$ and $U^{\prime \prime}<0$. We further assume that medical expenditures are worthwhile even if the individual is not insured.

Suppose the individual purchases insurance against the risk of being sick. For an insurance company to break even, the fair insurance premium would have to be $\pi=\mathrm{pm}$. The insurance company collects the premium each year and pays out $m$ when the individual is sick. If an individual chooses this policy, his utility would always be:

$$
\mathrm{V}_{\mathrm{I}}=\mathrm{U}(\mathrm{y}-\pi)
$$

${ }^{7}$ Assuming that medical expenditure is worthwhile, this analysis actually requires a less stringent condition. The same equation would apply if restored health imposed a fixed utility cost, $k$, relative to initial perfect health, so that $U(\mathrm{c}, \mathrm{H}[0,0])=\mathrm{U}(\mathrm{c}, \mathrm{H}[1, \mathrm{~m}])+\mathrm{k}$ for all $\mathrm{c}$. 
Using a Taylor series expansion of equation $(1),{ }^{8}$ we can approximate that equation as:

$$
\mathrm{V}_{\mathrm{N}} \approx \mathrm{U}(\mathrm{y}-\pi)+\mathrm{U}^{\prime}\left(\mathrm{U}^{\prime \prime} / 2 \mathrm{U}^{\prime}\right) \pi(\mathrm{m}-\pi)
$$

Therefore,

$$
\text { Value of Insurance }=\left(\mathrm{V}_{\mathrm{I}}-\mathrm{V}_{\mathrm{N}}\right) / \mathrm{U}^{\prime} \approx(1 / 2)\left(-\mathrm{U}^{\prime \prime} / \mathrm{U}^{\prime}\right) \pi(\mathrm{m}-\pi)
$$

The left hand side of equation (4) is the difference in utility from being uninsured relative to being insured, scaled by marginal utility to give a dollar value for removing risk. The right hand side is the benefit of risk removal. Here, $\left(-\mathrm{U}^{\prime \prime} / \mathrm{U}^{\prime}\right)$ is the coefficient of absolute risk aversion; it is the degree to which uncertainty about marginal utility makes a person worse off. Because $U^{\prime \prime}<0$ and $\mathrm{U}^{\prime}>0$, this term is positive. The term $\pi(\mathrm{m}-\pi)$ represents the extent to which after-medical expenditure income varies because the person does not have insurance. It too is positive. The product of terms on the right hand side of equation (4), therefore, is necessarily positive, implying that fair insurance is preferred to being uninsured. The dollar value of risk spreading increases with risk aversion and with the variability of medical spending.

The intuition supporting this result is that risk averse individuals would like to smooth the marginal utility of income - to transfer income from states of the world where their marginal utility is low to states of the world when their marginal utility is high. In the absence of insurance, a person's marginal utility of income when healthy is $U^{\prime}(y)$ and when sick is $U^{\prime}(y-m)$. Since marginal utility falls as income increases, marginal utility is lower when healthy than when sick. Transferring income from healthy states to sick states until marginal utility is equalized maximizes total utility,

${ }^{8}$ The Taylor series is taken about the level of income net of insurance premiums. From equation (1), $V_{N} \approx(1-p)\left[U(y-\pi)-U^{\prime} \pi+1 / 2 U^{\prime \prime} \pi^{2}\right]+p\left[U(y-\pi)+U^{\prime}(m-\pi)+1 / 2 U^{\prime \prime}(m-\pi)^{2}\right]$. Collecting terms, this simplifies to $V_{N} \approx U(y-\pi)-U^{\prime}\{(1-p) \pi-p(m-\pi)\}+1 / 2 U^{\prime \prime}\left\{(1-p) \pi^{2}+p(m-\pi)^{2}\right\}$. The term $(1-p) \pi-p(m-\pi)$ is zero. The term $(1-p) \pi^{2}+p(m-\pi)^{2}$ can be expanded as $(1-p) \pi^{2}+p^{2}-$ $2 \mathrm{pm} \pi+\mathrm{p} \pi^{2}$. Since $\mathrm{pm}=\pi$, this simplifies to $\mathrm{pm}^{2}-\pi^{2}=\pi(\mathrm{m}-\pi)$. 
assuming fair insurance. Health insurance carries out this transfer, charging premiums up front and reimbursing expenditures later. ${ }^{9}$

There is a diagrammatic way to make the same point; it is shown in Figure 2. We think of the two states of the world - being sick and being healthy - as if they were two goods. Individuals would like more consumption in each state. In the absence of any probability of being sick, people would be able to consume y in each state. Because of required medical spending, however, people can only consume $y-m$ when sick. This is shown as point $E$ in the figure.

The fair odds insurance line is the individual's implicit budget constraint. It is drawn for the case where $p=.2$. The slope of the line is $-1 / \mathrm{p}$, or $-5 .^{10}$ The indifference curve for consumption is also steeply sloped, recognizing that the sick state is unlikely to arise. Thus, people are not willing

${ }^{9}$ The situation is more complex when medical spending fails to restore the person to perfect health, and the marginal utility of income is affected by health status. Suppose that when sick a person still needs medical spending of $\mathrm{m}$, but that his after-expenditure health remains below what it would be had he never got sick; i.e., that $\mathrm{H}[1, \mathrm{~m}]<\mathrm{H}[0,0]$. Expected utility for people without insurance is given by $\mathrm{v}_{\mathrm{N}}=(1-\mathrm{p}) \mathrm{U}(\mathrm{y}, \mathrm{H}[0,0])+\mathrm{pU}(\mathrm{y}-\mathrm{m}, \mathrm{H}[1, \mathrm{~m}])$, and the marginal utilities of income are $U_{x}(y, H[0,0])$ when healthy and $U_{x}(y-m, H[1, m])$ when sick, where the subscripts indicate partial derivatives. Because the marginal utility of income may be affected by health and health varies across sickness states, it is not clear how much insurance the person will want. If people attach little value to money when sick - for example, if there are few pleasurable activities they can engage in - they may not want any health insurance at all. Alternatively, if the value of money when sick is particularly high, say because aides are needed to carry out the activities of daily life, people may want more than full insurance against medical expenditures.

This example highlights the difference between medical care insurance and what, if we used a strict interpretation, would be labeled health insurance. Health insurance transfers money across people -- generally from the healthy to the sick. The money can be used to purchase medical services the individual otherwise could not afford, or to allow the individual to purchase more of other goods and services after medical care has been paid for. But health insurance cannot guarantee that an individual's health will be unaffected by outside factors. Insuring one's health is technologically infeasible.

${ }^{10} \mathrm{~A}$ fair insurance policy that charges $\$ 1$ each year and pays an amount $\mathrm{k}$ when sick is defined by: $\mathrm{pk}+1=0$. Thus, $\mathrm{k}=-1 / \mathrm{p}$. 
to give up much consumption when healthy to get consumption when sick. A person can trade consumption when sick for consumption when healthy, at a rate given by the insurance premium. People will choose to purchase some insurance. If insurance is priced actuarially fairly, individuals will choose to be fully insured - they will have the same consumption when sick as when healthy. This optimum is shown as point $E^{\prime}$ in the figure. People are better off at $E^{\prime}$ than they are at $E$; they have moved to a higher indifference curve.

In our simplified world, the optimal insurance policy is an indemnity policy - it pays a fixed amount of money for a particular condition when the individual is sick. The amount paid equals the cost of the appropriate treatment for the person's disease; if there is more than one disease, the payments vary. Since each disease requires a fixed amount of care -- there is no more nor less that a person can consume -- there are no wasted resources in the policy; the indemnity insurance plan is efficient. Beyond its efficiency properties, the indemnity policy is the simplest health insurance policy. In effect, it operates as a contingent claims market; people get paid specified amount depending on which contingency occurs (Zeckhauser, 1970).

Health insurance started off as a quasi-indemnity policy — in most cases paying a fixed amount per day in the hospital. The first Blue Cross policies, for example, were developed just before and during the Great Depression. These policies, run by hospitals, guaranteed a certain number of hospital days per year (for example, 21 days) for an annual premium (for example, $\$ 5$ to $\$ 10$ in the early 1930s). After World War II, life insurance companies entered the health insurance market, driven by the profits of Blue Cross policies and the expanding demand for health insurance resulting from its favorable tax treatment. These nascent health insurers offered indemnity policies as well, limiting their potential losses by fixing the maximum amount they would pay per hospital 
day.

\section{Moral Hazard and Principal-Agent Problems}

Health insurance must address several problems beyond risk spreading. We now turn to some of these challenges.

\section{III.1 Moral hazard}

Moral hazard refers to the likely malfeasance of an individual making purchases that are partly or fully paid for by others (Arrow, 1965; Pauly, 1968, 1974; Zeckhauser, 1970; Spence and Zeckhauser, 1971; Kotowitz, 1987). " He will overspend; i.e., he will use more services than he would were he paying for the medical care himself. Since insurance is an arrangement where others pay for the lion's share of one's losses, it creates a moral hazard to use additional medical resources. The designation moral hazard, a disquieting term, frequently connotes some moral failure of individuals, but this is not meant to be so. Indeed, Kenneth Arrow (1985) employs the less judgmental and more informative term "hidden action" for moral hazard.

Moral hazard is a concern because it conflicts with risk-spreading goals. Insurance is valuable because it allows people to transfer income from when they need it less to when they need

11 The theory of moral hazard, if not the words, goes back at least to Adam Smith: "The directors of such companies, however, being the managers rather of other peoples' money than of their own, it cannot well be expected, that they should watch over it with the same anxious vigilance with which the partners in a private copartnery frequently watch over their own... Negligence and profusion, therefore, must always prevail, more or less, in the management of the affairs of such a company" (Smith, 1776, p. 700). 
it more. But this transfer is not perfect because people increase their consumption of medical care when it is subsidized. This creates an inherent second best problem in designing insurance policies: insurers must trade off the benefits from spreading more risk against the cost of increased moral hazard. We formalize this Lesson 1 about health insurance:

Lesson 1: Risk Spreading versus Incentives. Health insurance involves a fundamental tradeoff between risk spreading and appropriate incentives. Increasing the generosity of insurance spreads risk more broadly but also leads to increased losses because individuals choose more care (moral hazard) and providers supply more care (principal-agent problems).

Moral hazard, or hidden action, emerges in one form in the risks that individuals choose to take. People may take worse care of themselves when they have insurance than if they do not. If their actions were readily observed, the insurance company would merely not pay off were they reckless or negligent. But individual actions are difficult to observe; they are hidden. The extent of moral hazard in terms of actions that affect health may not be large for health insurance in most instances, since the uncompensated loss of health itself is so consequential. ${ }^{12}$ Thus, it would be surprising if people smoked because they knew health insurance would cover the costs of lung cancer.

Hidden action also arises because individuals may get treatments they would not pay for themselves. Though the action itself (seeking medical care) is not hidden, the motivation behind it

${ }^{12}$ This does not mean that people will not smoke or faithfully take their medications. But there is no moral hazard if their actions would be the same if they had no health insurance, i.e., if these health-harming behaviors are inelastic with respect to cost sharing. 
is. $^{13}$

Optimal insurance plans would pay for treatment only if the individual would have chosen the same treatment had he borne the full bill. The thought experiment here is whether the person would pay for the medical expenditure in expectation, before he knew his condition. For example, suppose that a person has income of $\$ 25,000$, and faces a 1 percent probability he will have a serious illness. If he could commit in advance, he would agree to receive $\$ 50,000$ of medical care when sick in exchange for a $\$ 500$ premium. If fully insured, however, the individual will choose to consume $\$ 60,000$ of care. The moral hazard in this example is $\$ 10,000$ - the additional spending beyond the optimal amount of care he would contract for in advance of being sick.

In the terminology of demand theory, moral hazard is the substitution effect of people spending more on medical care when its price is low, not the income effect of people spending more on medical care because of insurance, by efficiently transferring resources from the healthy state to the sick state, makes them richer when sicker (de Meza, 1983). In the example considered, say the individual would have spent half his income, $\$ 12,500$, on medical care in the absence of insurance. Insurance thus raises medical spending by $\$ 47,500$, but only a fraction of this increase is due to moral hazard.

If some fixed $\mathrm{m}$ were the known optimal medical expenditure for any sick person, insurance plans need experience no moral hazard. They could simply pay $m$ in medical expenditures to or for those who are sick. Moral hazard arises because medical needs are not fully monitorable, and different people with the same condition have different optimal expenditures, at least as best the

${ }^{13}$ Moral hazard also results from patients making less effort to search for low-cost providers. For example, when patients pay but one-fifth of the cost of their drugs, they will have weak incentives to switch to generic brands or stray beyond the local pharmacy. 
insurance company can determine. Suppose that the optimal medical expenditure for treating a particular condition is $m_{i}$, which varies across people, indexed by $i$. The insurance company requires the individual to pay a coinsurance amount $\mathrm{c}(\mathrm{m})$ for medical care received. The rest of the care, $\mathrm{m}$ $c(m)$, is paid by the insurer. In effect, the insurer takes the individual's medical expenditure to be a signal of his true medical needs; the coinsurance payment creates the necessary costs to have signaling operate.

Two polar extremes for the form of $\mathrm{c}(\mathrm{m})$ are commonly found. The first is the indemnity policy discussed above: the insurer pays a fixed amount, call it $\mathrm{m}^{*}$, and the individual pays $\mathrm{c}(\mathrm{m})=$ $\mathrm{m}-\mathrm{m}^{*}$. The second is full insurance: the insurer pays the full costs of medical care, regardless of its cost, and the individual pays nothing (i.e., $\mathrm{c}(\mathrm{m})=0)$. The full insurance policy removes all risk from the insured, but engenders greater moral hazard.

To understand the optimal insurance policy, consider a case where an indemnity policy is not optimal. Suppose that rather than being healthy or sick, the individual has a range of potential illness severities, $s$, with s distributed with density function $\mathrm{f}(\mathrm{s})$. Health is given as before by $\mathrm{h}=\mathrm{H}[\mathrm{s}, \mathrm{m}]$. The patient's s will determine the optimal treatment. The insurer cannot observe s, however. Thus, making a fixed indemnity payment to anyone sick is not optimal. The ex ante utility function for the insured consumer is:

$$
V_{I}=\int U(y-\pi-c(m(s)), H[s, m(s)]) f(s) d s
$$

where $\mathrm{m}(\mathrm{s})$ tells how much medical care an individual with condition s chooses to receive.

We consider first the optimal policy -- the amount of medical services the person would like to contract for if he could write a perfect state-contingent contract and thereby eliminate moral hazard. A perfect contract is one that pays an indemnity amount conditional on s, financing the 
payments by a uniform premium. This optimal amount $\mathrm{m}^{*}(\mathrm{~s})$ is the value of $\mathrm{m}$ that yields the maximum feasible utility:

$$
\operatorname{Max}_{m(s)} \int U(y-p m, H[s, m]) f(s) d s .
$$

The solution to this problem sets

$$
\mathrm{H}_{\mathrm{m}} \mathrm{U}_{\mathrm{H}}=\mathrm{E}\left[\mathrm{U}_{\mathrm{x}}\right]
$$

where the subscripts denote partial derivatives and $\mathrm{x}=\mathrm{y}-\mathrm{pm}$. The left-hand side represents the gain in utility from spending another dollar on medical care; it is the product of the effect of medical care on health and the effect of health on utility. The right hand side is a weighted average expectation of the marginal utility of consumption in different illness states, namely:

$$
E\left[U_{x}\right]=\int U_{x}(y-p m, H[s, m]) f(s) d s .
$$

Equation (9) says that with the optimal first-best policy, the expected marginal utility gained from an additional dollar of medical care in each state of the world equals the utility cost of that dollar. ${ }^{14}$

Now consider the situation severity of illness is not monitorable, hence the optimal policy cannot be implemented. At the time the consumer is seeking medical care, he alone knows his severity. We assume the consumer treats the insurance premium as fixed - nothing he does will raise or lower his insurance premium that year. Further, we assume for now that individuals are not penalized in future years for additional medical spending this year, because expected future changes in costs are spread equally over everyone in the group. The cost to the consumer of another dollar

${ }^{14}$ This assumes that these functions are well behaved, hence that local optima are global optima. Some medical expenditures may offer increasing returns over a relevant range. For example, it may cost $\$ 200,000$ to do a heart transplant, with $\$ 100,000$ accomplishing much less than half as much. Efficiency then requires the insurance program spend at least to the minimum average cost of benefits point, or not at all. 
of medical expenditure will be $c^{\prime}(m) .{ }^{15}$ The sick consumer will therefore choose medical care utilization to maximize utility when sick. Thus, he will choose $\mathrm{m}^{\sharp}(\mathrm{s})$ as the $\mathrm{m}$ which maximizes utility given knowledge of s:

(11) $\operatorname{Max}_{m(s)} U(Y-\pi-c(m), H[s, m])$ for each $s$.

The solution to this problem will depend on the specific $s$ the individual has realized, and is given by the first order condition:

$$
H_{m} U_{h}=c^{\prime}(m) U_{x} \quad \text { for each } s
$$

The left-hand side once again represents the gain in utility from spending another dollar on medical care. The right-hand side is the utility cost to the individual from spending that dollar; it is the product of the out-of-pocket cost of medical care and the utility loss from losing that dollar for consumption.

Comparing equations (9) and (12) shows the loss due to moral hazard. When $c^{\prime}(m)<1$, people will overconsume medical care when sick and thus pay more in health insurance than is optimal. ${ }^{16}$

${ }^{15}$ The structure of the insurance plan may present the insured with a range of decreasing marginal cost. Say a plan has a deductible of $\$ 600$ with a copayment of $20 \%$ beyond that point, a common structure. The insured can receive $\$ 600$ of benefits for $\$ 600$, but $\$ 1200$ of benefits for $\$ 720$. Say the individual solves, and finds a $\$ 400$ expenditure is locally optimal. He must also look globally to the optimal expenditure beyond $\$ 600$, which may be superior. Recognizing that using up a deductible gets one to a range of lower costs, gives the insured an interesting dynamic optimization program where there are two benefits from spending below the deductible: (1) the health care itself, and (2) the increased potential for getting to the low-cost range (Keeler, Newhouse, and Phelps, 1977).

${ }^{16}$ This can be derived by taking expectations of both sides of equation (12) and comparing to equation (9). 


\section{III.1.A Evidence on the Price Elasticity of Medical Care Demand}

How does an individual's demand for medical care respond to his required out-of-pocket expenses? Economists used to differ on this question. Table 3 details estimates of the elasticity of demand for medical care. ${ }^{17}$ A substantial literature in the 1970 s estimated the elasticity of demand for medical care using cross-sectional data, or cross-sectional time series data. Pre-eminent among these papers are Feldstein (1971), Phelps and Newhouse (1972), Rosett and Huang (1973), and Newhouse and Phelps (1976). Feldstein (1971) was the first statistically robust estimate of price elasticities using time-series micro data, in this case on hospitals. Feldstein identified the effect of coinsurance rates on demand using state-variation in insurance coverage and generosity, estimating a demand elasticity of about -0.5 . The subsequent papers use patient-level data and more sophisticated study designs. The elasticities that emerged from these papers ranged from as low as -.14 (Phelps and Newhouse, 1972) to as high as -1.5 (Rosett and Huang, 1973). The implication of this range of elasticity estimates was that moral hazard was likely a significant force.

This estimation literature suffered from two major difficulties, however. First, the generosity of health insurance at either the state or the individual level might be endogenous. Generous insurance might boost utilization of medical services, as posited; or alternately, areas where people desire or need more medical care may also be areas where people demand more health insurance. One cannot separate these two effects statistically without an instrument for the rate of insurance coverage in an area, but such instruments were not easy to find. Second, the studies typically failed to distinguish average and marginal coinsurance rates. Usually for data reasons, most of these

\footnotetext{
${ }^{17}$ Zweifel and Manning (this volume) discuss the elasticity of demand for medical care in more detail.
} 
studies related medical spending to the average coinsurance rate in an area. But theory predicts that medical spending should relate to the marginal coinsurance rate. Because insurance policies are non-linear, average and marginal prices may differ substantially. ${ }^{18}$ As a result of these problems, as late as the 1970s many critics still believed that medical care was determined by "needs" and no other economic factors, i.e. that demand was totally inelastic, although others believed that the demand elasticity was substantial -- perhaps -0.5 or more.

To address these problems, the United States government funded a social insurance experiment, designed to estimate the demand elasticity for medical care. The Rand Health Insurance Experiment (Newhouse et al., 1993; Zweifel and Manning, 1998) randomized nearly 6,000 people in 6 areas to different insurance plans over an 3- to 5-year period in the early 1970s. The insurance plans varied in contractual levels of cost sharing. Elasticity estimates were formed by comparing utilization in the different plans. The Rand Experiment found an overall medical care price elasticity of about -0.2 . This elasticity is statistically significantly different from zero, but noticeably smaller than the prior literature suggested. Sound methodology, supported by generous funding, carried the day. The demand elasticities in the Rand Experiment have become the standard in the literature, and essentially all economists accept that traditional health insurance leads to moderate moral hazard in demand. The Rand estimates are also commonly used by actuaries in the design of actual insurance policies.

\section{III.1.B Coinsurance in Practice}

${ }^{18}$ Of course, if individuals are appropriately forward looking, it is the expected marginal coinsurance rate at the end of the year that should affect behavior, rather than the ostensible marginal coinsurance rate at the time services are used. 
The indemnity policy, which characterized health insurance at its inception, became outdated over time. With increased medical technology, the range of optimal spending within a given condition became great. Indemnity policies left individuals bearing too much risk. As a result, insurance structures moved from indemnity payments to a service benefit policy -- a policy that covers all medical expenses, with some cost sharing. Service benefit policies grew steadily in importance in the post-war period, reaching their height in the early 1980s.

Service benefit policies use three cost-sharing features, sometimes in concert: the deductible, the coinsurance rate, and the stop loss amount. Figure 3 and Table 4 show how these cost sharing features operate. The deductible is the amount that an individual must pay before the insurance company pays anything. The deductible is usually set annually; the typical deductible in 1991 was about $\$ 200$ for an individual and $\$ 500$ for a family. Consumers pay the full price for care consumed under the deductible. The coinsurance rate is the percentage of the total bill above the deductible that a patient pays. Nearly all indemnity plans had a coinsurance rate of 20 percent. The coinsurance is paid until the patient reaches the stop loss -- the maximum out-of-pocket payment by the person in a year. A typical stop loss in an indemnity policy was about $\$ 1,000$ to $\$ 1,500$ in a year.

In addition to these features, many policies impose further cost sharing through caps on various types of expenditures. For example, policies may permit 8 mental health visits per year, or have a $\$ 1$ million lifetime limit on overall medical expenditures. Such provisions discourage use, and may deter high cost users from selecting the insurance plan, and providers from turning expensive cases into subsidized meal tickets. Table 4 details the frequencies with which various policy features were found in insurance policies in 1991.

Somewhat misleadingly, the service benefit policy is frequently called an "indemnity 
insurance plan" by economists, with the system that developed to provide this policy termed the "indemnity insurance system". In fact, true indemnity health insurance policies (a fixed payment per disease) had existed but were largely replaced by the service benefit policy. For consistency with other literature, we follow this nomenclature despite its inaccuracies. This nomenclature is particularly unfortunate since recently insurance has been moving back towards the indemnity model, frequently with the risk of above-average spending being placed on the provider rather than the patient. We discuss regimes of provider responsibility in Section IV.

\section{III.1.C Optimal Insurance Given Moral Hazard}

Knowledge of the utility function and the parameter values that determine medical spending elasticities can be combined to design the optimal insurance policy -- the actuarially fair policy that maximizes expected utility subject to the constraint that individuals will act in a self-interested fashion, i.e., that moral hazard will operate. Such a policy is inherently second-best; in calibrating its level of generosity, it balances the utility benefits of greater risk-sharing across people against the moral hazard costs incurred. The insurer's challenge is to define the function of risk sharing by insureds, the $c(m)$ function, that maximizes expected utility.

To analyze the optimal policy, we assume patients differ in the severity of their illness. ${ }^{19}$ The insurer will seek to find the $c^{*}\left(\mathrm{~m}^{\#}\right)$ function that produces the maximum possible expected utility with:

$$
E\left[U^{*}\right]=\operatorname{Max}_{c(m \#)} \int U\left(Y-\pi-c^{*}\left(m^{\#}\right), H\left[s, m^{\#}\right]\right) f(s) d s,
$$

${ }^{19}$ Moral hazard arises, let us remember, because individuals differ in unmonitorable ways. Thus it could be on income, on health status, or on some aspect of preferences. 
where $\mathrm{m}^{*}$ is defined as the solution to equation (12). Because insurers cannot tell an individual's health state, the insurance policy cannot differentiate payments on the basis of illness severity.

An additional constraint operates on the insurance company: premiums must cover expected costs. Thus,

$$
\pi=\int\left[m^{\sharp}(s)-c\left(m^{\sharp}(s)\right)\right] f(s) d s .
$$

The optimal insurance policy can be formally written as a problem in dynamic optimization (Blomqvist, 1997). ${ }^{20}$ Alas, this is a complicated problem, whose algebra is not particularly revealing. The analytic solution balances two factors. The first is the reduced overconsumption from making people pay more out of pocket for medical care. If the coinsurance rate is increased in some range, people in that range pay more for medical care, as do people at all higher levels of spending (because their coinsurance rates have been increased). This increases boosts the efficiency of provision. Countering this, however, is a loss in risk spreading benefits. As people are made to pay more out of pocket, they are exposed to more risk, and this reduces their welfare. The optimal coinsurance rate balances these two incentives.

A small literature has simulated optimal insurance policies using this framework. Table 5 shows the results of these simulations. Table 5 shows a wide range of disparities in optimal insurance policies. Some of the studies find that simulated insurance policies are substantially less generous than actual indemnity policies of the past 20 years (Feldstein and Friedman, 1977; Blomqvist, 1997), while other studies find that they are about the same (Buchanan et al., 1991;

${ }^{20}$ The problem is formally analogous to the optimal tax problem in public finance when ability is unobservable (Mirrlees, 1971; Diamond, 1998). 
Newhouse et al., 1993; Manning and Marquis, 1996). ${ }^{21}$ The difference between these various estimates has not been fully reconciled, although one suspects that differing degrees of risk aversion and moral hazard are important. One suspects that real world policies will be more generous than optimal policies because of the tax distortions favoring more generous insurance: payments to insurance which are then made to providers are not taxed as income to employees, while wage and salary payments, which might be used to pay for medical care out-of-pocket, are. Indeed, other research shows that the benefits that employer health insurance policies offer are sensitive to employee tax rates (Pauly, 1986).

A second importance difference between real world and optimal policies is that the former almost invariably have a constant coinsurance rate, i.e., linear structures, whereas the latter do not. The optimal policy can be substantially superior. Blomqvist (1997), for example, finds that coinsurance rates should range from over 25 percent at low levels of spending to 5 percent at high levels of spending. There is likely a tradeoff between optimality and simplicity. Optimal policies can be very complicated, while real world situations are characterized by relatively simplistic structures.

If services or diseases differ in the degree of moral hazard they entail, the optimal insurance policy will differ by service or disease as well. Suppose, for example, there is a fixed number of diseases that a person can have and that moral hazard varies by disease. The insurance company can observe the disease of the person (e.g., cancer or appendicitis) but not the severity of illness within the disease. Then, the optimal insurance policy will have different cost sharing by disease

${ }^{21}$ The implication of the Blomqvist estimates for health insurance cost sharing depend on whether income losses are compensated or not. 
(Zeckhauser, 1970). Coinsurance formulas could just as easily depend on service (e.g., outpatient psychiatry) or locale of medical care (e.g., hospital care) ${ }^{22}$ In practice, elasticity estimates do differ across services. The Rand Health Insurance Experience found higher demand elasticity for outpatient care than for inpatient care, and within outpatient care a greater demand elasticity for mental health care. Most health insurance policies, including Medicare, draw distinctions between services in their coinsurance schedules. Thus, Medicare has a separate hospital deductible, and private insurance plans frequently cover a fixed number of psychiatric visits.

Moral hazard is a significant concern in insurance policies but it is not one that necessarily argues for government intervention. Government insurance policies, after all, may engender just as much moral hazard as private insurance policies. There is a rationale for government to be involved in goods subject to moral hazard only if the government is better able to monitor or punish moral hazard than the private sector. This is not obviously the case in medical care.

\section{III.2 Patients, Doctors, and Insurers as Principals and Agents}

Thus far, we have implicitly assumed that patients choose the amount of medical care they want, knowing their illness, the range of possible treatments, and the prices of the treatments to them. But few patients are so well informed. In most cases of serious expenditure, it is the doctors who make the resource-spending decision, with patients and insurers bearing the costs; patients usually do not know the charge until the bill comes. Patients, physicians, and insurers are in a

${ }^{22}$ This is analogous to the Ramsey rule of optimal taxation. The Ramsey rule states that optimal taxes on a set of commodities should be inversely related to the elasticity of demand for each commodity - in minimizing inefficiency, inelastic factors should be taxed more. The statement here is the equivalent but for subsidies instead of taxes. 
principal-agent relationship: the patient (principal) expects the doctor (agent) to act in his best interest when he is sick. Similarly, the insurer would like the doctor to act in its interests. Of course, patients also bear the insurance costs for seeking care, so that ex ante the patient's incentives and the insurer's incentives line up. But once the patient becomes sick and requires care, the parties' incentives diverge.

This three-player agency problem creates substantial problems for health insurance. To the extent that medical treatments are decided upon jointly by physicians and patients, the supply side of the health insurance policy (the rules about paying physicians) will matter along with the demandside of the insurance policy (the rules about cost sharing for patients).

With the traditional service-benefit insurance policy, doctors and patients frequently have relatively congruent interests, which may differ from those of the insurer. Patients who face but a fraction of the costs they incur will desire excessive treatments. Service-benefit insurers usually pay more to physicians who provide more medical services. The result is that patients and physicians want essentially all care that improves health, respectively ignoring and welcoming resource expenditures. The view that physicians should do only what is best for the patient is codified in the Hippocratic Oath -- providers should promote the best medical outcomes for their patients. Hippocrates said nothing about providing care the patient or society would have deemed ex ante to be wasteful.

Plato anticipated the application of agency theory to the health care arena by a goodly margin. He wrote that, "No physician, insofar as he is a physician, considers his own good in what he prescribes, but the good of his patient; for the true physician is also a ruler having the human body 
as a subject, and is not a mere moneymaker." (The Republic, Book 1, 342-D). ${ }^{23}$ With the passage of 2,000+ years, fidelity to principals has slipped a bit, and new participants -- insurers, government, employers, and provider organizations -- have strode into the arena. But the principles are very much the same.

A more sinister view of the principal-agent problem contends that physicians manipulate patients into receiving more services than they would want, so that physicians can increase their income. This has been termed supplier-induced demand in the literature. An enormous amount of work in health economics have been devoted to the question of whether and to what extent suppliers induce demand. The empirical evidence on this issue is discussed by [CITE OTHER CHAPTER]. Lesson 1 notes the tradeoff between risk spreading and appropriate incentives applies on both the demand- and supply-sides of the market.

Increasingly, the arrows of responsibility among the players -- who is agent, who principal -- now point in all directions. For example, doctors now have responsibilities to other providers and insurers, not just to patients. Such added doctor responsibilities, primarily to hold down expenditures, ultimately enhance patient welfare, at least on an expected value basis, if not when the patient is sick. Insurers, acting for their customers as a whole, want to limit spending to only that care that is necessary; i.e., the care patients would select given a lump-sum transfer that depends on their condition and making them pay all costs at the margin. With patients, physicians and insurers pulling in different directions, a conflict over what care will be provided frequently results.

${ }^{23}$ One might instead heed the warning of George Bernard Shaw nearly a century ago: "That any sane nation, having observed that you could provide for the supply of bread by giving bakers a pecuniary interest in baking for you, should go on to give a surgeon a pecuniary interest in cutting off your leg, is enough to make one despair of political humanity." (Shaw, 1911) 


\section{III.3 Transactions costs}

Processing claims costs money, the more claims processed the more it costs. National estimates of medical expenditure suggest that 15 percent of insurance premiums are devoted to administrative expense. ${ }^{24}$ Someone must read the bill, approve the spending, and pay the claim. Insurance companies seek to control these costs, and policies are designed accordingly. ${ }^{25}$

A major part of claims processing costs -- monitoring, transferring money, and the like -- are invariant to the size of the claim. Size-invariant costs are a greater percentage burden for small bills than for larger bills. This suggests limiting health insurance to larger claims and having individuals pay directly smaller expenses (Arrow, 1963). This insight gives further justification to the widespread use of deductibles and coinsurance for small bills, and for the fact that historically insurance developed first for inpatient doctor and hospital charges, where bills are the largest.

\section{Relationships Between Insurers and Providers}

The medical care system is a network, with patients, monies and information flowing from one party to another. The information flow to insurers, however, is not so rich that they can

${ }^{24}$ This includes the expenses of paying bills as well as marketing. Divisions between these sources of administrative expense are not very precise.

${ }^{25}$ Of course, individuals must also bear some costs in paying bills on their own, so it is not self evident which method of payment, individually or through insurance, is cheaper. But most people implicitly assume that insurers have additional transactions costs for paying bills beyond what individuals face. Thus, there is likely to be a net transactions cost to purchasing insurance. There are also transactions costs associated with selling the policy, but they do not vary with the magnitude of claims. 
guarantee that only cost-effective care will be provided. Their monitoring difficulties provide the motivation for cost-sharing in insurance policies. But cost sharing has limited value: Patients do not make the most costly decisions, the Hippocratic Oath does not extend to conserving society's resources, and risk spreading considerations severely limit what charges can be imposed.

Return now to figure 1, the Medical Care Triad. Working solely on the left side of the triangle, the demand side, these arguments suggest that passive insurers are unlikely to be able to limit utilization appropriately. Recognizing this, insurers also work the right side of the triangle -the supply side. Increasingly, insurers attempt to provide incentives for providers to limit spending. The incentives may be imposed at arm's length, as Medicare does with its DRG system: treat a simple heart attack, and a hospital gets paid a flat amount, roughly $\$ 5,000$. Or the insurer may form a contracting alliance with providers, as it does say with network HMOs. At the extreme, insurers and providers merge into a single entity. Uniting disparate organizations in this way enhances monitoring possibilities and better aligns incentives, but it also creates the potential for diseconomies of scope, e.g., requiring another layer of management when care is delivered.

The sweeping nature of insurer-provider interactions is indicated by figure 4 (see also Glied, 1998). In 1980, over 90 percent of the privately insured -- i.e., employer- or self-paid -- population in the United States was covered by "unmanaged" indemnity insurance. By 1996, that share had shrunk to a mere 3 percent.

Table 6 provides a taxonomy of different insurance-provider arrangements. The most limited arrangement is a "managed" indemnity insurance policy. It bundles a traditional indemnity policy with limited utilization review, for example requiring that non-emergency hospital admissions be precertified. At the most intrusive, insurers can seek to monitor care on a retail basis through tissue 
review committees, or on a statistical, wholesale basis by monitoring a physician or hospital's overall utilization. Such reviews can be used to refuse or reduce payment. Such intrusiveness by insurers may be unhelpful and, coming after-the-fact, may be ineffectual. It certainly is not welcome to physicians. As Figure 4 shows, managed indemnity insurance, though non-existent in 1980, claimed a 41 percent share by 1992 , but has fallen to 22 percent today.

Preferred Provider Organizations (PPOs), a second type of managed care, form a network of providers, including physicians, hospitals, pharmaceutical purveyors, and others, and control costs by securing discounts from them. The quid pro quo for the discounted fee is that insureds are steered to in-network providers. Out-of-network providers may get reduced coverage or no coverage at all. More typically, the patient's coinsurance or copayment rates are merely set lower for in-network providers. In 1991, for example, the typical PPO had an in-network coinsurance rate of 10 percent and an out-of-network coinsurance rate of 20 percent. PPOs usually impose pre-authorization requirements as well, though they are rarely especially strict. As Figure 4 shows, PPO enrollment, zero in 1980, now makes up about one-quarter of the privately insured population.

Full integration creates the strongest link between insurance and provision. In the United States, these merged entities are called health maintenance organizations (HMOs). They sell their services directly to employers or individuals on an annual fee basis, and then they deliver care. There are three major types of HMOs. Within a group/staff HMO -- the most common form, with Kaiser being the best known example -- physicians are paid a salary and work exclusively for the HMO. The HMO may have hospitals on contract, or may run its own.

HMOs employ a range of mechanisms to limit utilization. They reflect the traditional economic instruments of regulation, incentives, and selection of types. HMOs frequently regulate 
physicians' practices, for example limiting the referrals they can make or the tests they can order. But the efficiency benefits of HMOs arise much more from aligning the incentives of provider and insurer, rather than through direct regulation. Some group/staff HMO physicians are salaried; as a result, they have a weaker incentive to provide marginal care than their fee-for-service counterparts. Moreover, HMOs monitor the services that physicians provide. They may reward parsimonious resource use directly with compensation, though more likely with perks or subsequent promotion. Extravagant users are kicked out of the network. Finally, since physicians differ substantially in their treatment philosophies, HMOs can select physicians whose natural inclination is toward conservative treatment.

Given the ability of HMOs to limit utilization on the supply-side, price-related demand-side limitations can be less severe. Cost-sharing to enrollees is generally quite low -- typically about $\$ 5$ to $\$ 10$ per provider visit, although other forms of demand-side limitation survive (for example, patients may have to get approval from their internist before seeing a specialist).

Independent Practice Associations (IPAs), or Network Model HMOs, represent a more recent innovation in managed care. ${ }^{26}$ These plans neither employ their own physicians nor run their own hospitals. Instead, they contract with providers in the community. By limiting the size of the network, the plans secure lower costs from willing providers. In addition, these plans employ stringent review procedures. For example, patients may need approval to receive particular tests. Finally, IPAs often provide financial incentives to limit the care that they provide. For example, some plans pay physicians on a "capitated" basis. The physician receives a fixed payment per patient per year. Out of this capitated stipend, the physician must pay for all necessary medical services,

${ }^{26}$ Some IPAs are older, but thet form gained popularity only recently. 
possibly including hospital services and prescription drugs. The physician's incentives for cost control become even more significant when all expenditures come out of his own pocket.

In many HMOs, patients can go outside of the network and still receive some reimbursement. This is termed a Point of Service [POS] option. But reimbursement out-of-network is not as generous as reimbursement within. Use of non-network services, for example, frequently requires a deductible followed by a 10 to 40 percent coinsurance payment.

As Figure 4 shows, HMO enrollment of all forms (including POS enrollment) has increased from 8 percent of the population in 1980 (then predominantly group/staff model enrollment) to nearly half of the privately insured population today.

This vertical integration in managed care, with insurers and providers linked or united, is virtually unheard of in insurance of other types. Auto insurance, for example, is an indemnity policy. People choose what coverage they will have, what deductibles will be in force, etc. When there is a crash, the insured and the adjuster get together, perhaps at the repair shop, to negotiate the cost of the repair. The insured or the repair shop, entities having no particular relationship to the insurer, are paid that amount, less any deductibles, which are the responsibility of the insured. After major crashes, cost-ineffective repairs are avoided by declaring the car a total loss, giving the wreck to the insurance company and reimbursing the owner.

But such a contingent claims system could not work with health care. The claims are more frequent and uncertainties much greater, making costs much harder and more expensive to estimate. "Scrapping" a human body is rarely an inexpensive or palatable proposition. The burgeoning links between insurers and providers in health care, we believe, are a response to the a priori difficulty of writing contingent claims contracts in the medical sector. 
Vertical integration is also important because it can elicit price discounts. Managed care partly represents a price club. In exchange for an up-front fee, the patient gets to purchase goods at a significant discount. The discounts are secured through bulk purchase bargaining, or by directly hiring the sellers. In exchange for lower prices, patients precommit to receive care from a limited set of providers, or to pay harshly for the privilege of going elsewhere.

Finally, vertical integration is important because it fundamentally transforms the principalagent conflicts in the medical system. Physicians no longer look out for the interests of just their patients, or perhaps their patients' interests and their own. Now, physicians must watch out for the insurer as well. And patients must be more attuned to the incentives their physician is under. We note the integration of insurance and provision as the second lesson of health insurance:

Lesson 2: Integration of Insurance and Provision. With medical care, unlike other insurance markets, insurers are often directly involved in the provision of the good in addition to insuring its cost. The integration of insurance and provision, intended to align incentives, has increased over time. Managed care, where the functions are united, is an extreme version. Under it, doctors have dual loyalties, to the insurer as well as to the patient.

\section{IV.1 Equilibrium Treatment Decisions in Managed Care}

One can understand the impacts of managed care using a framework similar in spirit to what we described for patient cost sharing, only the physician's choices are targeted. A typical physician payment, for example, is

$$
\text { Payment }=R+r \text { Cost. }
$$


Here, $\mathrm{R}$ is the prospective amount and $\mathrm{r}$ is the retrospective amount. A fully capitated system sets $r=0$ and $R>0$, while a fully retrospective system sets $R=0$ and $r \geq 1$. Thus, the capitated system focuses solely on incentives; the retrospective system removes all risk from the doctor.

Changing to a capitated system might affect treatment decisions in several ways. One effect is to raise the physician's "shadow price" for providing treatment -- physicians might require a greater expected health benefit before providing care under managed care than under traditional indemnity insurance (Frank, Glazer, and McGuire, 1997; Keeler, Carter, and Newhouse, 1998). This effect is particularly strong when the physician is capitated, and thus bears the marginal cost for providing additional care.

In addition, managed care might harmonize treatment decisions across patients. Protocols in managed care, for example, encourage or require physicians to treat patients with the same condition similarly.

In both of these circumstances, the physician's views about optimal treatment may differ from the patient's. Doctors may want to limit care while patients may want more. This divergence is particularly likely if patients pay little at the margin for medical care, as they do in many managed care plans (at least for in network services). The conflict of incentives between physicians and patients in managed care contrasts with the situation in traditional indemnity insurance, where the incentives of patients and physicians are generally aligned (although both differ from the incentives of insurers).

Figure 5 shows a potential conflict; at the prices each faces, the patient demands much more 
care $\left(\mathrm{Q}_{\mathrm{D}}^{*}\right)$ than the physician wants to provide $\left(\mathrm{Q}_{\mathrm{S}}^{*}\right){ }^{27}$ Which level of care will ultimately be provided? Knowing how treatment decisions will be made in such an environment is difficult, as economic analysis of rationed goods in general does not reach uniform conclusions. The situation is particularly severe in the medical care market because patients do not pay substantial amounts at the margin for medical care; thus, willingness to pay is not an accurate way of gauging individual value of services. There are several possible outcomes. One possibility is that the short-side principle applies, which predicts that the equilibrium quantity will be the lesser of demand and supply. This is shown as the thickened line in figure 5 and corresponds to a situation where treatment decisions in managed care are made predominantly by physicians. The short-side principle underlies much of the work on managed care (see, e.g., Baumgardner, 1991; Ramsey and Pauly, 1997; Pauly and Ramsey, 1998).

But the short-side principle assumes patient wishes play no role when demand exceeds supply. Treatment decisions may come out of a "bargaining" process that balances the wishes of physicians and patients (Ellis and McGuire, 1990). One can interpret this bargaining either as an explicit process between the parties, or as the physician balancing his own self-interest (or the insurer's profits) with the best interests of the patient.

The actual level of service delivered is likely to vary with the particular medical situation. Patients with chronic conditions may know a great deal about their treatment options; the outcome may thus be close to the patient's demand. In emergency situations, the opposite may be true. The effectiveness of managed care in limiting medical spending may thus differ across settings.

${ }^{27}$ We have drawn the physician's supply curve as upward sloping. This needn't be. It could be vertical or backward bending. Our point would carry through, nevertheless. 


\section{IV.2 Evidence on Supply-side Payment and Medical Treatment}

A substantial literature examines the role of supply-side payment systems in influencing medical treatments. A change from retrospective, or cost-based reimbursement, to prospective reimbursement is typically analyzed.

Table 7 presents studies on this topic. It documents the impact of prospective payment on five aspects of hospital care: the number of admissions and transfers; average length of stay or other inputs; hospital profits; and quality of care. Prospective payment might increase or decrease hospital admissions. On the one hand, sick people might be less likely to be admitted to a hospital under prospective payment, since reimbursement for these individuals falls short of expected cost. On the other hand, hospitals might be more eager to admit healthy patients, for whom reimbursement exceeds costs. As table 7 shows, admissions generally declined with the implementation of prospective payment.

While one might worry about whether care for the sick is excessively rationed in such a system, the literature on whether patients are being "dumped" under prospective payment (e.g., sent to public hospitals) is not particularly clear. A loose consensus is that there is some dumping of patients under PPS, but the magnitude is not particularly great (Morrisey, Sloan, and Valvona, 1988; Newhouse, 1989; Newhouse, 1992).

Studies examining the effect of prospective payment on average lengths of hospital stay and other inputs find nearly uniformly that average hospital stays fell with the reimbursement change. This is what theory predicts: hospitals no longer paid for each additional service will cut back on marginal care, which is expensive relative to health benefits. The effect of prospective payment on hospitals stays is uniformly strong and impressive; many studies find reductions of 20 to 25 percent 
over a period of 5 years or less. These studies provide among the clearest evidence that supply-side reimbursement changes do affect medical treatments.

Despite the reduction in average lengths of hospital stay, a number of studies find that profit margins fell under prospective payment. This reduction in profits came largely from a reduction in revenues. As the reduction in length of stay indicates, costs fell with the introduction of prospective payment.

In addition to examining the effect of prospective payment on quality, the literature has also examined how managed care as a whole affects medical spending. Studies of this quetion are summarized elsewhere, including in this volume (Miller and Luft, 1997; Congressional Budget Office, 1992; Glied, 1998); we discuss it only cursorily here.

Virtually all studies find that managed care insurance reduces medical spending in comparison to traditional indemnity insurance. The consensus estimate would be that patients under managed care spend about 10 percent less than patients in indemnity plans, adjusted for differences in the underlying health of the two groups. The effect is somewhat greater for inpatient hospital spending, but is offset by some additional outpatient utilization in managed care insurance. Overall, therefore, incentives on the physician side clearly have an effect on overall utilization.

\section{Optimal Mix of Demand and Supply-Side Controls}

Given the availability of both demand and supply-side controls, which should be employed? A first pass suggests that supply-side limitations are preferable, since providers are relatively less risk averse than are patients. In practice, however, plans with both types of limitations are sold, and 
indeed most plans available have a mix of demand- and supply-side cost containment features (for example, capitation with high cost sharing on out-of-network use, or indemnity insurance with utilization review) ${ }^{28}$

Both demand- and supply-side controls may be desirable in the presence of the other. First, patients and providers may control different features of the medical interaction. For example, the Rand Health Insurance Experiment found that patient cost sharing had a substantially greater impact on the probability that a patient uses services than on the level of services provided conditional on use (Newhouse et al., 1993). One can interpret this as saying that cost sharing affects insureds, but not their physicians. The evidence cited above shows that managed care can limit the level of services provided, however. An insurer or provider facing this situation might then want to combine demand- and supply-side cost sharing, the former to limit the initiation of visits and the latter to control the intensity of treatment provided within visits (Ma and McGuire, 1997).

Combining demand- and supply-side controls can also promote flexibility in types of treatment. Consider the situation in Figure 6 (Baumgardner, 1991; Ramsey and Pauly, 1997; Pauly and Ramsey, 1998). There are two types of patients: those who are moderately ill (denoted M), and those who are more seriously ill (denoted S).$^{29}$ Moderately ill patients demand less medical care at any price than severely ill patients. We assume the insurer cannot distinguish the two groups, however; thus, cost sharing or quantity restrictions must apply equally to the two.

${ }^{28}$ The coexisting prevalence of both types of plans may be transitional, since managed care is still relatively new. But managed care plans have increasingly been incorporating more consumer choice and cost sharing (for example, in out-of-network use). This suggests the combination is not just transitional.

${ }^{29}$ Note that this may apply conditional on a diagnosis. For example, the conditions could be severe and moderate heart attacks. 
Given a price of medical care $\mathrm{P}$, the optimal amounts of medical care to receive are $\mathrm{Q}_{\mathrm{M}}{ }_{\mathrm{M}}$ and $\mathrm{Q}_{\mathrm{S}}^{*}$ respectively for the moderately and severely ill. With a coinsurance policy that requires the patient to pay $c$ for each unit of care, the equilibrium will be medical care levels of $Q^{\prime}{ }_{M}$ and $Q_{S}^{\prime}$. Because of moral hazard, medical care demand will be too high. Insurers might alternately adopt a fixed quantity constraint, for example $\overline{\mathrm{Q}}$ for each patient. ${ }^{30}$ At $\overline{\mathrm{Q}}$, the right amount of medical care is provided in total, but not for each patient; the moderately ill patient will receive too much medical care, while the severely ill patient will not receive enough. Thus, neither demand- nor supply-side cost containment by itself yields an optimal allocation.

Combining demand- and supply-side cost containment can improve the situation, however. For example, starting from $\bar{Q}$, raising coinsurance will discourage utilization by the moderately ill person before the severely ill person (because the marginal value of care is much lower for the former). If the coinsurance rate necessary to deter low value utilization is small, the risk spreading loss from such coinsurance will be small, and the net welfare consequences of deterrence will be positive. The ability to limit demand by the moderately ill person, in turn, allows an increase in $\overline{\mathrm{Q}}$, since this constraint applies only to the severely ill person. Indeed, if demand for the moderately ill person is fully constrained by the cost sharing, $\overline{\mathrm{Q}}$ could be increased to the optimal level of care for the severely ill person. More generally, coinsurance and constrains can be combined to enable rationing in more than one dimension whether there is heterogeneity of optimal treatment. A combination of the two systems may be superior to using either system alone.

A third rationale for combining demand- and supply-side controls is to limit selection behavior by providers. Providers paid on a capitated basis will have incentives to attract healthy

${ }^{30}$ We assume that managed care features this type of restriction. 
patients and "dump" sick ones, since the provider's payment is the same with the two patients but the costs are much greater in treating the sick patient. Incorporating patient cost sharing into the insurance policy can relax the supply-side constraints and thus limit the incentives to dump patients (Ellis, 1998). We return to this type of adverse selection in the next section.

Theoretical results to date generally suggest a combination of demand- and supply-side controls may offer significant advantages. Moreover, with so many differing incentives in the medical care system, optimal reimbursement schemes undoubtedly differ across specialties (for example, in response to moral hazard propensities) and groups of providers (for example, if the ability to bear risk differs with group size), which increases the potential for working both sides of the market. The way demand- and supply-side systems interact with each other, however, is not well understood; neither is the tradeoff between a fine-tuned system and a system that is simple and comprehensible. Real world structures suggest simplicity has its virtues. It is noteworthy, for example, that virtually all coinsurance operates at a flat rate between the deductible and any stop loss amount. $^{31}$

\section{Markets for Health Insurance: Plan Choice and Adverse Selection}

To this point, we have talked of the design of a single health insurance plan. Most private insurance in the United States is offered on a menu basis, however, with different insureds selecting

${ }^{31}$ Simplicity and transparency may be a handicap. Conceivably insureds and doctors, not understanding what they will be respectively charged or paid for something, may behave more reasonably. For example, a low but complex coinsurance rate might be the best way to discourage utilization. It imposes less financial risk than, say, a higher flat rate, but might be just as effective in controlling use. 
different plans. Health insurance choice is a natural way to meet differing individual preferences. Some people will prefer managed care insurance, which limits utilization but costs less, while others will opt for a more open-ended indemnity-style policy. Within indemnity insurance policies, some will be willing to bear more financial risk than others. Having these preferences reflected in market outcomes is beneficial.

In addition, health insurance choice is important to promote efficiency. Customers shopping for the lowest prices drive costs to their lowest level. Moreover, product characteristics will be shifted and new products.introduced to meet consumer demands. These benefits of competition for health insurance are analogous to the benefits competition yields in other markets.

But health insurance is fundamentally different from other markets in ways that create harmful side effects from competition. The key problem is that with health insurance, unlike other services or commodities, the identity of the buyer can dramatically affect costs. Insuring a 60 year old costs 3 times as much as insuring a 30 year old, and among 30 year olds, some will have far higher costs than others. Who one pools with in health insurance dramatically affects what one has to pay.

Generally, the sick are drawn to more generous plans than the healthy. Those expecting to use more services will, all else equal, want more generous policies than those expecting to use fewer services. If plans could charge individuals their expected cost for enrolling in each plan, the market would efficiently sort people. Such charges are generally not imposed, however, since it is widely believed that it is not fair to make people pay a lot more just because they are sick. Knowing the individual-specific prices may also not be technically feasible.

When plans can only charge average prices, generous plans will disproportionately attract 
sicker people, and more moderate plans will disproportionately attract healthier ones. This phenomenon is termed adverse selection (Akerlof, 1970; Arrow, 1985). As a result of adverse selection, generous plans will have to charge premiums above moderate plans not only because they offer more benefits but also because they attract a worse mix of enrollees. These premium differentials, if passed on to insureds, will tilt unfairly against generous plans. ${ }^{32}$

Adverse selection into more generous plans leads to two fundamental difficulties. First, people will choose to be in less generous plans, so that they can avoid paying for the higher costs of very sick people. Second, plans will have incentives to distort their offerings to attract the healthy and repel the sick. Since no plan would like to enroll the sickest people, all plans will find it profitable to distort their benefits. Indeed, even innovations that improve quality of health care may be unattractive to plans even if they come without additional cost, if they attract the wrong people. The distortion in plan provisions resulting from adverse selection is variously termed plan manipulation, skimping (Ellis, 1998), or stinting (Newhouse, 1997).

The consequences of these undesired side effects of competition are felt in market equilibrium. The equilibrium with adverse selection may be inefficient; it may not even exist. We express this as the third lessons of health insurance:

Lesson 3: Competition When Consumer Identity Matters. When consumer identity affects costs, competition is a mixed blessing. Allowing individuals to choose among competing health insurance plans can allocate people to appropriate plans and provide incentives for

32 This would happen, for example, if employers make a fixed dollar contribution to the premiums of each plan offered to their employees. The converse is also true; if employers heavily subsidize the difference between plan costs, employees will choose the generous plan too often. 
efficient provision. But it can also bring with it adverse selection -- the tendency of the sick to differentially choose the most generous plans. Adverse selection induces people to enroll in less generous plans, so they can be in a healthier pool, and gives plans incentives to distort their offerings to be less generous on care for the sick.

Many models of adverse selection have been developed. We start with simple models and then present more advanced models.

\section{VI.I Equilibrium with Adverse Selection - The Basics}

To understand the patterns in adverse selection, we start with the simplest possible situation (Rothschild and Stiglitz, 1976; Wilson, 1980). Assume there are two individuals, one HIGH risk and one LOW risk, and two plans, a generous plan and a moderate plan. Table 8 gives the hypothetical benefits and costs for the generous and moderate plans. We suppose that the generous and moderate plans are what $\mathrm{HIGH}$ and LOW respectively would design for themselves, assuming that each had to pay his own costs. ${ }^{33}$ Note that HIGH costs more in either plan and both people use more services in the generous plan than in the moderate plan.

Equilibrium Efficiency requires people to be in the generous plan if the additional benefits of that plan to them are greater than the additional costs they incur. In this case HIGH should be in the generous plan, and LOW should be in the moderate plan, since the additional value to HIGH of the generous plan $(\$ 13)$ is greater than its additional cost $(\$ 12)$, while the converse is true for LOW (a benefit of $\$ 1$ compared to an additional cost of $\$ 3$ ). The efficient outcome thus separates the

${ }^{33}$ This assumption of respective optimality facilitates exposition, but is not required. 
insureds.

Were separation to happen, the premiums would be $\$ 16$ for the generous plan (the cost of $\mathrm{HIGH}$ ) and $\$ 1$ for the moderate plan (the cost of LOW). At these prices, however, HIGH would select the moderate plan; the $\$ 15$ savings are greater than the $\$ 13$ loss. Of course, once HIGH joins the moderate plan costs escalate, but they are still only $\$ 2.50$ (the average of 4 and 1 ). HIGH's cost savings by enrolling in the moderate plan $(\$ 13.50)$ are still greater than his loss in benefits $(\$ 13)$. LOW will also prefer the moderate plan.

The market equilibrium will thus have both individuals in the moderate plan, a pooling equilibrium. This is not efficient, however. The reason this inefficiency arises is that individuals do not pay their own costs in each plan, but rather the average cost of the plan. Hence, HIGH mimics LOW so that he can share his costs with LOW.

There are a variety of ways to struggle back towards efficiency. Two logical candidates, assigning people to plans or charging people on the basis of expected cost, are undesirable because they respectively override free choice or sacrifice risk spreading. ${ }^{34}$ Two additional possibilities would be to cross subsidize the generous plan by the moderate plan (Cave, 1985), or to distort the plan offerings (Rothschild and Stiglitz, 1976).

Cross Subsidy. Suppose the moderate plan is taxed an additional $\$ 1.25$ per capita, which is used to offset the premium of the generous plan. In the separating equilibrium, the premiums in the two plans will be $\$ 14.75$ and $\$ 2.25$, and HIGH will now prefer the generous to the moderate plan. Both insureds are better off with the subsidy than without. HIGH clearly prefers a subsidy to no

${ }^{34}$ Partial measures are possible. For example, many employers "carve out" mental health benefits from all plans and provide those services using one insurer. Adverse selection is one rationale for this (Frank et al., 1998). 
subsidy. LOW also prefers the subsidy, because he pays only a $\$ 1.25$ subsidy, compared to an additional $\$ 1.50$ premium if he pooled with HIGH in the moderate plan.

Plan manipulation. A second mechanism to induce a separating equilibrium is to replace the moderate plan with something stingier. When faced with a stingier plan, HIGH might choose the generous plan over pooling with LOW. Making the moderate plan stingier is distasteful to LOW, but the cost to HIGH is substantially greater. This disparity in costs is what allows "hurting" the plan to produce separation.

Consider a plan called basic, also detailed in table 8, which gives both HIGH and LOW 70 percent of the benefits and costs they would receive from the moderate plan. Thus, LOW would receive benefits of $\$ 3.50$ at a cost of $\$ 0.70$ were he in the basic plan and HIGH would receive benefits of $\$ 14$, incurring a cost of $\$ 2.80$. If basic and generous were the two plans offered, LOW would select the basic plan. If HIGH selects the basic plan as well, his premium, i.e., average cost, would be $\$ 1.75$. He'd prefer the generous plan, which offers an additional $\$ 19$ in benefits, but would cost only $\$ 14.25$ more. LOW prefers the basic plan to pooling with HIGH in the moderate plan. Plan manipulation sacrifices efficiency, since LOW generates more net benefits in the moderate plan.

In practice, plan manipulation can take many forms. Aerobics programs, for example, will attract the vigorous healthy while spinal cord injury or high tech cancer care facilities pull in the costly sick. There are generally more opportunities to trim a high cost-attracting service than to add aerobics equivalents. ${ }^{35}$ Thus, we expect plans to be ungenerous with services for conditions that will predictably have high costs.

${ }^{35}$ However, the Harvard University Group Health Plan -- an option for Harvard faculty -offers a $\$ 50$ wellness payment, which can be used say for sneakers, as an attractor. 
Market competition will lead to the manipulated equilibrium. Assume that the moderate and generous plans were the only offerings. All participants would pool in moderate. Introducing the basic plan would then attract LOW, HIGH would go off to generous, and the moderate plan would be abandoned. ${ }^{36}$

In practice, plan manipulation and cross-subsidy of premiums can be combined to promote separation. The market equilibrium will have two plans. One will be the optimal plan for HIGH, given whatever subsidy he is receiving. The other plan, which will enroll LOW, will be the plan as close as possible to moderate whose combination of subsidy and manipulation just makes HIGH prefer his optimal plan.

We show this graphically in Figure 7(a), assuming there is a continuous choice of plans. ${ }^{37}$ We array the plans in Figure 7(a) from least to most generous - in this case variability among plans is due to differences in the percent of expenses covered. The figure shows the expected utility of LOW (the upper two lines) and HIGH (the lower two lines) at each possible level of generosity, and for both the pooling and separating equilibria. LOW does better than HIGH, since he have a lesser chance of incurring the cost of sickness. HIGH is better off pooling than separating for it allows him to shed costs; the opposite is true for LOW. For both LOW and HIGH, their optimal separating equilibrium offers less than full insurance. This might be because of moral hazard or administrative

\footnotetext{
${ }^{36}$ The efficiency costs of separation produced through plan manipulation may be small. That is because the moderate plan was designed for LOW. Assuming smoothness, the costs of moving away from the optimal plan are initially trivial. But the costs to HIGH, who is already far from his optimum, may be great. This disparity allows cheap distortion to produce target efficiency (Nichols and Zeckahuser, 1982).

${ }^{37}$ The classic diagrammatic presentation of plan manipulation (dating from Rothschild and Stiglitz) uses indifference curves. We present this in the Appendix.
} 
costs; without these factors each in isolation would want the most generous policy. We show HIGH as wanting full insurance in the pooled equilibrium; in our example, the benefits from the subsidy in that plan are greater than the moral hazard or administrative cost loss. In the least generous plan (no insurance), both HIGH and LOW are indifferent between pooling and separating equilibria. In the most generous plan (full insurance) the two pay the same price and get the same utility in the pooling equilibrium.

Consider the situation if HIGH and LOW are initially at $\mathrm{A}$, the full insurance pooling equilibrium. An insurer that offered a plan with generosity $G_{1}$ would attract LOW, since LOW prefers $G_{1}$ to $A$. HIGH would then move to $G_{1}$, because $E$ is preferred to $C$, the separating equilibrium if only HIGH is in the generous plan. As the pooled policy becomes less generous, its attractiveness to HIGH falls. Policy $\mathrm{G}_{2}$ makes $\mathrm{HIGH}$ just indifferent between pooling with LOW and the separating equilibrium at $\mathrm{C}$. The stable equilibrium will thus have two policies: LOW will be at point $\hat{\mathrm{s}}_{\mathrm{L}}$ with policy $\mathrm{G}_{2}$ and HIGH will be at point $\mathrm{C}$.

With slight chnages in the curves, however, the situation at $\mathrm{G}_{2}$ may not be stable either. Consider the situation in Figure 7(b), drawn for the case where the risk difference between HIGH and LOW is less than in 7(a). Here LOW's preferred pooling equilibrium is superior to his best sustainable separating plan, $\hat{\mathrm{s}}_{\mathrm{L}}$. Thus, the separating equilibrium at $\mathrm{G}_{2}$ will be broken by the pooling equilibrium at $G_{1}$. But the converse is also true; the pooling equilibrium at $G_{1}$ is broken by a plan say at $\mathrm{G}_{3}$, with a price just low enough to attract LOW at $F$, whereas HIGH would prefer to stick with the premium and coverage at $\mathrm{E}$. Once LOW went to $\mathrm{F}$, however, the premium at $\mathrm{E}$ would have to rise, and HIGH would chase LOW to $\mathrm{G}_{3}$. Thus, there is no stable equilibrium in Figure 7(b).

The model underlying Figure 7 assumes a frictionless world, where individuals shuttle 
costlessly between plans and there are no costs involved in establishing new plans. If such costs play a role, they may enable otherwise breakable equilibria to survive. For example, if establishing a plan entails high fixed costs, but individuals' transit costs remain low, $\mathrm{p}_{\mathrm{L}}^{*}$ becomes stable, since breaking $\mathrm{p}_{\mathrm{L}}^{*}$ with $\mathrm{G}_{3}$ is costly but yields only temporary profits. Interestingly, greater transit costs for individuals may promote instability, since a temporary period for attracting individuals to an unstable equilibrium may last longer, and therefore be more attractive despite the fixed costs of establishing a plan. Even in this simple model, the ultimate outcome of markets with adverse selection is uncertain.

\section{VI.2 Equilibria with Multiple Individuals in a Risk Group}

The simple model of adverse selection had a single HIGH and LOW risk. The lumpiness of movement implied by this specification is an important limitation of the model. With multiple individuals of a given risk type, there can also be a third class of equilibria, a "hybrid" equilibrium, to join the pooling and separating equilibria. We now show this equilibrium.

Imagine that there are now many HIGHs and LOWs, with similar tastes for insurance within each group. ${ }^{38}$ Our example uses the parameter values from Table 8 , with the $\$ 33$ benefit for HIGH under the generous plan changed to $\$ 34$. Suppose we start in the separating equilibrium, with HIGHs in the generous plan and LOWs in the basic plan. The expected utility in this equilibrium is shown by the points $\mathrm{A}$ and $\mathrm{B}$ in Figure 8. Recall that the LOWs all prefer the moderate plan to the basic plan. Imagine that they all enroll in that plan. Now suppose that instead of all the HIGHs

${ }^{38}$ A more general formulation would allow individuals within a cost class to differ on such factors as risk aversion, or in tastes for plans. Then the division of HIGHs between the moderate and generous plans would reflect the individuals' preferences. 
choosing the moderate plan, only a share of them choose it. Figure 8 traces expected utility for HIGHs and LOWs as a greater share of the HIGHs choose the moderate plan. Once $\mathrm{H}^{*}$ of the HIGHs have enrolled in the moderate plan -- the number is 50 percent for our parameters -- HIGHs will be indifferent between the two plans. No additional movement of HIGHs will occur.

The LOWs in the moderate plan are worse off pooling with some of the HIGHs than they would be if they had the moderate plan to themselves. But that does not indicate whether the LOWs prefer to separate themselves in basic. Indeed, in Figure 8, expected utility for the LOWs with a share $\mathrm{B}_{\mathrm{H}}^{*}$ of HIGHs in the moderate plan (point D) is greater than expected utility in the basic plan (point C). The equilibrium with all of the $\mathrm{LOWs}^{39}$ and a share $\mathrm{H}^{*}$ of the HIGHs in the moderate plan - what we term the "hybrid equilibrium" - is stable.

The hybrid equilibrium need not be stable, however. If the HIGHs are sufficiently costly, the LOWs will prefer the separating equilibrium to the hybrid equilibrium (point $\mathrm{C}$ will be above point D) and thus the two groups would separate competely.

\section{VI.3 Continuous Risk Groups}

Our two risk types model suggests that at least some high risks will enroll in their most preferred plan while low risks may be distorted into less generous plans. In situations with more than two risk groups, however, this situation may be reversed; the low risks may be in their preferred plans but the high risks may not. We show this using a model developed by Feldman and Dowd

${ }^{39}$ The LOWs will never end up split between the basic and moderate plan. Say the basic and moderate plans were equally attractive with a fraction of the LOWs in the moderate plan. As more LOWs moved to the moderate plan it would become more attractive. Hence, the equilibrium would tip all the LOWs into the moderate plan. 
(1991), Cutler and Reber (1998), and Cutler and Zeckhauser (1998). The model assumes there are two pre-established plan types.

Suppose there is a continuous distribution of risks in the population, denoted by s. For simplicity, we normalize s to be the person's expected spending in the generous policy. There are two plans, one generous and one moderate. The value of more generous insurance to an individual is $V(s)$, where $V^{\prime}>0$ (the sick value generous policies more than the healthy). Figure 9 shows $V(s)$. At any additional cost for choosing the more generous policy, people will strictly divide into plans. If $\mathrm{s}^{*}$ is the sickness level of the person indifferent between the two policies, people with $s>s^{*}$ will choose the generous policy, whereas people with $s<s^{*}$ will choose the moderate policy. Average sickness in the generous policy is $\mathrm{s}_{\mathrm{G}}=\mathrm{E}\left[\mathrm{s} \mid \mathrm{s}>\mathrm{s}^{*}\right]$, and average sickness in the moderate policy, is $\mathrm{s}_{\mathrm{M}}$ $=E\left[s \mid s^{*} \mathbf{s}^{*}\right]$.

Plan premiums, in turn, depend on who enrolls. We assume people in the moderate policy cost a fraction $\alpha(\alpha<1)$ of what they would cost in the generous policy. ${ }^{40}$ In a competitive insurance market, premiums will equal costs: $P_{G}=s_{G}$, and $P_{M}=\alpha S_{M}$. The premium difference between the two plans is therefore:

$$
\Delta P(s)=P_{G}-P_{M}=(1-\alpha) s_{M}+\left[s_{G}-s_{M}\right]
$$

The first term in the final expression is the cost savings the moderate plan offers to its average enrollee. The second term is the difference in the average sickness level in the two plans; it is the consequence of adverse selection.

As marginal people move from the generous to the moderate plan, the average sickness in

${ }^{40}$ The literature reviewed above suggests that $\alpha \approx .9$ for an HMO relative to an indemnity policy. 
each of the plans will rise. Depending on the distribution of $s$, the price difference between plan may widen or narrow. Because medical spending in practice is significantly right-skewed (Table 2), it is natural to conjecture that the premium in the generous plan will rise by more than the premium in the moderate plan. Figure 9 reflects this expectation as an upward sloping $\Delta P(s)$ curve.

The guideline for efficiency is that the price differential must be appropriate for the individual at the margin in choosing between plans. All other people would be appropriate sorted, with sicker people choosing the generous plan and healthier people choosing the moderate plan. ${ }^{41}$ The price for the marginal individual is given by:

$$
\Delta \mathrm{P}^{\mathrm{marg}}(\hat{\mathrm{s}})=(1-\alpha) \hat{\mathrm{s}},
$$

where $\mathrm{s}$ is the person for whom equation (16) holds. We show this schedule in Figure 9 as lying below the $\Delta \mathrm{P}(\mathrm{s})$ line. $\mathrm{s}$ optimally delineates people in the moderate and generous plans.

Comparing equations (15) and (16) shows that only by coincidence will the equilibrium be efficient. Suppose that the efficient allocation prevailed. From equation (15), the price difference between the two policies will differ from this amount for two reasons. The first term in equation (15) is generally below the efficient differential; it represents the savings from the moderate plan for the average person in the moderate plan, not the marginal person in the plan, for whom the savings would be greater. Working in the opposite direction, adverse selection (the second term in equation (15)) will raise the premium in the generous plan relative to the premium in the moderate plan. Depending on the distribution of medical expenditures, the market differential could thus be above or below the efficient level. The right skewness of medical spending suggests that the adverse

${ }^{41}$ If preferences as well as sickness level affect the value of the generous plan, then each individual must may his personal cost differential, $\Delta \mathrm{P}^{\mathrm{i}}(\mathrm{s})=(1-\alpha) \mathrm{s}_{\mathrm{i}}$ 
selection effect will tend to predominate. This is the situation shown in Figure 9 (by virtue of the fact that the $\Delta \mathrm{P}(\mathrm{s})$ line is above the $\Delta \mathrm{P}^{\mathrm{marg}}(\mathrm{s})$ line). The premium differential for the generous plan will then be above the efficient differential, and too few people will enroll in the generous plan.

Because of adverse selection, small deviations in price can drive large differences in allocations, and indeed, the generous plan may fail to survive. Starting from $s$, suppose the generous plan is priced too high. Marginal enrollees will depart, driving prices up still further, inducing new departures, and so on. The final equilibrium may be quite far from the efficient point. Indeed, Figure 9 also shows the possibility that the entire generous plan is depopulated. If $\Delta \mathrm{P}^{\text {alt }}(\mathrm{s})$ described the cost differential, then $\mathrm{V}(\mathrm{s})$ would not intersect that line and the equilibrium would have no enrollment in the generous plan. ${ }^{42}$ The disappearance of generous plans as a result of dynamic processes of adverse selection is termed a "death spiral". In such a situation, high risks end up in less generous plans than is optimal, while low risks get their preferred policy.

\section{VI.4 Evidence on the Importance of Biased Enrollment}

A substantial literature has examined adverse selection in insurance markets. Table 9

42 Whether a death spiral actually occurs will depend on the distribution of risk levels, and the strength of the risk-preference interaction. The fatter the upper tail, the stronger the interaction, the more threatening is the possibility of a spiral. A numerical example illustrates this possibility. Suppose that the highest cost person has expected spending of $\$ 50,000$ and that average costs of the whole population in the moderate policy (with or without this person, if he comprises a small part of the total risk) is $\$ 3,000$. Suppose further that the high cost person values the generous policy at $\$ 20,000$ more than the moderate policy, and that he spends only $\$ 5,000$ less in the moderate policy than with the generous policy (for example, a 10 percent savings if the plans are an indemnity policy and an HMO). Efficiency demands that he should be in the generous policy; the additional value of that policy $(\$ 20,000)$ is greater than the additional cost he imposes there $(\$ 5,000)$. If the high cost person were the only person in the generous policy, however, the cost of that policy would be $\$ 47,000$ more than the cost of the moderate policy, which would lead him to opt for the moderate policy. 
summarizes this literature, breaking selection into three categories: traditional insurance versus managed care; overall levels of insurance coverage; and high versus low option coverage.

Most empirical work on adverse selection involves data from employers who allow choices of different health insurance plans of varying generosity; a minority of studies look at the Medicare market, where choices are also given. Within these contexts, adverse selection can be quantified in a variety of fashions. Some authors report the difference in premiums or claims generated by adverse selection after controlling for other relevant factors (for example, Price and Mays, 1985; Brown et al., 1993). Other papers examine the likelihood of enrollment in a generous plan conditional on expected health status (for example, Cutler and Reber, 1998). A third group measure the predominance of known risk factors among enrollees of more generous health plans compared to those in less generous plans (for example, Ellis, 1989).

Regardless of the exact measurement strategy, however, the data nearly uniformly suggest that adverse selection is quantitatively large. Adverse selection is present in the choice between feefor-service and managed care plans ( 8 out of 12 studies, with 2 findings of favorable selection and 3 studies ambiguous), in the choice between being insured and being uninsured ( 3 out of 4 studies, with 1 ambiguous finding), and in the choice between high-option and low-option plans within a given type (14 out of 14 studies).

Figure 10 shows a particularly salient example of adverse selection, taken from experience at Harvard University. ${ }^{43}$ The Harvard experience is nice because adverse selection was driven by a policy change, and thus one can view the beginning of adverse selection and its subsequent effects. In the early 1990s, Harvard University offered its employees two types of health insurance plans: a

\footnotetext{
${ }^{43}$ See Cutler and Reber (1998) and Cutler and Zeckhauser (1998).
} 
generous PPO and a number of HMOs. The University paid about 90 percent of each plan's premium; thus, the employee cost of the PPO, shown in Figure 10(a), was a relatively modest $\$ 500$ per year. To trim costs, Harvard in 1995 moved to a more competitive health insurance system. Under the new system, the University pegged its contribution at a fixed percentage of the lowest cost plan. Employees paid the entire amount above this for the plan of their choice. The hope was that competition among plans would drive down premiums and thus save the University money.

When the new system was introduced, the cost of the PPO rose, and PPO enrollment fell. As Figure 10(a) shows, about 1/4 of PPO enrollees left the PPO between 1994 and 1995. These enrollees were disproportionately the younger and healthier employees in the PPO, however. As a result of the biased disenrollment, the PPO lost money in 1995; in 1996, it had to raise its premium by nearly $\$ 1,000$. This led to a further decline in PPO enrollment; over half the remaining PPO enrollees left the plan after 1996. Again, these employees were disproportionately younger and healthier than those that remained in the PPO. Thus, the PPO premium lost money again in 1997 and would have had to increase premiums substantially in 1998, just to prevent losses. In fact, the required premium increase would have been too large for the insurer and Harvard to bear. The PPO was disbanded before that year. Adverse selection thus produced a death spiral, and did so very quickly. The disappearance of the PPO is a welfare loss to employees who would have chosen it at their individual-specific cost. Cutler and Reber estimate the size of the welfare loss at 2 to 4 percent of baseline premiums.

The importance of adverse selection has had direct impacts on policy. For example, Brown et al. (1993) found that Medicare enrollees who enroll in a managed care plan would have spent 10 percent below average if they had been in the traditional system. Since Medicare paid only 5 percent 
less to managed care companies for enrolling these people, Medicare lost money as HMO enrollment increased. In 1997, Federal legislation reduced payments to HMOs by an additional 5 percent, to avoid these continuing losses.

\section{5 Evidence on the Importance of Plan Manipulation}

There are substantially fewer empirical studies on plan manipulation than on adverse selection. Plans, of course, differ greatly in their generosity. But it is difficult to know, and plans do not want to reveal, the extent to which the observed variation in plan benefits reflects manipulation by the plans to attract healthy risks as opposed to the self-interested choice of insurance arrangements among people already enrolled in the plans. Adverse selection aside, plans with sicker enrollees probably should be more generous.

Though evidence on plan structures is ambiguous, the marketing of managed care plans shows clear efforts to promote favorable selection. Maibach et al. (1998) document the marketing practices managed care plans use to attract healthy Medicare enrollees, including television ads that show seniors engaged in physical and social activities and marketing seminars held in buildings that were not wheelchair accessible. Whether such practices extend to the types of benefits these plans offer is unknown.

\section{VI.6 The Tradeoff Between Competition and Selection}

In weighting the consequences of competition, losses from adverse selection must be balanced against the gains, if any, from lower premiums that competition induces. The Harvard University study discussed above (Cutler and Reber, 1998) shows such a tradeoff. As Figure 10(b) 
demonstrates, premiums for the HMOs fell by over $\$ 1,000$ when the University moved to flat-rate pricing. The savings to Harvard from these lower premiums was estimated at 5 to 8 percent of baseline health spending. This cost savings is greater than the 2 to 4 percent loss from adverse selection noted above. Thus. the net effect of competition in the Harvard circumstance appears to be beneficial, although the adverse selection losses were quite large.

With few exceptions (Wholey et al., 1995; Feldman and Dowd, 1993; Baker and Corts, 1995), few studies have examined how competition affects health insurance premiums. It is often difficult to gather data on premiums, since most insurers charge different groups different amounts. In addition, premiums need to be adjusted for differences in the quality of benefits, but the many dimensions of quality are very difficult to control for. Thus, the tradeoff between cost savings and adverse selection in other situations is generally unknown.

\section{VI.7 Risk Adjustment}

The fundamental question about health insurance design is how to achieve the benefits of competition while containing the costs of adverse selection. A natural solution is suggested by the model above. Suppose that individuals were not charged the full difference in premiums between plans, but that instead the employer or government entirely running the insurance system offset some of the difference. For example, if the generous plan has above average risks in the amount $E\left[\mathrm{~s} \mid \mathrm{s}>\mathrm{s}^{*}\right]$ $\mathrm{E}[\mathrm{s}]$, the government would give the plan a per capita subsidy equal to this amount. The subsidy would be financed by a tax on the moderate plan, which has below average risks, by the amount 
$E\left[s \mid s<s^{*}\right]-E[s]$. The contribution from the plans would just match, ${ }^{44}$ so there would be no net cost to the government.

In a competitive market, plans that receive subsidies (or are forced to pay taxes) would pass these subsidies on to consumers. Therefore, the premium for the generous plan would fall to $\mathrm{P}_{\mathrm{G}}=$ $\mathrm{s}_{\mathrm{G}}-$ subsidy $_{G}=E[\mathrm{~s}]$, and the premium for the moderate plan would rise to $\mathrm{P}_{\mathrm{M}}=\alpha \mathrm{s}_{\mathrm{M}}+\operatorname{tax}_{\mathrm{M}}=\mathrm{E}[\mathrm{s}]-$ $(1-\alpha) \mathrm{s}_{\mathrm{M}}$. The adjusted premium difference between the plans, which individuals would face, would thus be

$$
\Delta P^{a d j}=P_{G}-P_{M}=(1-\alpha) S_{M}
$$

This quantity is the savings for the average person in the moderate plan. It is closely related to the optimal price difference in equation (16), which is the savings for the marginal person in the moderate plan. Plan choices made on the basis of the price difference in equation (17), though not optimal, are likely to be more efficient than plan choices made on the basis of unadjusted price differences.

This form of differential payment is termed "risk adjustment" (Ellis and VandeVen, 1998). Risk adjustment must be carried out by some entity that can require individuals to insure or convince them to do so through subsidies. Otherwise, low cost individuals would choose not to participate. One possibility would be for the government to impose risk adjustment, whoever is the payer. But employers providing subsidized health insurance can do the job just as well. Employers have an incentive to risk adjust since it promotes efficiency and thus lowers the overall cost of providing

${ }^{44}$ This is because $\left(E\left[s \mid s>s^{*}\right]+E\left[s \mid s^{*} s^{*}\right]\right) / 2=E[s]$. 
health coverage. ${ }^{45}$

Empirically, risk adjustment can be carried out in four ways. Plans can pay or receive payments based on: (1) demographic variables (for example, more for taking on older people); (2) medical conditions (for example, more for people with diabetes); (3) past medical expenditures, which help predict future expenditures; or (4) actual experience in a year (for example, $\$ 50,000$ extra for each organ transplant patient). The first three approaches attempt to predict experience; the last is after-the-fact reinsurance.

The tradeoffs between these different forms of risk adjustment is related to the ability of health plans to manipulate the risk adjustment system. Information about diagnosis, past claims, and actual use increase the ability to measure differential enrollment, but are susceptible to distortion by the plans. For example, plans may code borderline people as having diabetes if risk adjustment is done on the basis of the number of diabetics. Plans might creatively assign costs to high cost cases, when such cases are largely reimbursed. Even if risk adjustment is done on a prospective basis, plans have an incentive to exaggerate current sickness and expenditure levels, since the vast majority of insureds stick with their plans from year to year. A final, at least theoretical, concern about risk adjustment is that it may diminish plans' incentives to maintain their enrollees' health. Keeping people healthy disqualifies the plan from receiving additional risk adjustment payments, thus reducing the value of the health investment.

Because so few employers or governments have used formal risk adjustment systems, the

${ }^{45}$ Some employers have made second best efforts to implement risk adjustment, at times inadvertently. The heavy subsidy of premiums -- many employers pay 85 percent or more -- in effect covers 85 percent of cost differentials due to varying mixes of insureds. Alas, heavy subsidies also significantly diminish the incentives of insureds to shop around, hence of health plans to hold down their costs. 
relative advantages and drawbacks of different risk adjustment methodologies are unknown. New efforts may provide some of this information, however, In January 1999, in a major initiative, the Federal government announced its intention to employ risk adjustment on the basis of past diagnoses to pay HMOs that enroll individuals in Medicare. Evaluating the impact of this system is a major research priority.

\section{Person-Specific Pricing, Contract Length, and Premium Uncertainty}

Adverse selection is a problem of asymmetric information -- individuals know their likely medical care utilization but insurers either do not, or are not allowed to use this information. Increasingly, however, information is becoming equalized. Insurers question individuals or monitor their past utilization to forecast their future costs. Equipped with such knowledge, insurers may know more about expected costs for the groups they are insuring than the members of the groups do themselves.

Insurers can use this information to set premiums. While such "experience rating" is rare at the individual level, it is common at the group level. Most private health insurance in the United States is at least partly experience rated. The bigger the group purchasing insurance, the more likely is experience rating. Hence, older and sicker groups are charged more per capita for the same coverage.

But experience rating creates its own set of problems, particularly when carried out at the individual level. When people face premiums that depend on their sickness, they are denied a form of insurance -- the ability to obtain the same insurance premiums as their peers at the same price. 
The welfare loss can be significant.

Consider, for example, a situation where individuals are insuring themselves, diabetes is the only disease, and both people and plans know who is diabetic. Plans would offer full insurance to everyone but would charge diabetics more than non-diabetics; after all, no one who is not diabetic would be willing to pay extra to insure the diabetics. Given the distribution of diabetics and nondiabetics, the higher premiums charged to diabetics create a distributional issue. Diabetics pay more, and non-diabetics pay less relative to level premiums.

But from an ex ante perspective, before anyone knows who will contract diabetes, the distributional issue represents an efficiency loss. Suppose that before an individual knew if she would be diabetic or not -- potentially before birth - she was offered insurance against the risk that she would become diabetic and thus face higher insurance premiums in the future. Full insurance would guarantee that if she developed diabetes, the policy would give her sufficient income each year to cover the higher diabetes premium she would then face. The benefits would be financed by payments from non-diabetics. Individuals would be willing to purchase this insurance were it sold at fair odds; they get a reduction in financial risk at no expected cost.

In real-world markets, however, such insurance against falling into a worse risk class is not offered. Some of the insurance would have to be purchased before birth. People obviously cannot do this, and even their parents might be unable to buy it for them, if there is a genetic predisposition towards disease. Other insurance could wait until mid-life for the unpredictable infirmities of old age. The key is to contract for insurance before the risk is resolved. While long-term anticipatory insurance is possible, health insurance in actual markets is rarely sold for over one year. People consequently lose welfare ex ante; there is an insurance policy they want but cannot obtain. 
This loss at first may seem counterintuitive: everyone has full information and everyone gets full insurance every year. Where is the source of the loss? The welfare loss derives from a missing market for insurance against one's risk type. Risk averse individuals would like to insure against the possibility of being discovered to be high risk. There is no market where they can do so, however. Given that a market is missing, there is no guarantee that efficient pricing on the basis of known information as opposed to level pricing (as if ignorant) will enhance welfare. This illustrates the theory of the second best. The market failure might also be thought of as a recontracting failure. We recontract for health insurance annually despite the fact that we learn about expected future health costs during the year. Such periodic recontracting breaks the contractual arrangements that would characterize optimal insurance.

This problem has variously been termed the problem of renewable insurance or the problem of intertemporal insurance (Pauly, Kunreuther, and Hirth, 1995; Cochrane, 1995; Cutler, 1996; and Zeckhauser, 1974). It is likely to grow in importance in health insurance markets as our ability to predict medical spending rises, as it will, for example, through advances in genetic screening. We note this as the fourth lesson of health insurance:

Lesson 4: Information and Long-term Insurance: More information about individual risk levels allows for more efficient pricing of risk, but portends a welfare loss from incomplete insurance contracts.

Might markets develop to deal with this problem? Some possibilities suggest themselves. People might purchase insurance for their lifetime rather than annually. If insurance choices were 
made early enough (or high-cost people were compensated when insurance choices were made), people would not suffer from knowledge gained over time. Long-term purchases, such as those associated with whole life insurance. are made in this fashion. Individuals buy level premium life insurance when they are young and healthy; they will wish to retain it, even if relatively healthy, when they grow old and annual risks escalate.

In theory, health insurance could be sold for the long term on a level premium basis. In practice, matters will be more complex. Much health insurance is now bundled with the provision of care. If an individual left a geographic region, he might have to change provider, and no new provider/insurer would want to take him own at his old level rate. Portability is but one problem. Once individuals purchase lifetime medical insurance, why should an insurer strive for efficiency when people are stuck in his plan? This problem is exacerbated since the insurer must agree to pay for or provide a changing level of services. Health insurance policies optimally change from year to year, as medical technology improves and knowledge about optimal treatments expands. Finally, with future medical costs so unpredictable, insurers cannot take on the risk, which would apply to all policies, that costs will escalate beyond expectation. With life insurance, by contrast, portability, changing service mix, and varying costs are not problems.

A second approach to long-term health insurance would be to develop policies offering insurance against learning one is high cost (Cochrane, 1995). Imagine that people purchase two insurance policies in a year; one to cover their medical costs that year, and a second to cover any increase in premiums they may face in the future. The second policy -- the "premium insurance" policy might look like a standard health insurance policy: people pay in money and if they learn they are likely to have high costs in the future they receive money back. Full premium insurance would 
give people an amount of money equivalent to the discounted expected increase in their future medical spending they learn about during the year. ${ }^{46}$ Why don 't' we observe premium insurance? Several factors have been identified. Moral hazard (people with premium insurance would take insufficient care of their health) and adverse selection (people expecting declines in health would more likely take up the insurance) are possibilities.

The aggregate risk phenomenon provides still a third explanation (Cutler, 1996). Full premium insurance would have to insure a person against the risk that the medical policy that a representative individual will need in the future will cost more then than it is forecast to cost today. But future medical costs are not known. For example, a half century ago, the cost of treating cardiovascular disease treatment was minimal with little prospect for rapid increase. Bypass surgery, angioplasty, and the like unexpectedly increased the cost of treating cardiovascular disease. Diversifying such a risk of significant cost increases for a common ailment is not possible. It is what is termed an aggregate as opposed to an idiosyncratic risk, where the latter apply to individuals one at a time. Insurers generally eschew aggregate risks. By contrast, insurers accept risks readily when they can lean comfortably on the Law of Large Numbers to spread them, as they can with idiosyncratic risks. They generally refuse to write insurance for risks that are unpredictable or nondiversifiable since they could bankrupt the company. Cost increases associated with future medical care suffer both disqualifications.

The result is that even though improved insurer information may reduce adverse selection over time, problems in insurance markets may grow. If people are increasingly charged on the basis

\footnotetext{
${ }^{46}$ This is related to the solution in Pauly, Kunreuther, and Hirth (1995). They propose paying a large premium in the first year, which is used to finance additional care for those who become sick in later years.
} 
of their individual risk characteristics, the efficiency losses could be severe.

Does employer-based insurance, where individuals choose from a menu of options, help? Under such plans, there is a range of potential costs individuals can face for choosing more generous insurance. At one extreme such plans are fully subsidized; people pay the same amount for each plan. At the other extreme there is no subsidy; people pay the expected cost in each plan on a group of individual basis. A system of risk adjustment lies in between; people pay the average cost of more generous plans assuming the mix of insureds is constant across plans.

We have stressed the efficiency aspects of risk-adjusted premiums, but such a system may not spread risks to a sufficient extent. Even in the perfect risk-adjusted equilibrium, the sick will pay more than the healthy, since they will be more attracted to the generous plan. People would presumably like to insure some of even this efficient price difference. There is, in terms of our earlier discussion, a tradeoff between moral hazard and risk sharing. Risk spreading considerations suggest that people should pay nothing additional for selecting more generous plans, assuming risk level was the driving factor in their choice. Efficiency dictates that they should pay the expected additional cost they incur by choosing more generous care. The optimal differential lies between the two extremes, at the point where the marginal costs in terms of misallocation of people across plans exactly offsets the marginal benefits of increased risk sharing. Of course, price setting to this level of refinement may not be possible.

\section{Insurance and Health Outcomes}

Our empirical analysis to this point has focused on the impact of health insurance on medical 
spending. Ultimately, people care about health insurance because they are concerned about their health. A central research issue is therefore how alternate insurance arrangements affect health. Much policy rhetoric expounds on the effects of not having insurance on health. Evidence on this issue shows that the effect of being without insurance can be large. See Weissman and Epstein, 1994, for a review. For our purposes, however, we are interested in how variations among the set of insurance plans affects health. One might expect an attenuated version of the same finding -- that people carrying less generous insurance, either indemnity insurance with high cost sharing or managed care insurance, would suffer worse health outcomes than people with more generous insurance. This might be particularly expected since medical treatment differs across insurance categories.

But several factors work in the other direction. Some of the additional care provided under more generous insurance may be iatrogenic (harmful to the patient), conceivably provided by physicians to increase their income. Perhaps more important, managed care policies may improve outcomes. One feature of managed care is that it standardizes the care that is received by classes of patients. These standards, if based on sound science and carefully crafted to patient characteristics, may be superior to what physicians conclude on their own. In addition, managed care usually involves less cost sharing for primary care, preventive services, and prescription drugs than does indemnity insurance. Greater use of these services may improve health outcomes.

Evidence on the effect of different insurance arrangements on health outcomes generally suggests very little difference in health produced across plans. The clearest findings on the impact of differing levels of demand-side cost sharing emerge from the Rand Health Insurance Experiment (Newhouse et al., 1993). The Rand study measured a broad array of health indicators. For most 
people, outcomes did not differ across plans. This is true even though spending differed across plans by up to one-third. Insurance did have a small effect of the health of the sick poor: Poor people achieved better outcomes in more generous plans with blood pressure control, vision correction, and filling decayed teeth. Of course. the Health Insurance Experiment lasted for only a few years, which may have tilted the test against more generous plans. Increased primary and preventive care, even if strongly beneficial, may not be so important in such a short period of time.

Many studies have examined the impact of supply-side cost sharing on medical outcomes. Such studies must adjust for differing population mixes across plans, which is a difficult challenge. Important evidence comes from the implementation of prospective payment for hospital admissions covered by Medicare. At the time of the change, the critics of the new prospective payment warned that patients would be discharged from hospitals "quicker and sicker". Several papers examined this question, as shown in Table 7. The most detailed studies are the papers grouped under Kahn et al. (1991), which examined patient medical reviews before and after prospective payment was implemented to measure changes in health. That research found no increase in adverse outcomes for the average patient after prospective reimbursement, although they did find that with prospective payment more patients were discharged from the hospital in an unstable condition. The lack of significant adverse effect on quality of care was also found by DesHarnais, Chesney, and Fleming (1988).

Some papers have found evidence of adverse outcomes resulting from prospective payment. Fitzgerald et al. $(1987,1988)$ found that patients admitted to a hospital in the midwest with a hip fracture were discharged sooner after prospective payment but were more likely to be in a nursing home 6 months and 1 year after the hip fracture. In response, many other researchers have examined 
this question, finding that length of stay for hip fracture patients fell but there was no effect on nursing home residence, functional status, or mortality after 1 year (Gerety et al., 1989; Palmer et al., 1989; Roy, Griffin, and Baugh, 1990).

Two studies have looked at the impact not of the prospective payment system, but of the revenue changes stemming from prospective payment (Cutler, 1995; and Staiger and Gaumer, 1997). These studies compared patients admitted to hospitals that lost revenue with patients admitted to hospitals that gained revenue. The former patients experience a compression of mortality into the period just after the hospital admission in comparison to the latter; some classes of patients that formerly survived several months after being hospitalized did not live as long after revenues fell. The effect diminished over the succeeding year, however. For patients who survived a year or longer, there was no increase in mortality. ${ }^{47}$ The authors conclude that price changes have a small adverse effect on the very sick, but little effect on others.

A second set of evidence examines the effect of managed care on health. Miller and Luft (1997) summarize 35 studies comparing medical outcomes in managed care and indemnity insurance. They find no clear difference; some studies find that managed care does worse, while an equally large number find it does better. Many find no difference in outcomes. ${ }^{48}$

One is tempted to conclude from these findings that managed care is superior to traditional insurance -- it saves money without substantial adverse effects. Such a conclusion is premature, however, until long-term evidence on the effect of managed care has been obtained. We note the

${ }^{47}$ After a phase-in period, hospital payments in total were not substantially affected by prospective payment, so these results are consistent with the Kahn et al. (1991) finding of no change in health for the average patient.

${ }^{48}$ See also Cutler, McClellan and Newhouse (1998). 
focus on health and lack of conclusive results as the fifth lesson of health insurance.

Lesson 5: Health Insurance and Health. The primary purpose of health insurance and delivery is to improve health. Unfortunately, conclusive results are not in on which insurance and provision arrangements do this most effectively.

\section{Conclusions and Implications}

Health insurance has a complex anatomy. The lens of economics brings many of its critical features - incentives, risk spreading and asymmetric information - into strong relief. The understanding thus gained, however helpful, does not solve all of the problems. Indeed, the primary message of this chapter is that health insurance design is a challenging exercise in the second best. On each of a variety of dimensions, goals must be traded off against each another, since first principles are in conflict.

Our lessons about health insurance, highlighted in Table 10, are instructive in this respect. We start with a single insurer. Lesson 1 stresses the tradeoff between efficient risk spreading and excessive utilization. Optimal risk sharing puts all the burden on the risk-neutral insurer, but this induces moral hazard (excess consumption of services) and possibly supplier-induced demand (excessive provision). Lesson 2 finds that integration of insurance and provision of services, which is absent in other insurance contexts, may be desirable to align producer and insurer incentives in the delivery of medical care. 
Lessons 3 and 4 highlight second-best problems in the health insurance marketplace. Lesson 3 shows that competitive markets, the traditional lodestar of economics, may have undesirable side effects in health insurance. Most important, competition induces adverse selection, hence the misallocation of people to plans and the incentive for insurers to trim their offerings to deter the sick. In theory at least, risk-adjustment methods, which are just now being tried in practice, can counter these phenomena. Lesson 4 alerts us, however, that even if we slay the dragons of adverse selection and plan manipulation, a fierce risk remains. Since insurance is written on an annual basis, individuals are denied crucial protection against becoming sick and having their premiums escalate substantially in the future.

Lesson 5 reminds us that the ultimate goal of health insurance does not involve the usual economic concepts of prices, incentives and costs. Rather, the central objective of health insurance is to maintain and enhance our health. The payoff question, therefore, is what can we get for alternative levels of expenditure? The contribution of economics is to enable us to sketch the production function.

Health insurance is a service in society, like a hair cut or tennis lesson. Why then does health insurance cause so many more problems than the other two? Both the insurance aspect, and its area of application, health, produce problems. In any insurance situation, moral hazard and adverse selection plague outcomes. In the case of health insurance, the problems are magnified, since healthpromoting and care-seeking actions are difficult to monitor, and it is widely believed to be unfair to charge people more if they contract diseases that are not their fault. Moreover, the payoff from health insurance, unlike say life insurance, is quite variable, and subject to human choice made after the contract is written. In addition, for justifiable reasons, health care is written on an annual basis, 
though today's chance outcomes often have cost implications that stretch for decades. Finally, health has a privileged position above other goods and services. For a range of philosophical and moral reasons, societies care deeply that out citizens receive health care, even if that is not what they would buy were we to give them the money.

These fundamental issues surrounding the equitable and efficient provision of health insurance make government involvement inevitable, and in many contexts desirable. The range of government involvement in health care and health insurance is enormous. At one end, many governments provide medical care directly; they raise money through taxes, hire doctors and run public hospitals. Less extreme are countries where the government is the sole insurer, but provision of services remains private. More market-oriented systems such as the United States have most of the population in private insurance and most of the provision of medical care done by private providers. Even there, though, government plays a sizeable role, refereeing the playing field and insuring those who the market would leave behind. Thus, the Federal government insures people through Medicare and Medicaid, provides tax subsidies to private insurance, defines permissible structures for supplementary Medicare insurance, and requires insurers to cover people who recently lost or changed jobs. Moreover, many states mandate that particular benefits be part of any health insurance plan.

Discussions of medical care reform in the United States and elsewhere often lead to extreme positions. Advocates at one end believe that the problems with markets in health care are so severe that government control, at least of expenditures, is necessary. The Canadian system - taxsupported, privately provided, but publicly regulated - is held up as an exemplar. The claimed merits are that one insurer eliminates adverse selection, tight supply restrictions manage costs, and 
tax financing enables everyone to be insured. Of course, in such a system competition between insurers plays no role in promoting efficiency.

At the other extreme are free-market advocates, who believe that market institutions, if guided correctly, would produce a superior outcome. The government should stay out of the insurance business, but implement a risk adjustment system, directly or at arm's length, so that people face efficient prices. Moreover, the government should remove the tax subsidy favoring employer provision of insurance, which would lead to trimmed plan generosity and more cost sharing by employees. Where necessary, the government should give high cost individuals riskrelated subsidies that enable them to buy health insurance in the marketplace.

The fundamental difference between the public and private approaches to medical care reform are indicative of the enormous problems in medical care markets and the central role that health plays in our utility. Can risk adjustment work well enough to deter plan manipulation and cream skimming? Without subsidies, would employers provide insurance? If they stopped doing so, how many more people would be uninsured, and how much would their health suffer? These are questions at the heart of health insurance reform.

And beyond the question about organizing the health insurance system, there remain questions of how plans should interact with providers. Should providers be paid by capitation or by fee-for-service, or might there be a happy medium? Will providers respond to a payment schedule by either skimping on patients or driving up costs? Only experience in the future, coupled with a delicately balanced wisdom, will enable us to answer these questions.

Economics does not offer robust conclusions about the virtues and liabilities of markets in second-best situations. Hence, it is not surprising that the debate on who should provide health 
insurance and how it best should be structured rages on, even among economists. Ultimately, of course, many of the issues cannot be answered on the basis of first principles, much less the dogma that is too often brought to the debate. They require empirical investigations.

An impressive array of data has been brought to bear one-to-one on central issues in health insurance, but the grand synthesis needed for effective prescription awaits us. Which medical system around the world is best, and what would make it even better? Might the best system for Germany or Japan differ significantly from that for the United States? To understand the attractiveness of alternative health insurance structures, not unlike much of medical care itself, many consequences must be weighed, and many side effects considered. This chapter provided an anatomy to help organize those investigations. 


\section{References}

Akerlof, George, "The Market for 'Lemons': Qualitative Uncertainty and the Market Mechanism", Quarterly Journal of Economics, 1970, 74: 488-500.

Altman, Daniel, David M. Cutler and Richard J. Zeckhauser, "Adverse selection and adverse retention," American Economic Review, Vol. 88, No. 2 (May, 1998), pp. 122-26.

Arrow, Kenneth, "Uncertainty and the Welfare Economics of Medical Care", American Economic Review, 1963, 53(5), 941-973.

Arrow, Kenneth, Aspects of the Theory of Risk Bearing, Helsinki: Yrjo Jahnssonin Saatio, 1965.

Arrow, Kenneth, "The Economics of Agency", in John Pratt and Richard Zeckhauser, eds., Principals and Agents: The Structure of Business, Cambridge, MA: Harvard Business School Press, 1985, 37-51.

Baker, Laurence C, and Kenneth S. Corts, "The Effects of HMOs on Conventional Insurance Premiums: Theory and Evidence”, NBER Working Paper No. 5356, November 1995.

Baumgardner, James, "The Interaction between Forms of Insurance Contract and Types of Technical Change in Medical Care", Rand Journal of Economics, Vol. 22 (1), Spring 1991, 36-53.

Beck, R. G., "The effects of co-payment on the poor," Journal of Human Resources, Vol. 9, No. 1 (Winter 1974), pp. 129-142.

Berk, Marc L., and Alan C. Monheit, "The Concentration of Health Expenditures: An Update", Health Affairs, Winter 1992, 145-149.

Bhattacharya, Jayanta, William B. Vogt, Aki Yoshikawa and Toshitaka Nakahara, "The utilization of outpatient medical services in Japan," Journal of Human Resources, Vol. 31, No. 2 (Spring 1996), pp. 450-76.

Bice, Thomas W., "Risk vulnerability and enrollment in a prepaid group practice," Medical Care, Vol. 13, No. 8 (August 1975), pp. 698-703.

Blomqvist, Ake G., "Optimal non-linear health insurance," Journal of Health Economics, Vol. 16, No. 3 (June 1997), pp. 303-21.

Brown, Randall S., et al., The Medicare Risk Program for HMOs -- Final Summary Report on Findings from the Evaluation, Final Reprot under HCFA Contract Number 500-88-0006, (Princeton, NJ: Mathematica Policy Research, Inc., 1993). 
Buchanan, Joan L., Emmett B. Keeler, John E. Rolph and Martin R. Holmer, "Simulating health expenditures under alternative insurance plans," Management Science, Vol. 37, No. 9 (September 1991), pp. 1067-89.

Buchmueller, Thomas C. and Paul J. Feldstein, "The effect of price on switching among health plans," Journal of Health Economics, Vol. 16, No. 2 (April 1997), pp. 231-47.

Cardon, James and Igal Hendel, "Asymmetric information in health care and health insurance markets: Evidence from the National Medical Expenditure Survey," mimeo (July 8, 1996).

Carroll, Norman V. and W. Gary Erwin, "Patient shifting as a response to Medicare prospective payment," Medical Care, Vol. 25, No. 12 (December 1987), pp. 1161-67.

Cave, Jonathan, "Subsidy Equilibrium and Multiple-Option Insurance Markets", in Richard Scheffler and Louis F. Rossiter, eds., Advances in Health Economics and Health Services Research. Volume 6. Biased Selection in Health Care Markets. Greenwich, CT: JAI Press, 1985, 27-45.

Cherkin, Daniel C., Louis Grothaus and Edward H. Wagner, "The effect of office visit copayments on utilization in a health maintenance organization," Medical Care, Vol. 27, No. 7 (July 1989), pp. 669-79.

Cochrane, John, "Time Consistent Health Insurance", Journal of Political Economy, 103 (3), June $1995,445-73$.

Colle, Ann D. and Michael Grossman, "Determinants of pediatric care utilization," Journal of Human Resources, Vol. 13 (Supp. 1978), pp. 115-53.

Conrad, Douglas A.. David Grembowski and Peter Milgrom, "Adverse selection within dental insurance markets," Advances in Health Economics and Health Services Research, Vol. 6, Richard M. Scheffler and Louis F. Rossiter, eds. (Greenwich, CT: JAI Press, 1985), pp. 171 90 .

Congressional Budget Office, "The Effects of Managed Care on Use and Costs of Health Services", mimeo, June 1992.

Cutler, David M., Estimating the Effect of Reimbursement Policy on Medical Outcomes, doctoral dissertation, Massachusetts Institute of Technology, 1991.

, "The incidence of adverse medical outcomes under prospective payment," Econometrica. Vol. 63, No. 1 (January 1995), pp. 29-50.

, "Why Don't Markets Insure Long-Term Risk", mimeo, 1996. 
Cutler, David M. and Sarah J. Reber, "Paying for health insurance: The tradeoff between competition and adverse selection" Quarterly Journal of Economics, Vol. 113, No. 2 (May 1998), pp. 433-66.

Cutler, David M. and Richard J. Zeckhauser, "Adverse selection in health insurance," Frontiers in Health Policy Research, Vol. 1, Alan Garber, ed. (Cambridge, MA: MIT Press, 1998).

Cutler, David M., Mark McClellan, and Joseph P. Newhouse, "What Does Managed Care Do?", mimeo, 1998.

Davis, Karen and Louise B. Russell, "The substitution of hospital outpatient care for inpatient care," Review of Economics and Statistics, Vol. 54, No. 2 (May 1972), pp. 109-120.

De Meza, David, "Health Insurance and the Demand for Medical Care", Journal of Health Economics, Vol. 2 (1), March 1983, 47-54.

Desharnais, Susan I., James Chesney and Steven Fleming, "Trends and regional variations in hospital utilization and quality during the first two years of the prospective payment system," Inquiry, Vol. 25 (Fall 1988), pp. 374-82.

Desharnais, Susan I., Roger Wroblewski and Dale Schumacher, "How the Medicare prospective payment system affects psychiatric patients treated in short-term general hospitals," Inquiry, Vol. 27 (Winter 1990). pp. 382-88.

Diamond, Peter, "Optimal Income Taxation: An Example with a U-Shaped Pattern of Optimal Marginal Tax Rates", American Economic Review, 88 (1), March 1998, p 83-95.

Dowd, Bryan and Roger Feldman, "Biased selection in twin cities health plans," Advances in Health Economics and Health Services Research, Vol. 6, Richard M. Scheffler and Louis F. Rossiter, eds. (Greenwich, CT: JAI Press, 1985), pp. 253-71.

Eggers, Paul W., "Risk differential between Medicare beneficiaries enrolled and not enrolled in an HMO," Health Care Financing Review, Vol. 1 (1980), pp. 91-99.

Eichner, Matthew J., "Incentives, price expectations and medical expenditures: an analysis of claims under employer-provided health insurance," mimeo (July 30,1998).

Eichner, Matthew J., Mark McClellan, and David Wise, "Insurance or Self-Insurance?: Variation, Persistence, and Individual Health Accounts", in David Wise, ed., Inquiries in the Economics of Aging, Chicago: University of Chicago Press, 1998.

Ellis, Randall P., "The effect of prior-year health expenditures on health coverage plan choice," Advances in Health Economics and Health Services Research, Vol. 6, Richard M. Scheffler and Louis F. Rossiter, eds. (Greenwich, CT: JAI Press, 1985), pp 127-47. 
."Employee choice of health insurance." Review of Economics and Statistics, Vol. 71, No. 2 (May 1989). pp. 215-23.

,"Creaming, Skimping and Dumping: Provider Competition on the Intensive and Extensive Margins", Journal of Health Economics, Vol. 17 (5), October 1998, p 537-55.

Ellis, Randall P. and Andrew Van de Ven, "NEED FINAL TITLE" this volume.

Ellis, Randall P. and Thomas G. McGuire, "Hospital response to prospective payment: Moral hazard, selection, and practice-style effects," Journal of Health Economics, Vol. 15 (1996), pp. 257-77.

Eze, Pius and Barbara Wolfe. "Is dumping socially inefficient? An analysis of the effect of Medicare's prospective payment system on the utilization of Veterans Affairs inpatient services," Journal of Public Economics, Vol. 52 (1993), pp. 329-44.

Farley, Pamela J. and Alan C. Monheit, "Selectivity in the demand for health insurance and health care," Advances in Health Economics and Health Services Research, Vol. 6, Richard M. Scheffler and Louis F. Rossiter, eds. (Greenwich, CT: JAI Press, 1985), pp. 231-52.

Feder, Judith, Jack Hadley and Stephen Zuckerman, "How did Medicare's prospective payment system affect hospitals?" New England Journal of Medicine, Vol. 317, No. 14 (October 1, 1987), pp. 867-73.

Feldman, Roger, Michael Finch, Bryan Dowd and Steven Cassou, "The demand for employmentbased health insurance plans," Journal of Human Resources, Vol. 24, No. 1 (Winter 1989), pp. 117-42.

Feldman, Roger and Dowd, Bryan, "Must Adverse Selection Cause Premium Spirals", Journal of Health Economics, 10 (October 1991), 350-357.

Feldman, Roger and Bryan Dowd, "The Effectiveness of Managed Competition in Reducing the Costs of Health Insurance", in Robert B. Helms, ed., Health policy reform: Competition and controls, Washington. D.C.: AEI Press, 1993, p 176-217.

Feldstein, Paul J., "General report," Report of the Commission on the Cost of Medical Care (Chicago: American Medical Association, 1964), part 1.

Feldstein, Martin S., "The rising price of physicians' services," Review of Economics and Statistics, Vol. 52, No. 2 (May 1970), pp. 121-33.

, "Hospital cost inflation: A study of nonprofit price dynamics," American Economic Review, Vol. 60 (1971), pp. 853-72. 
Feldstein, Martin S. and Bernard Friedman, "Tax Subsidies, the Rational Demand for Insurance and the Health Care Crisis," Journal of Public Economics, Vol. 7, No. 2 (April 1977), pp. $155-$ 78.

Fisher, Charles R., "Hospital and Medicare financial performance under PPS, 1985-90," Health Care Financing Review, Vol. 14, No. 1 (Fall 1992), pp. 171-83.

Fitzgerald, John F., Patricia S. Moore and Robert S. Dittus, "The care of elderly patients with hip fracture: Changes since implementation of the prospective payment system," New England Journal of Medicine, Vol. 319, No. 21 (November 24, 1988), p. 1392-97.

Folland, Sherman and Robert Kleiman, "The effect of prospective payment under DRGs on the market value of hospitals," Quarterly Review of Economics and Business, Vol. 30, No. 2 (Summer 1990), pp. 50-68.

Frank, Richard G. and Judith R. Lave, "The effect of benefit design on the length of stay of Medicaid psychiatric patients," Journal of Human Resources, Vol. 21, No. 3 (Summer 1986), pp. 321-37.

, "A comparison of hospital responses to reimbursement policies for Medicaid psychiatric patients," RAND Journal of Economics, Vol. 20, No. 4 (Winter 1989), pp. 588600.

Frank, Richard G., and Thomas McGuire, "Economic Functions of Carve-Outs", American Journal of Managed Care, 4(SP), 1998, SP31-SP39.

Fuchs, Victor R. and Marcia J. Kramer, "Determinants of expenditures for physicians' services in the United States, 1948-68," National Bureau of Economic Research Occasional Paper Series, No. 117 (1972).

Gaumer, Gary L., Eugene L. Poggio, Craig G. Coelen, Cary S. Sennett and Robert J. Schmitz, "Effects of state prospective reimbursement programs on hospital mortality," Medical Care, Vol. 27, No. 7 (July 1989), pp. 724-36.

Gerety, M. B., V. Soderholm-Difatte and C. H. Winograd, "Impact of prospective payment and discharge location on the outcome of hip fracture," Journal of General Internal Medicine, Vol. 4, No. 5 (September-October 1989), pp. 388-91.

Glied, Sherry, "Managed Care", this volume.

Goldman, Fred and Michael Grossman, "The demand for pediatric care: An hedonic approach," Journal of Political Economy, Vol. 86, No. 2 (April 1978), pp. 259-80. 
Griffith, Mary Jane, Nicholas Baloff and Edward L. Spitznagel, "Utilization patterns of health maintenance organization disenrollees," Medical Care, Vol. 22, No. 9 (September 1984), pp. 827-34.

Guterman, Stuart and Allen Dobson, "Impact of the Medicare prospective payment system for hospitals," Health Care Financing Review, Vol. 7, No. 3 (Spring 1986), pp. 97-114.

Guterman, Stuart, Stuart H. Altman and Donald A. Young, "Hospitals' financial performance in the first five years of PPS," Health Affairs, Vol. 9, No. 1 (Spring 1990), pp. 125-134.

Hadley, Jack, Stephen Zuckerman and Judith Feder, "Profits and fiscal pressure in the prospective payment system: Their impacts on hospitals," Inquiry, Vol. 26 (Fall 1989), pp. 354-65.

Hodgkin, Dominic and Thomas G. McGuire, "Payment levels and hospital response to prospective payment," Journal of Health Economics, Vol. 13 (1994), pp. 1-29.

Jackson-Beeck, Marilyn and John H. Kleinman, "Evidence for self-selection among health maintenance organization enrollees," Journal of the american Medical Association, Vol. 250, No. 20 (November 25, 1983), pp. 2826-29.

Juba, David A., Judith R. Lave and Jonathan Shaddy, "An analsyis of the choice of health benefits plans," Inquiry, Vol. 17 (Spring 1980), pp. 62-71.

Kahn, Katherine L. et al. (series), "The effects of the DRG-based prospective payment system on quality of care for hospitalized Medicare patients," Journal of the American Medical Association, Vol. 264, No. 15 (October 17, 1990), pp. 1953-1994 (eight articles).

Kotowitz, Yehuda, "Moral Hazard", in the New Palgrave Dictionary of Economics, 1987.

Langwell, Katherine M. and James P. Hadley, "Evaluation of the Medicare competition demonstrations," Health Care Financing Review, Vol. 11, No. 2 (Winter 1989), pp. 65-80.

Lave, Judith R., Richard G. Frank, Carl Taube, Howard Goldman and Agnes Rupp, "The early effects of Medicare's prospective payment system on psychiatry," Inquiry, Vol. 25 (Fall 1988), pp. 354-63.

Long, Stephen H., Russell F. Settle and Charles W. Wrightson, "Employee premiums, availability of alternative plans, and HMO disenrollment," Medical Care, Vol. 26, No. 10 (October 1988), pp. 927-38.

Luft, Harold S., Joan B. Trauner and Susan C. Maerki, "Adverse selection in a large, multiple-option health benefits program: A case study of the California Public Employees' Retirement System," Advances in Health Economics and Health Services Research, Vol. 6, Richard M. Scheffler and Louis F. Rossiter, eds. (Greenwich, CT: JAI Press, 1985), pp. 197-229. 
Ma, Ching-to Albert. and Thomas McGuire, "Optimal Health Insurance and Provider Payment", American Economic Review, Vol. 87 (4), September, 1997, pp. 685-704.

Maibach, Ed., Katharine Dusenbury, Pamel Zupp, et al., "Marketing HMOs to Medicare Beneficiaries: An Analysis of Four Medicare Markets", Menlo Park, CA: Kaiser Family Foundation, 1998.

Manning, Willard G. and M. Susan Marquis, "Health insurance: The tradeoff between risk pooling and moral hazard," Journal of Health Economics, Vol. 15, No. 5 (October 1996), pp. 609-39.

Marquis, M. Susan, "Adverse selection with a multiple choice among health insurance plans: A simulation analysis," Journal of Health Economics, Vol. 11, No. 2 (August 1992), pp. 12951 .

Marquis, M. Susan and Charles E. Phelps, "Price elasticity and adverse selection in the demand for supplemental health insurance." Economic Inquiry, Vol. 25, No. 2 (April 1987), pp. 299-313.

McAvinchey, Ian D. and Andreas Yannopoulos, "Elasticity estimates from a dynamic model of interrelated demands for private and public acute health care," Journal of Health Economics, Vol. 12 (July 1993), pp. 171-86.

McGuire, Thomas G., "Price and membership in a prepaid group medical practice," Medical Care, Vol. 19, No. 2 (February 1981), pp. 172-83.

Menke, Terri, "Impacts of PPS on Medicare Part B expenditures and utilization for hospital episodes of care," Inquiry, Vol. 27 (Summer 1990), pp. 114-26.

Merrill, Jeffrey, Catherine Jackson and James Reuter, "Factors that affect the HMO enrollment decision: A tale of two cities," Inquiry, Vol. 22 (Winter 1985), pp. 388-95.

Miller, Robert H. and Harold S. Luft. “Does Managed Care Lead to Better or Worse Quality of Care?", Health Affairs. 16(5), September/October 1997, pp. 7-25.

Morrisey, Michael A., Frank A. Sloan and Joseph Valvona, "Medicare prospective payment and posthospital transfers to subacute care," Medical Care, Vol. 26, No. 7 (July 1988), pp. 68598.

Newhouse, Joseph P., "Do unprofitable patients face access problems?" Health Care Financing Review, Vol. 11, No. 2 (Winter 1989), pp. 33-42.

Newhouse, Joseph P., "Reimbursing Health Plans and Health Providers: Efficiency in Production Versus Selection," Journal of Economic Literature, XXXIV (September 1996), 1236-1263.

Newhouse, Joseph P. and the Insurance Experiment Group, Free for All? Lessons from the RAND Health Insurance Experiment (Cambridge, MA: Harvard University Press, 1993). 
Newhouse, Joseph P. and Daniel J. Byrne, "Did Medicare's prospective payment system cause length of stay to fall?" Journal of Health Economics, Vol. 7 (1988), pp. 413-16.

Newhouse, Joseph P. and Charles E. Phelps, "Price and income elasticities for medical care services," The Economics of Health and Medical Care, ch. 9 (New York: John Wiley \& Sons, 1974), pp. 140-61.

, "New estimates of price and income elasticities of medical care services," The Role of Health Insurance in the Health Services Sector, ch. 7 (New York: National Bureau of Economic Research, 1976), pp. 261-313.

Nichols, Albert, and Richard Zeckhauser, "Targeting Transfers through Restrictions on Recipients" American Economic Review, 72 (2), May 1982, p 372-77.

Palmer, R. M., R. M. Saywell, Jr., T. W. Zollinger, B. K. Erner, A. D. LaBov, D. A. Freund, J. E. Garber, G. W. Misamore and F. B. Throop, "The impact of the prospective payment system on the treatment of hip fractures in the elderly," Archives of Internal Medicine, Vol. 149, No. 10 (October 1989), pp. 2237-41.

Pauly, Mark, "The Economics of Moral Hazard: Comment", American Economic Review, 1968, 58: 531-536.

Pauly, Mark, "Overinsurance and Public Provision of Insurance: The Roles of Moral Hazard and Adverse Selection", Quarterly Journal of Economics, 1974, 88: 44-54.

Pauly, Mark, "Taxation, Health Insurance and Market Failure", Journal of Economic Literature, 1986, 24 (6): 629-675.

Pauly, Mark, and Scott Ramsey, "Would You Like Suspenders to Go With that Belt? An Analysis of Optimal Combinations of Cost Sharing and Managed Care", mimeo, 1998.

Pauly, Mark, Howard Kunreuther, and Richard Hirth, "Guaranteed Renewability in Insurance", Journal of Risk \& Uncertainty. Vol. 10 (2), March 1995, pp. 143-56.

Phelps, Charles E., "The demand for health insurance: A theoretical and empirical investigation," RAND Research Paper Series, No. R-1054-OEO (July 1973).

Phelps, Charles E. and Joseph P. Newhouse, "Effect of coinsurance: A multivariate analysis," Social Security Bulletin (June 1972), pp. 20-28.

,"Effects on coinsurance on demand for physician services," RAND Research Paper Series, No. R-976-OEO (June 1972).

, "Coinsurance. the price of time, and the demand for medical services," Review of Economics and Statistics, Vol. 56, No. 3 (August 1974), pp. 334-42. 
Plato, The Republic.

Price, James R. and James W. Mays, "Biased selection in the Federal Employees Health Benefits Program," Inquiry. Vol. 22 (Spring 1985), pp. 67-77.

Ramsey, Scott D, and Mark Pauly, "Structural Incentives and Adoption of Medical Technologies in HMO and Fee-for-Service Health Insurance Plans", Inquiry, 34 (3), Fall 1997, p 228-36.

Ray, W. A., M. R. Griffin and D. K. Baugh, "Mortality following hip fracture before and after implementation of the prospective payment system," Archives of Internal Medicine, Vol. 150, No. 10 (October 1990), pp. 2109-14.

Rodgers, Jack and Karen E. Smith, "Is there biased selection in Medicare HMOs?" Health Policy Economics Group Report (Washington, DC: Price Waterhouse LLP, May 16, 1996).

Roos, NP, E. Shapiro, and R. Tate, "Does a small minority of elderly account for a majority of health care expenditures? A sixteen-year perspective" Milbank Quarterly, 1989 67(3-4):347-69.

Rosenthal, Gerald, "Price elasticity of demand for short-term general hospital services," Empirical Studies in Health Economics, Herbert E. Klarman, ed., (Baltimore, MD: Johns Hopkins Press, 1970), pp. 101-117.

Rosett, Richard N. and Lien-fu Huang, "The effect of health insurance on the demand for medical care," Journal of Political Economy, Vol. 81 (March/April 1973), pp. 281-305.

Rothschild, Michael, and Joseph E. Stiglitz, "Equilibrium in Competitive Insurance Markets: An Essay on the Economics of Imperfect Information", Quarterly Journal of Economics, 1976, 90: $629-650$.

Russell, Louise B. and Carrie Lynn Manning, "The effect of prospective payment on Medicare expenditures," New England Journal of Medicine, Vol. 320, No. 7 (1989), pp. 439-44.

Sager, Mark A., Douglas V. Easterling, David A Kindig and Odin W. Anderson, "Changes in the location of death after passage of Medicare's prospective payment system," New England Journal of Medicine, Vol. 320, No. 7 (1989), pp. 433-39.

Scitovsky, Anne A. and Nelda McCall, "Coinsurance and the demand for physician services: Four years later," Social Security Bulletin (May 1977), pp. 19-27.

Scitovsky, Anne A., Nelda McCall and Lee Benham, "Factors affecting the choice between two prepaid plans," Medical Care. Vol. 16, No. 8 (August 1978), pp. 660-675.

Scitovsky, Anne A. and Nelda M. Snyder, "Effect of coinsurance on use of physician services," Social Security Bulletin (June 1972), pp. 3-19. 
Shaw, George Bernard. The Doctors Dilemma, 1911.

Sheingold, Steven H., “The first three years of PPS: Impact on Medicare costs," Health Affairs, Vol. 8, No. 3 (Fall 1989), p. 191-204.

Sheingold, Steven H. and Thomas Buchberger, "Implications of Medicare's prospective payment system for the provision of uncompensated hospital care," Inquiry, Vol. 23 (Winter 1986), pp. 371-81.

Sloan, Frank A., Michael A. Morrisey and Joseph Valvona, "Medicare prospective payment and the use of medical technologies in hospitals," Medical Care, Vol. 26, No. 9 (September 1988), pp. 837-50.

Smith, Adam, The Wealth of Nations, 1776.

Spence, Michael, and Richard Zeckhauser, "Insurance, Information, and Individual Action", American Economic Revew, Papers and Proceedings, 1971, 61(2): 380-387.

Staiger, Douglas and Gary L. Gaumer, "Price regulation and patient mortality in hospitals," mimeo (August 1995).

van de Ven, Wyn, and P. M. M. and Rene C. J. A. van Vliet, "Consumer surplus and adverse selection in competitive health insurance markets: An empirical study," Journal of Health Economics, Vol. 14, No. 2 (June 1995), pp. 149-69.

Welch, W. Pete, "Restructuring the Federal Employees Health Benefits Program: The private sector option," Inquiry, Vol. 26 (Fall 1989), pp. 321-34.

Weissman, Joel, and Arnold Epstein, Falling Through the Safety Net: Insurance and Access to Medical Care. Baltimore, MD: Johns Hopkins University Press, 1994.

Wholey, Douglas, Roger Feldman, and Jon B. Christianson, "The Effect of Market Structure on HMO Premiums", Journal of Health Economics, 14 (1), May 1995, pp. 81-105.

Willke, Richard J, William S. Custer, James W. Moser and Robert A. Musacchio, "Collaborative production and resource allocation: The consequences of prospective payment for hospital care," Quarterly Review of Economics and Business, Vol. 31, No. 1 (Spring 1991), pp. 2847.

Wilson, Charles, "The Nature of Equilibrium in Markets with Adverse Selection”, The Bell Journal of Economics. 11 (1), Spring 1980, pp. 108-30.

Wrightson, William. James Genuardi and Sharman Stephens, "Demographic and utilization characteristics of HMO disenrollees," GHAA Journal (Summer 1987), pp. 23-42. 
Zeckhauser, Richard, "Medical Insurance: A Case Study of the Tradeoff Between Risk Spreading and Appropriate Incentives", Journal of Economic Theory, 1970, 2: 10-26.

Zeckhauser, Richard, "Risk Spreading and Distribution," in Harold M. Hochman and George E. Peterson, eds., Redistribution Through Public Choice, New York: Columbia University Press, 1974, 206-28.

Zweifel, Peter, and Willard G. Manning, "Consumer Incentives in Health Care", this volume. 
$</$ ref_section $>$ 


\section{Appendix}

This appendix shows the classic treatment of equilibrium with adverse selection and two individuals, from Rothschild and Stiglitz (1976).

For simplicity, assume that spending when sick, $m$, is the same for HIGH and LOW, i.e.. there is no moral hazard. HIGH is more likely to be sick. Figure A(1) shows the indifference curves for these two people. LOW's indifference curve is stepper than HIGH's, since LOW is not willing to give up as much money when healthy to get a dollar when sick. With no moral hazard, both LOW and HIGH would optimally want full insurance, if charged their fair price for it. Points A and B represent their respective efficient levels of insurance when purchased at fair actuarial rates.

Figure $A(2)$ shows the potential pooling equilibrium. The fair odds line that is shown is the average premium for the two together. At point $\mathrm{C}$, both LOW and HIGH purchase full insurance at this price. But this equilibrium cannot prevail. If an insurer entered the market offering policy $\mathrm{D}$, which has incomplete coverage but a lower premium, he would attract LOW but not HIGH. LOW prefers the policy because he gets the cost savings from not pooling with HIGH, which more than makes up for his loss of full insurance. This is parallel to what happens with the introduction of the basic plan in our numerical analysis, which breaks the pooling equilibrium at moderate.

Figure A(3) shows the equilibrium with plan manipulation. HIGH receives full insurance (point A). To separate himself out and thereby reduce his payments, LOW insures incompletely, at point G. Ppoint G makes HIGH just indifferent between staying in the full insurance plan and enrolling in the less generous, but less expensive, policy. Though optimality requires that both groups insure fully, only HIGH does so.

Figure A(4) shows how the separating equilibrium may be broken. We show two fair odds line for the average of HIGH and LOW -- one where costs for the two are far apart and one where they are closer together (for simplicity, we show only one indifference curve for HIGH). In the case where HIGH and low have very different costs, the pooled fair odds line will not attract LOW; they do not want to pay the additional amount for more generous coverage because doing so necessitate pooling with HIGH. If the costs are closer together, in contrast, the average fair odds line for the two as a whole will be close to the fair odds line for LOW. Relative to points A and G, there may be a point such as $\mathrm{H}$ that will be preferred by LOW to the separating equilibrium. It will also be preferred by HIGH, who benefits from pooling with the healthier group in the population. It will thus undermine the separating equilibrium. With no stable pooling equilibrium and no stable separating equilibrium, the market will not reach an equilibrium. 
Table 1: Sources of Health Insurance Coverage for the United States Population

\begin{tabular}{|c|c|c|c|}
\hline Source & Groups insured & $\begin{array}{l}\text { Share of total } \\
\text { population }\end{array}$ & $\begin{array}{l}\text { Share of total } \\
\text { payments }\end{array}$ \\
\hline \multicolumn{4}{|l|}{ Public } \\
\hline Medicare & $\begin{array}{l}\text { Elderly; disabled; end-stage } \\
\text { renal disease }\end{array}$ & $13 \%$ & $22 \%$ \\
\hline Medicaid & $\begin{array}{l}\text { Elderly; blind and disabled; } \\
\text { poor women and children }\end{array}$ & 10 & 15 \\
\hline Other* & $\begin{array}{l}\text { Military personnel and their } \\
\text { dependents }\end{array}$ & 1 & 8 \\
\hline \multicolumn{4}{|l|}{ Private } \\
\hline Employer sponsored & Workers and dependents & 56 & \multirow{2}{*}{53} \\
\hline Nongroup & Families & 6 & \\
\hline Uninsured & & 16 & 2 \\
\hline \multicolumn{4}{|c|}{$\begin{array}{l}\text { * Other public spending includes non-insurance costs such as public hospitals, the Veterans } \\
\text { Administration, etc. } \\
\text { Source: Authors' calculations based on data from Department of Health and Human Services, } \\
\text { National Health Accounts (medical spending), and from Employee Benefit Research Institute } \\
\text { (insurance coverage). }\end{array}$} \\
\hline
\end{tabular}


Table 2: Distribution of Medical Spending, 1987

\begin{tabular}{lc}
\hline Share of Distribution & $\begin{array}{c}\text { Cumulative } \\
\text { Share of } \\
\text { Spending }\end{array}$ \\
\hline Top 1 percent & $30 \%$ \\
Top 5 percent & 58 \\
Top 10 percent & 72 \\
Top 50 percent & 98 \\
Total population & 100 \\
\hline Source: Berk and Monheit (1992). \\
\hline
\end{tabular}




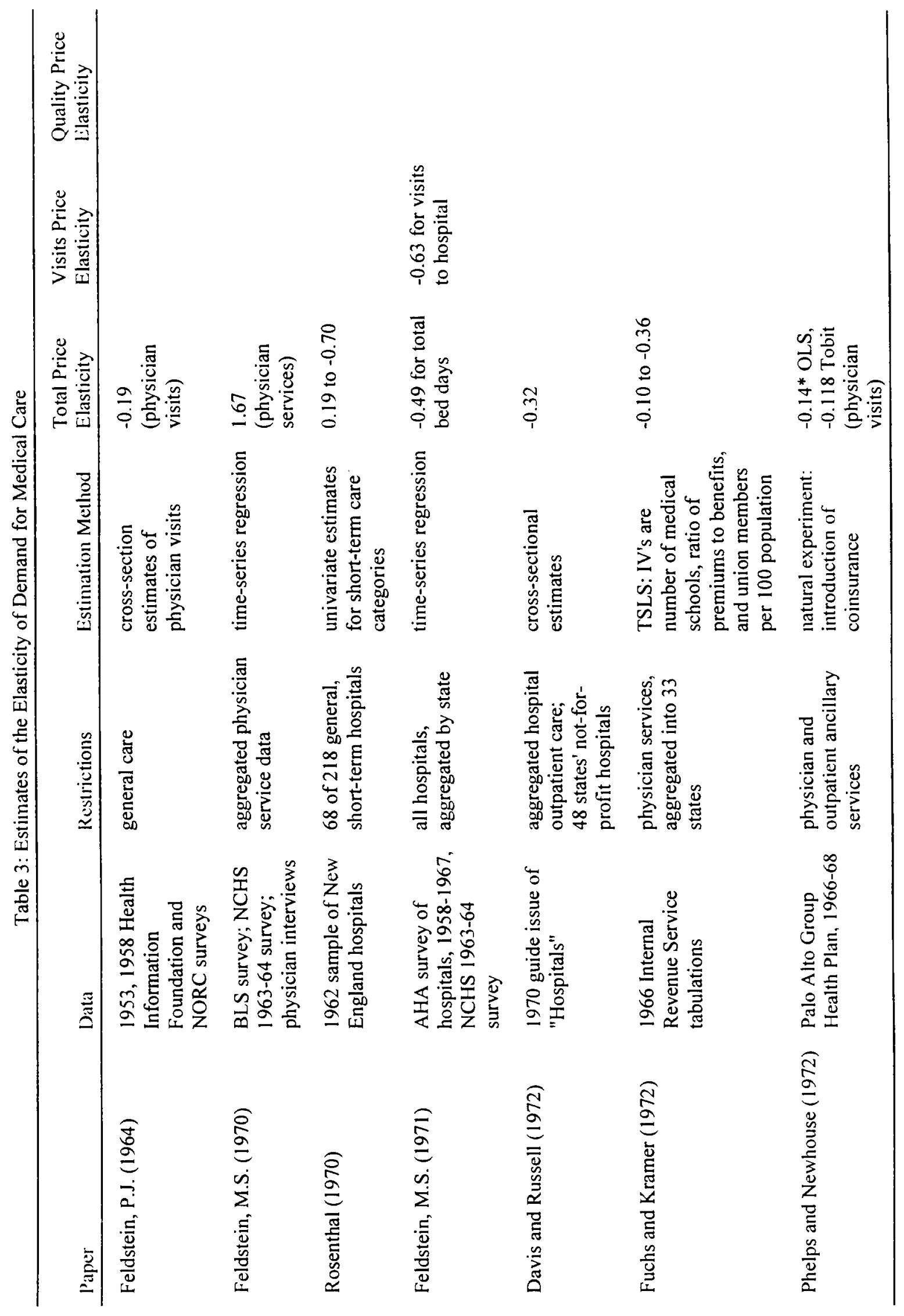




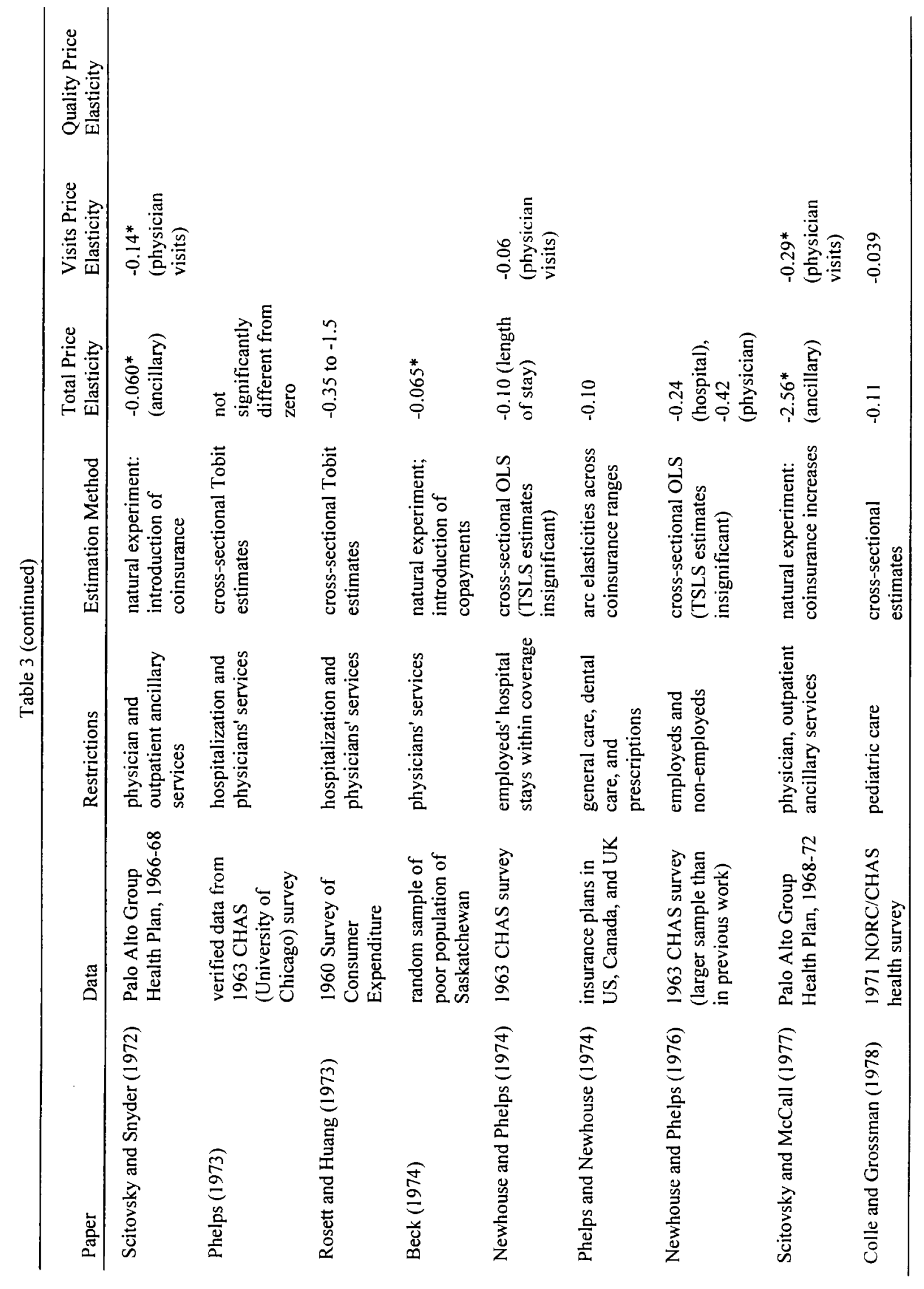




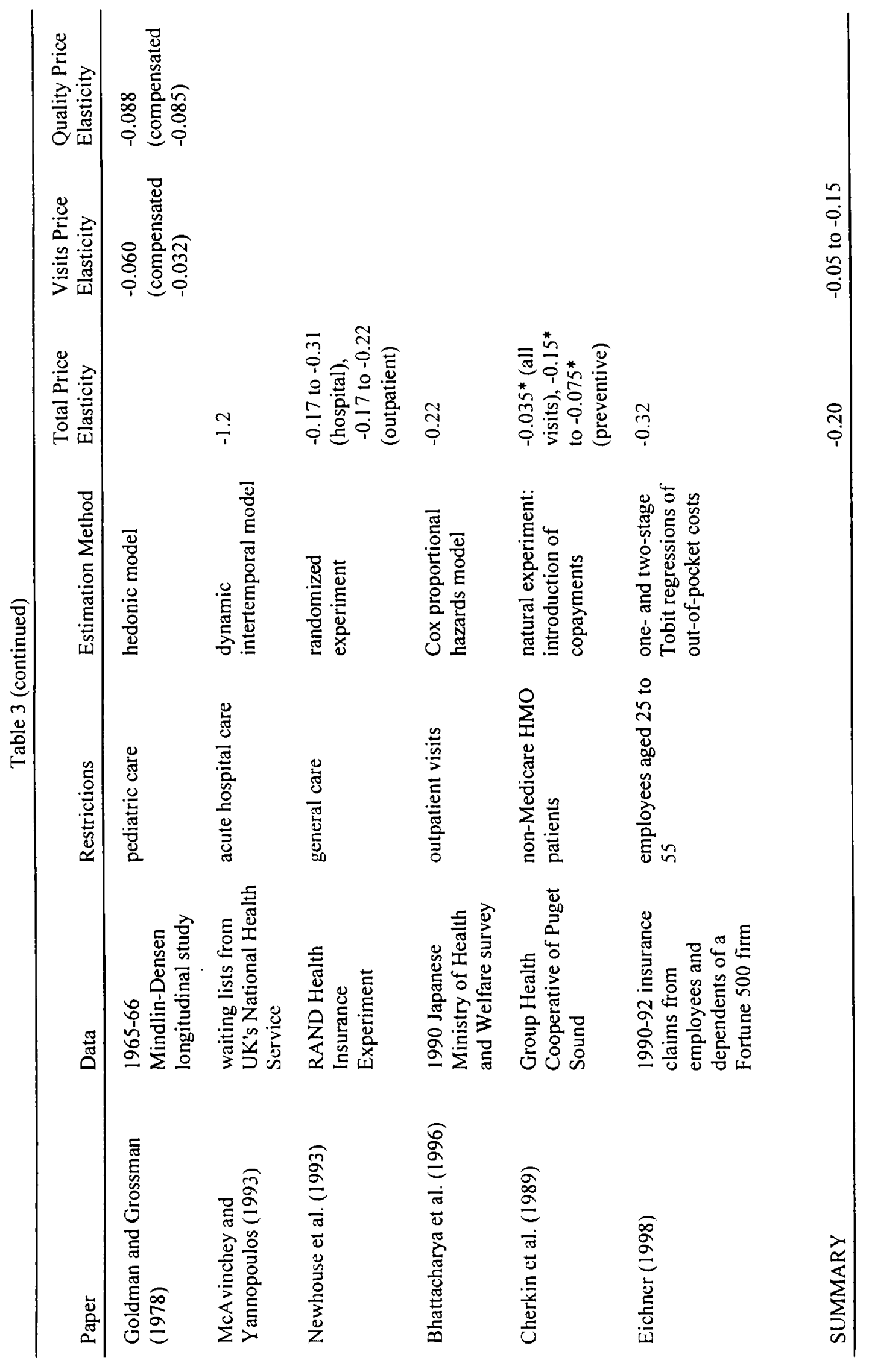


Table 4: Risk-Sharing Features of Indemnity Insurance Policies, 1991

\begin{tabular}{lc}
\hline Characteristic & $\begin{array}{c}\text { Average/ } \\
\text { Percent }\end{array}$ \\
\hline $\begin{array}{l}\text { Deductible } \\
\text { Individual }\end{array}$ & $\$ 205$ \\
Family & $\$ 475$ \\
Coinsurance rate & \\
$<20$ percent & \\
20 percent & $13 \%$ \\
$>20$ percent & $78 \%$ \\
& \\
Stop Loss & 4 \\
$\leq \$ 500$ & \\
$\$ 501-\$ 1,000$ & \\
$\$ 1,001-\$ 2,000$ & $21 \%$ \\
$>\$ 2,000$ & $30 \%$ \\
& $32 \%$ \\
Maximum Lifetime Benefit - Individual & \\
$\leq 250,000$ & $17 \%$ \\
$\$ 250,001-\$ 999,999$ & \\
$\geq \$ 1,000,000$ & $95 \%$ \\
\hline
\end{tabular}

Source: HIAA Employer Survey, 1991.

"Remaining responses are "rate varies" and "other". 
Table 5: Estimates of the Optimal Insurance Policy

\begin{tabular}{ll}
\hline Author & Optimal Policy \\
\hline Feldstein and Friedman (1977) & \\
van de Ven and van Praag (1981) & \\
Buchanan, Keeler, et al. (1991) & \\
Newhouse et al. (1993)* & $\$ 200$ to $\$ 300$ deductible; \\
& 25 percent cost sharing; \\
& $\$ 1,000$ stop loss (assumed) \\
Marquis and Holmer (1996) & 25 percent coinsurance; \\
Manning and Marquis (1996) & $>\$ 25,000$ stop loss \\
& $\begin{array}{l}\text { Cost sharing declines from } 27 \% \text { at } \\
\text { roughly } \$ 1,000 \text { of spending to } 5 \% \\
\text { Blomqvist (1997)** }\end{array}$ \\
& above roughly $\$ 30,000$ \\
\hline A Amounts are in 1983 dollars. & \\
** Amounts are based on the Rand Health Insurance Experiment data.
\end{tabular}


Table 6: Key Characteristics of Insurance Policies

\begin{tabular}{|c|c|c|c|c|}
\hline \multirow[b]{2}{*}{ Dimension } & \multirow[b]{2}{*}{$\begin{array}{l}\text { Indemnity } \\
\text { Insurance }\end{array}$} & \multicolumn{3}{|c|}{ Managed Care } \\
\hline & & $\mathrm{PPO}$ & $\begin{array}{c}\text { IPA/Network } \\
\text { HMO }\end{array}$ & $\begin{array}{c}\text { Group/Staff } \\
\text { HMO }\end{array}$ \\
\hline Qualified Providers & Almost all & $\begin{array}{l}\text { Almost all } \\
\text { (Network) }\end{array}$ & Network & Network \\
\hline Choice of Providers & Patient & Patient & $\begin{array}{l}\text { Gatekeeper } \\
\text { (in network) }\end{array}$ & $\begin{array}{l}\text { Gatekeeper } \\
\text { (in network) }\end{array}$ \\
\hline Payment of Providers & Fee-for-service & $\begin{array}{l}\text { Discounted } \\
\text { FFS }\end{array}$ & Capitation & Salary \\
\hline Cost Sharing & Moderate & $\begin{array}{c}\text { Low in } \\
\text { network; } \\
\text { High out of } \\
\text { network }\end{array}$ & $\begin{array}{l}\text { Low in } \\
\text { network; } \\
\text { High out of } \\
\text { network }\end{array}$ & $\begin{array}{c}\text { Low in network; } \\
\text { High/all out of } \\
\text { network }\end{array}$ \\
\hline Roles of insurer & Pay bills & $\begin{array}{c}\text { Pay bills; } \\
\text { Form network }\end{array}$ & $\begin{array}{l}\text { Pay bills; } \\
\text { Form network; } \\
\text { Monitor } \\
\text { utilization }\end{array}$ & Provide care \\
\hline Limits on utilization & Demand-side & $\begin{array}{l}\text { Supply-side } \\
\text { (price) }\end{array}$ & $\begin{array}{c}\text { Supply-side } \\
\text { (price, quantity) }\end{array}$ & $\begin{array}{c}\text { Supply-side } \\
\text { (price, quantity) }\end{array}$ \\
\hline
\end{tabular}




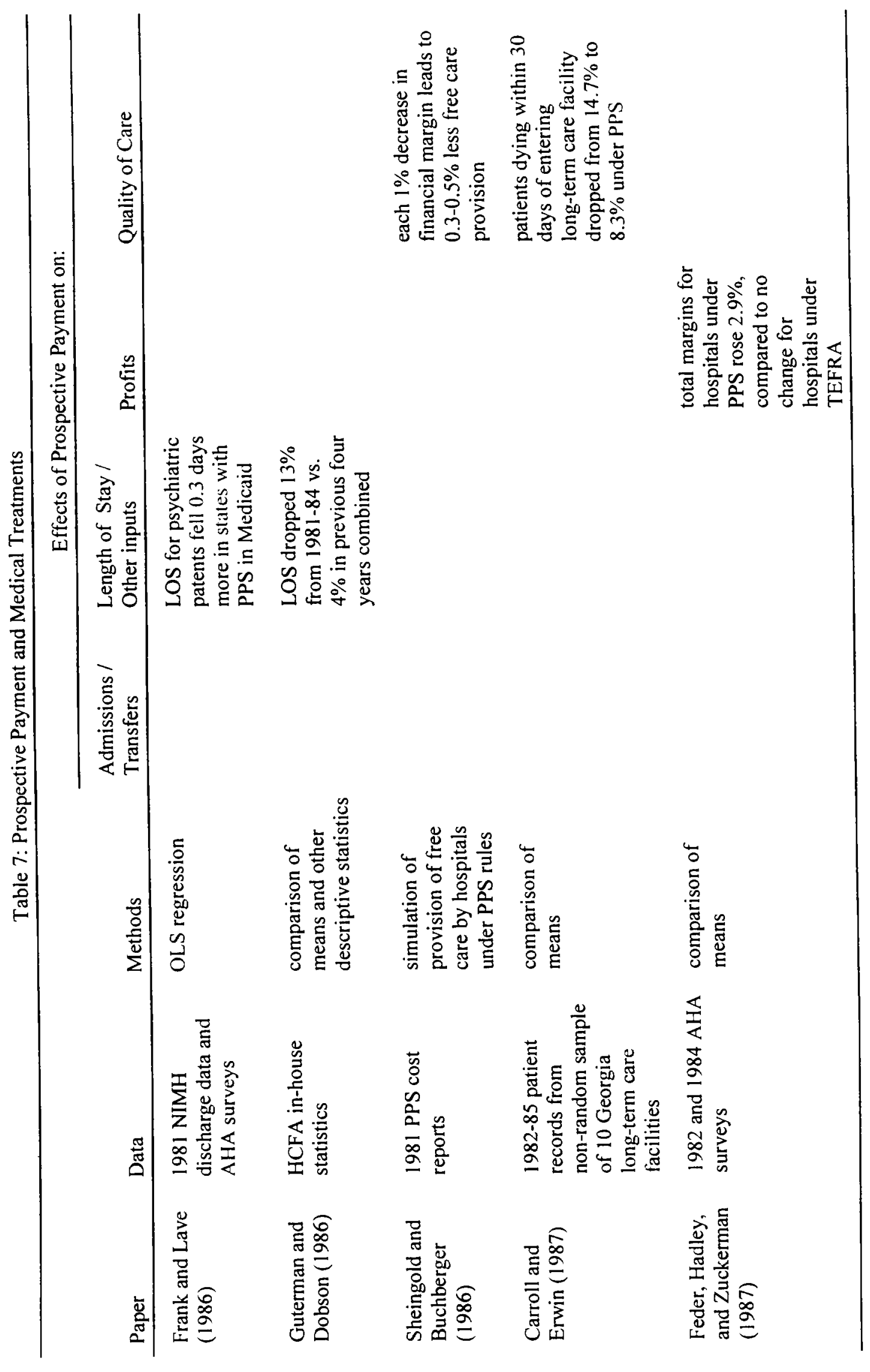




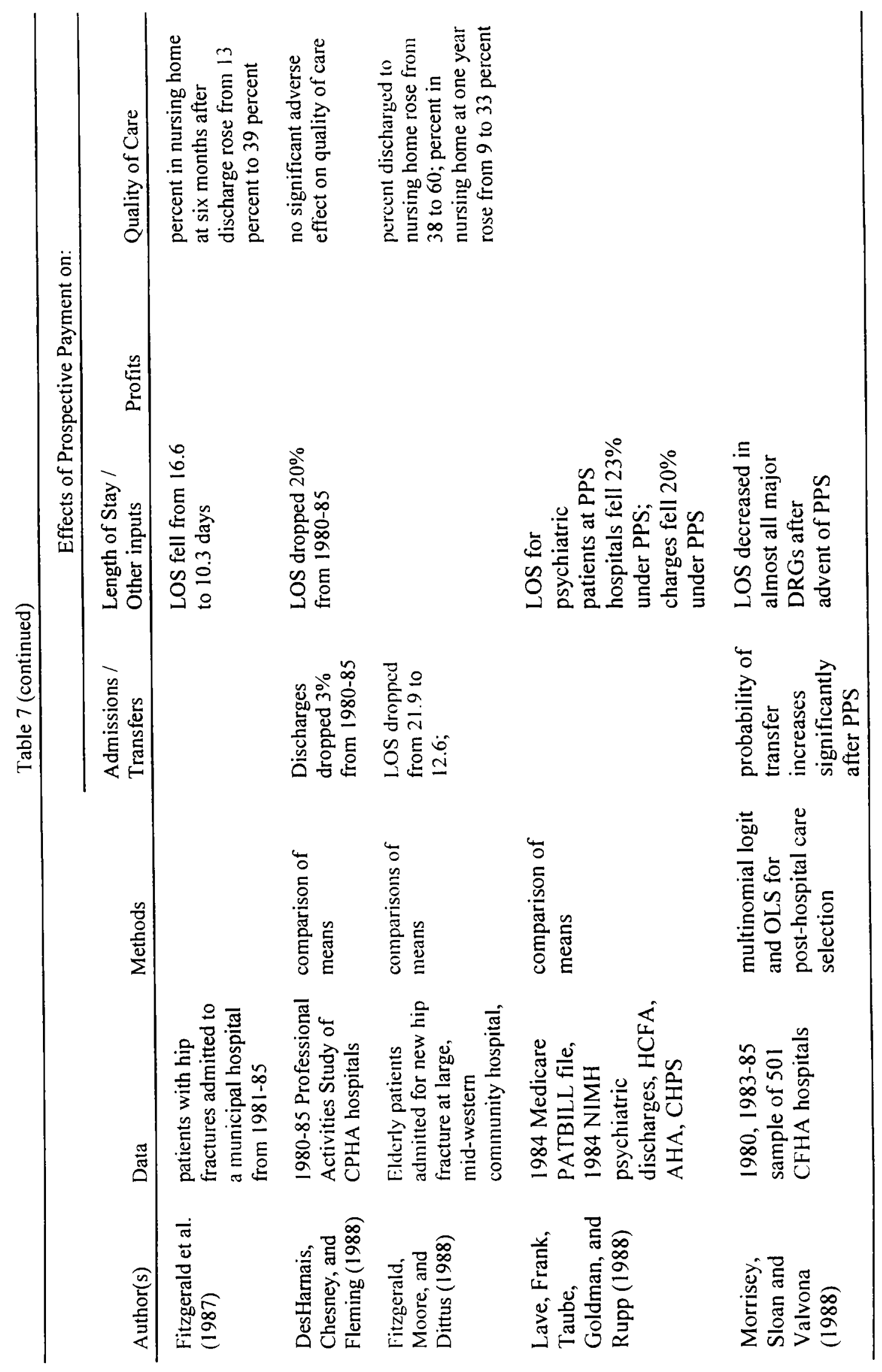




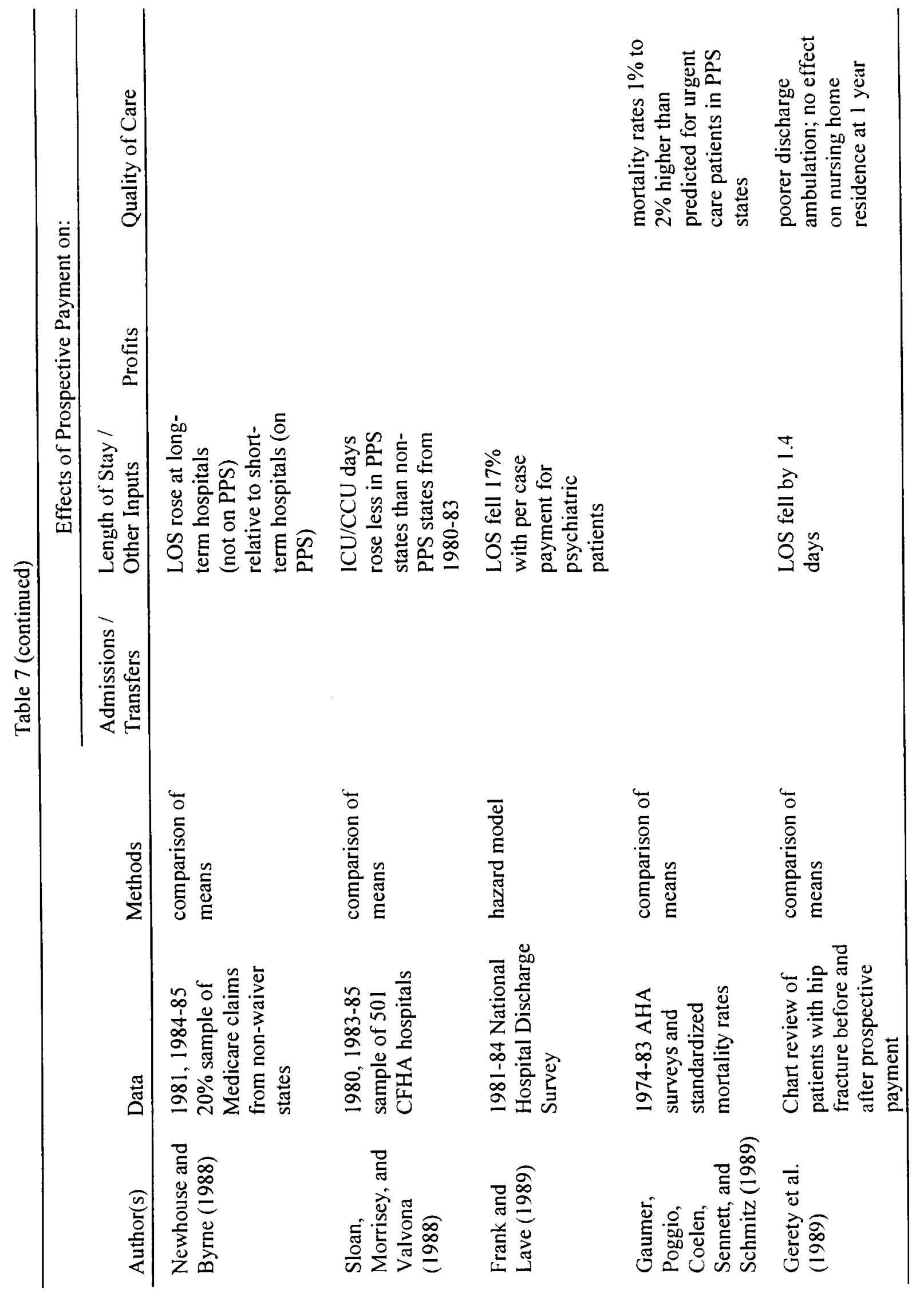




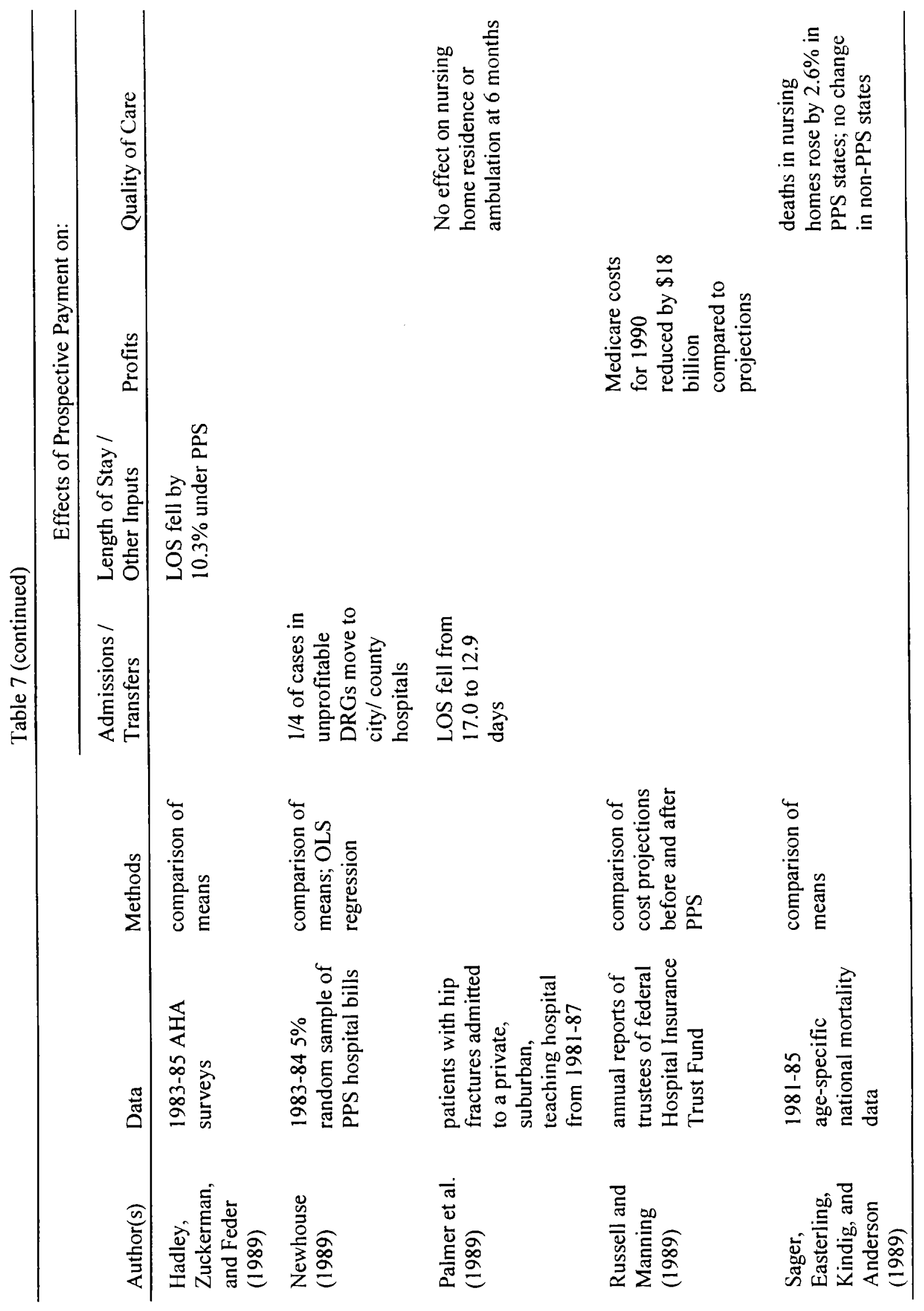




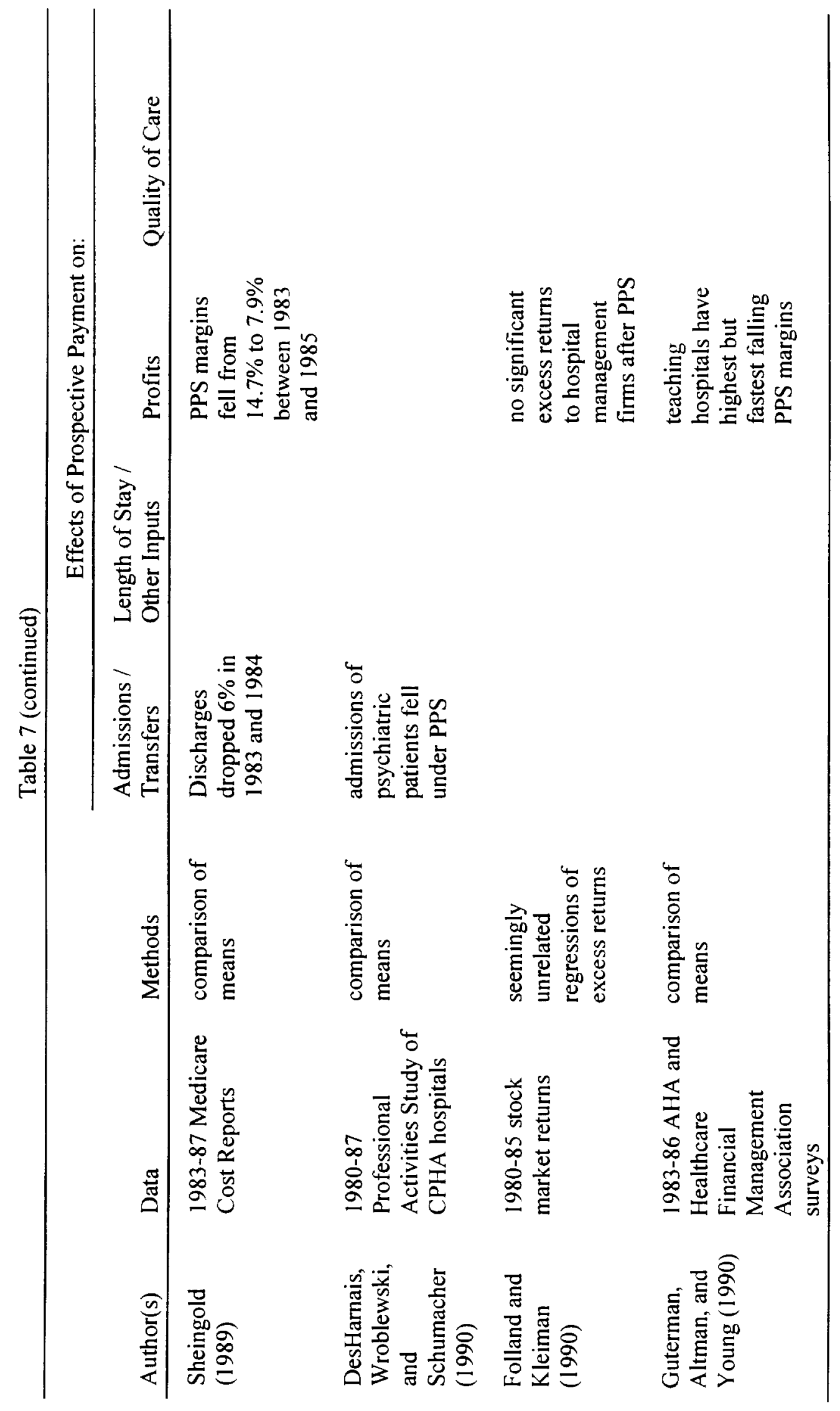




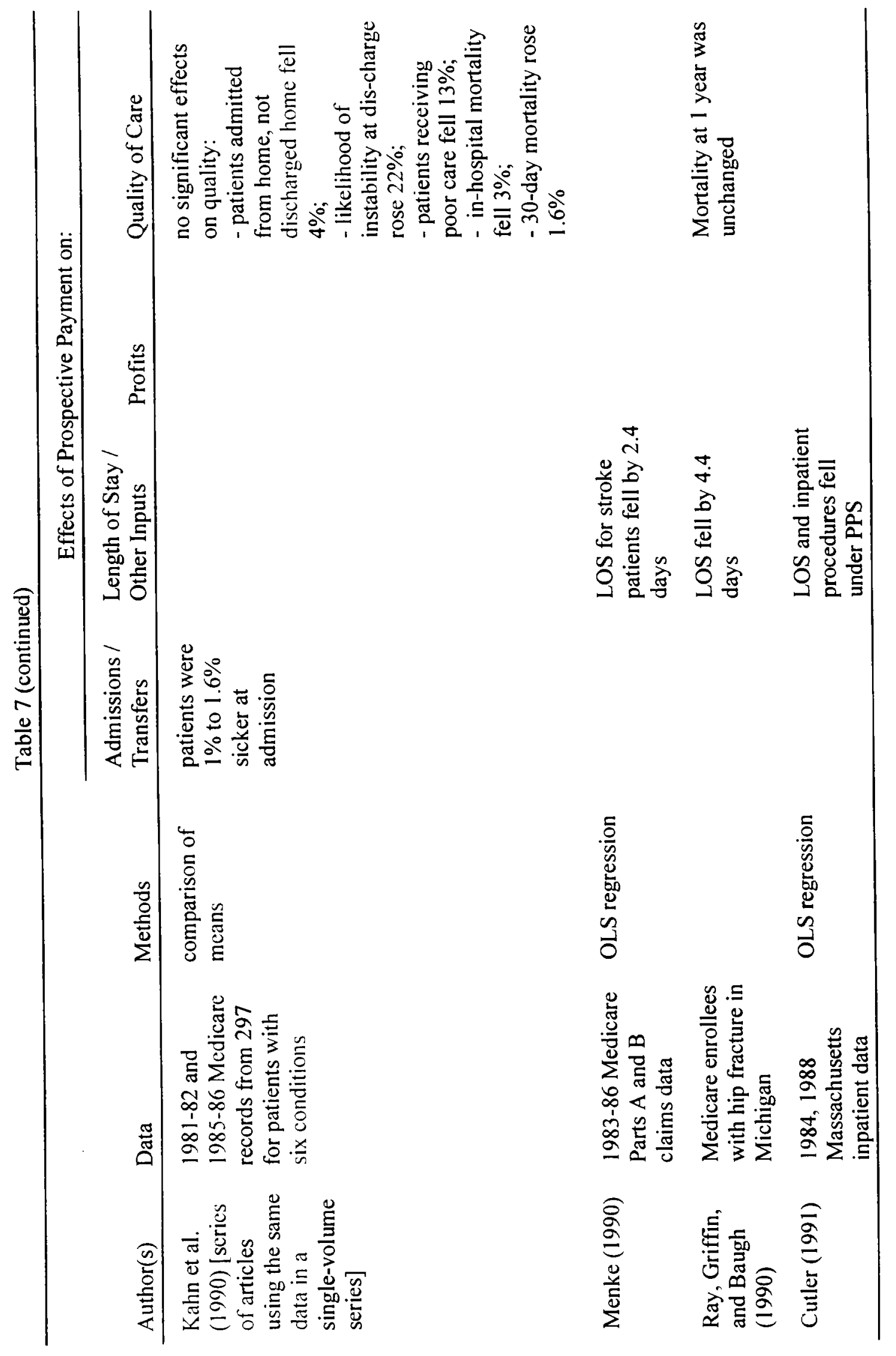




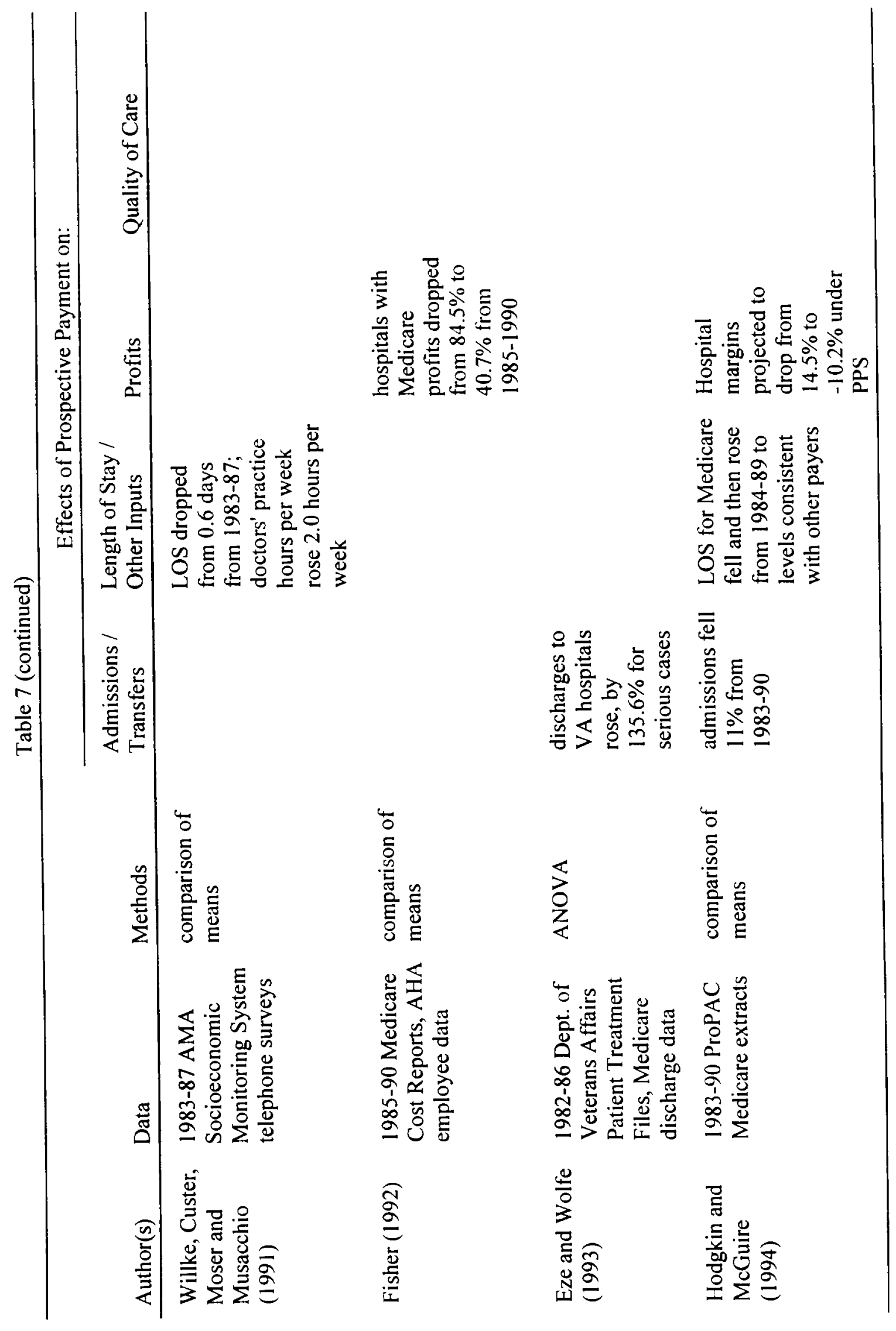




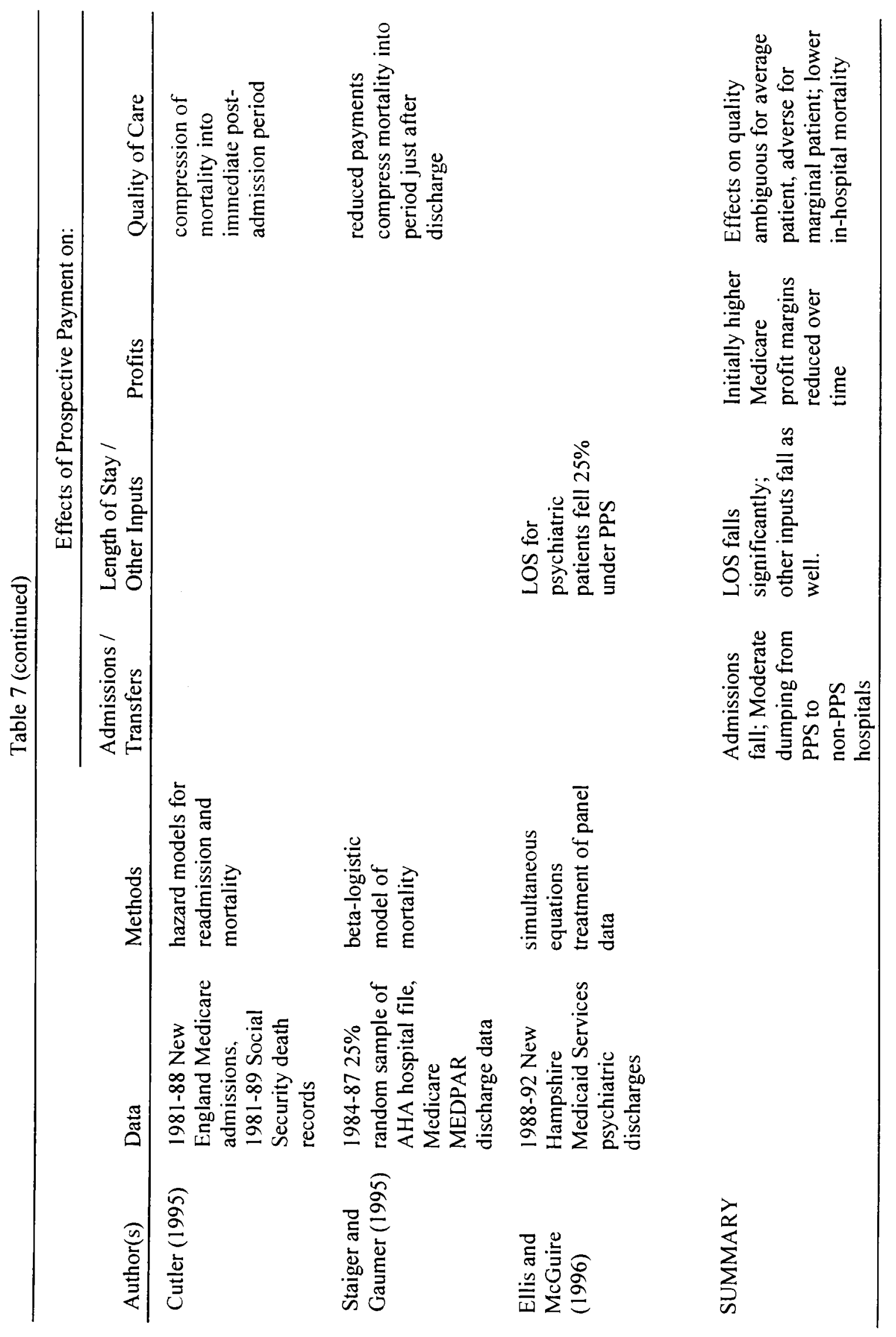


Table 8: Benefits and Costs for HIGH and LOW Risk Individuals

\begin{tabular}{lcclcccccc}
\hline & \multicolumn{2}{c}{ Generous Plan } & & \multicolumn{2}{c}{ Moderate Plan } & & \multicolumn{2}{c}{ Basic Plan } \\
\cline { 2 - 3 } & Benefits & Costs & & Benefits & Costs & & Benefits & Costs \\
\hline HIGH risk & $\$ 33$ & $\$ 16$ & & $\$ 20$ & $\$ 4$ & & $\$ 14.00$ & $\$ 2.80$ \\
LOW risk & 6 & 4 & & 5 & 1 & & 3.50 & .70 \\
\hline \hline
\end{tabular}




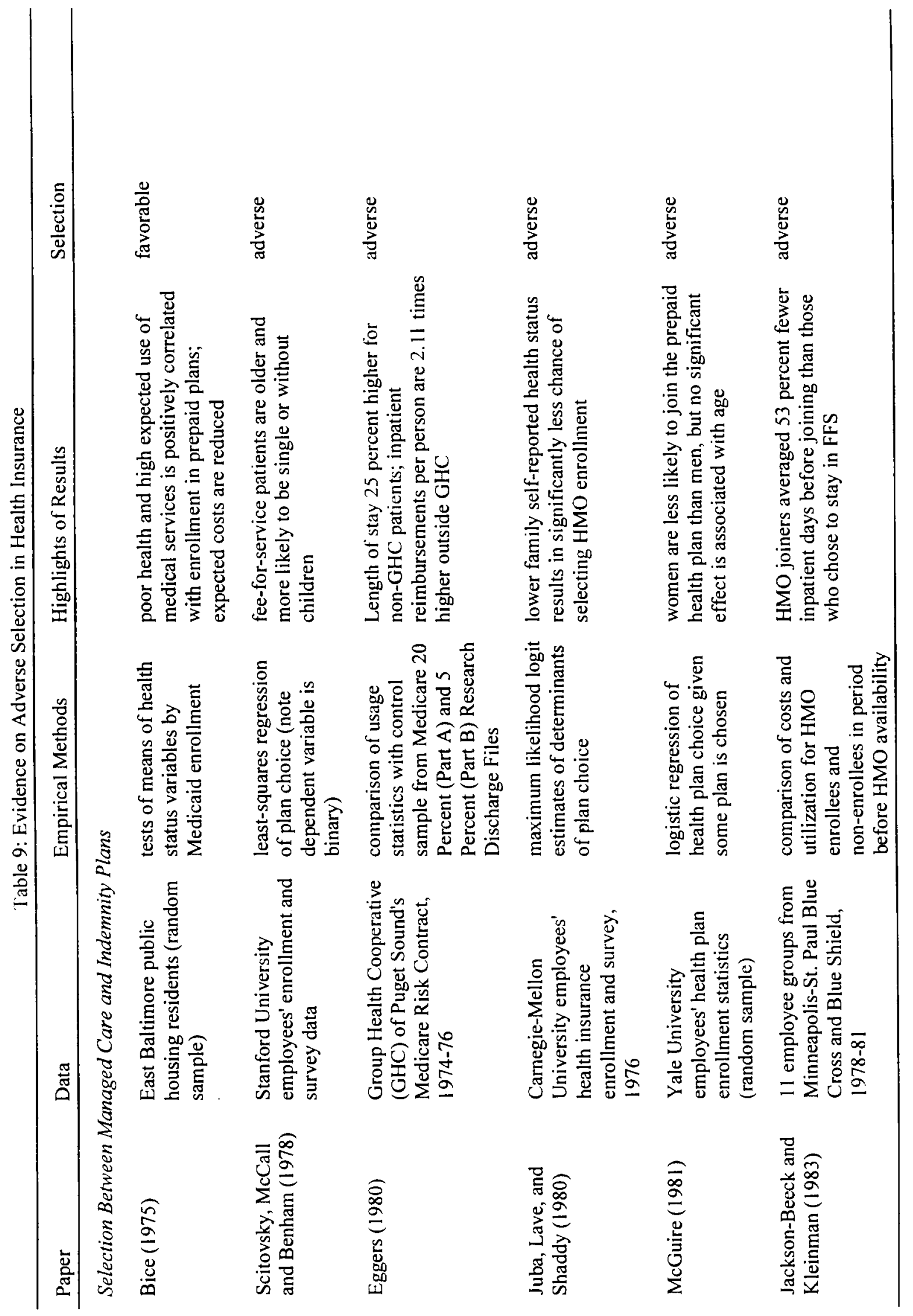




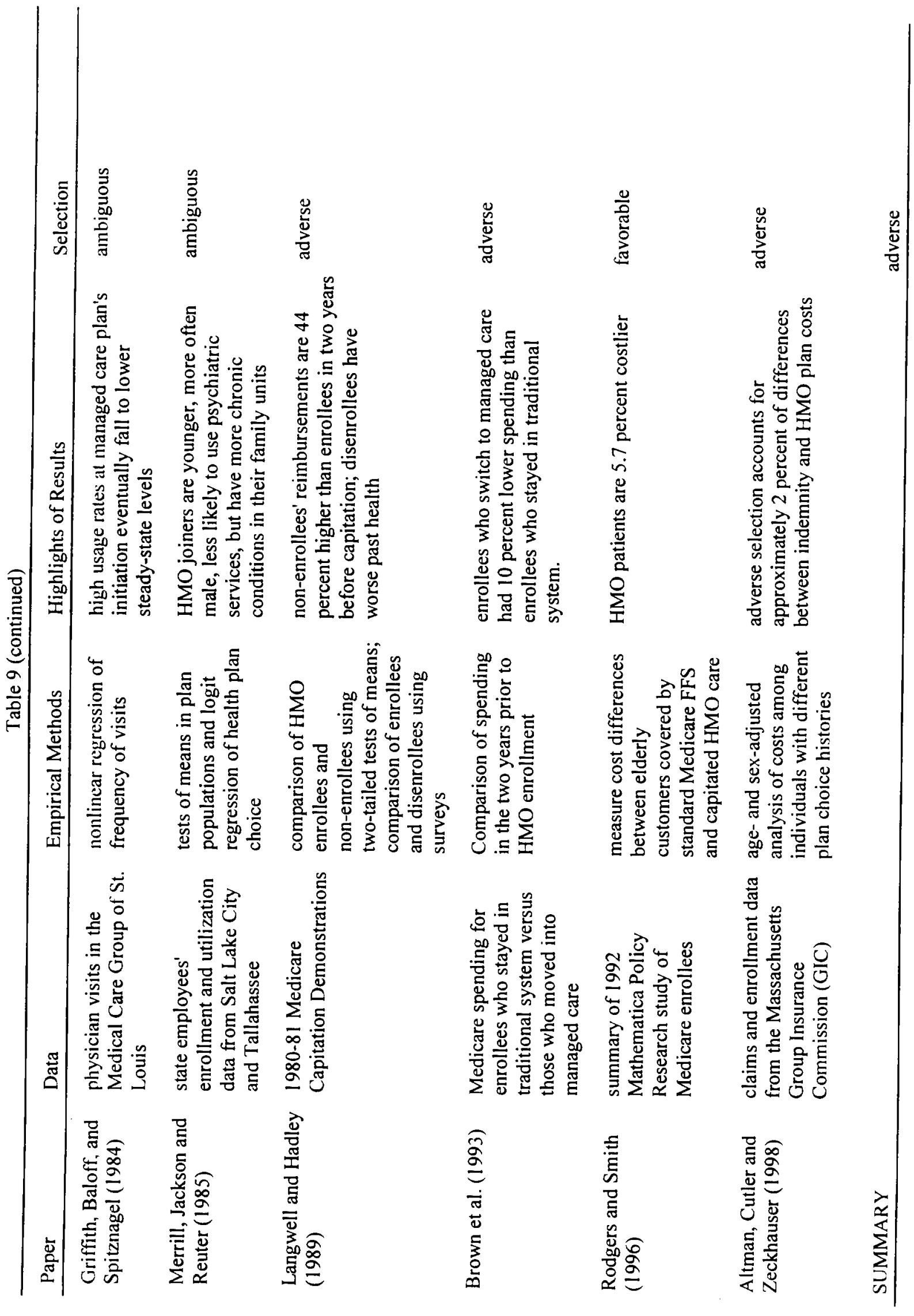




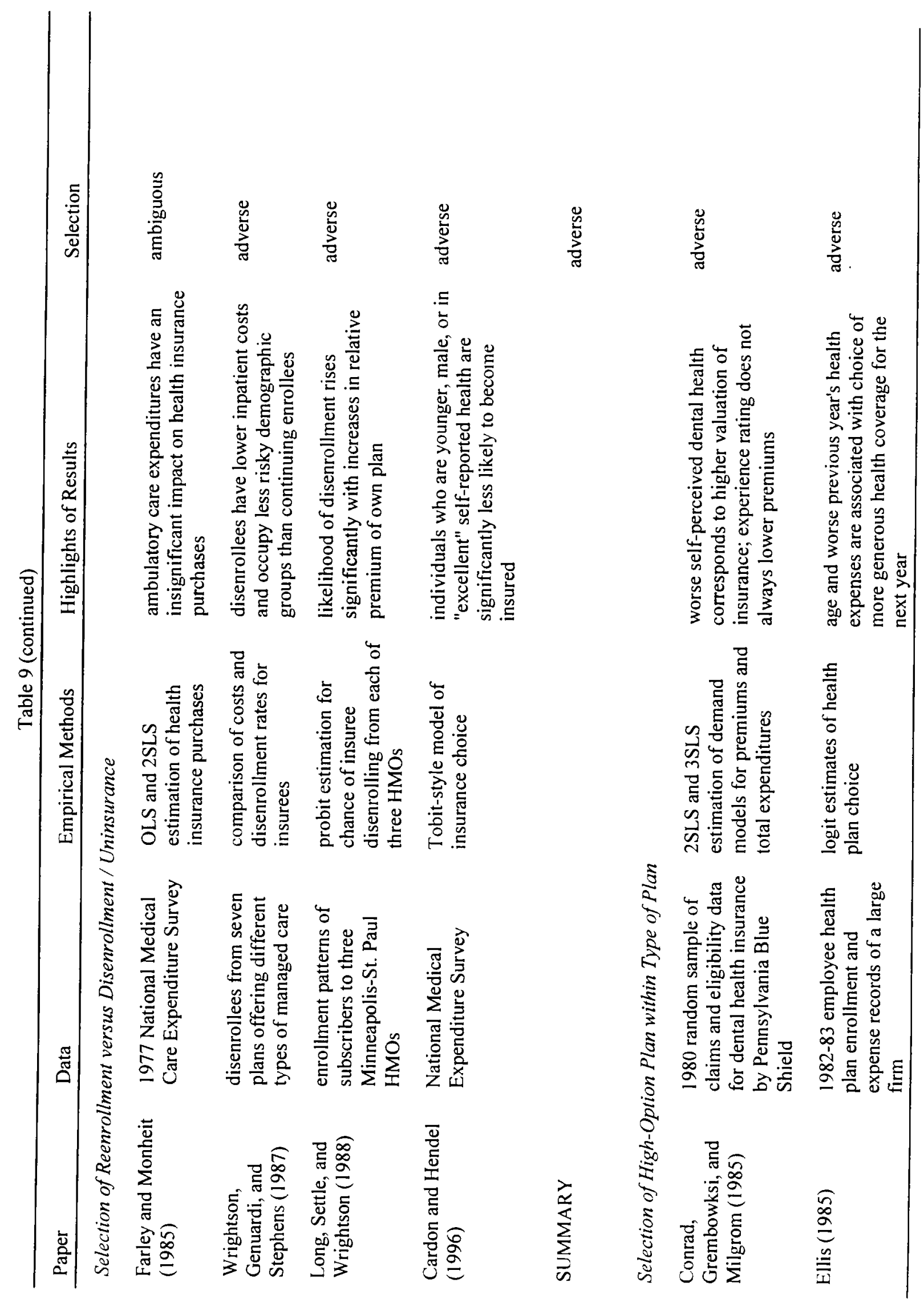




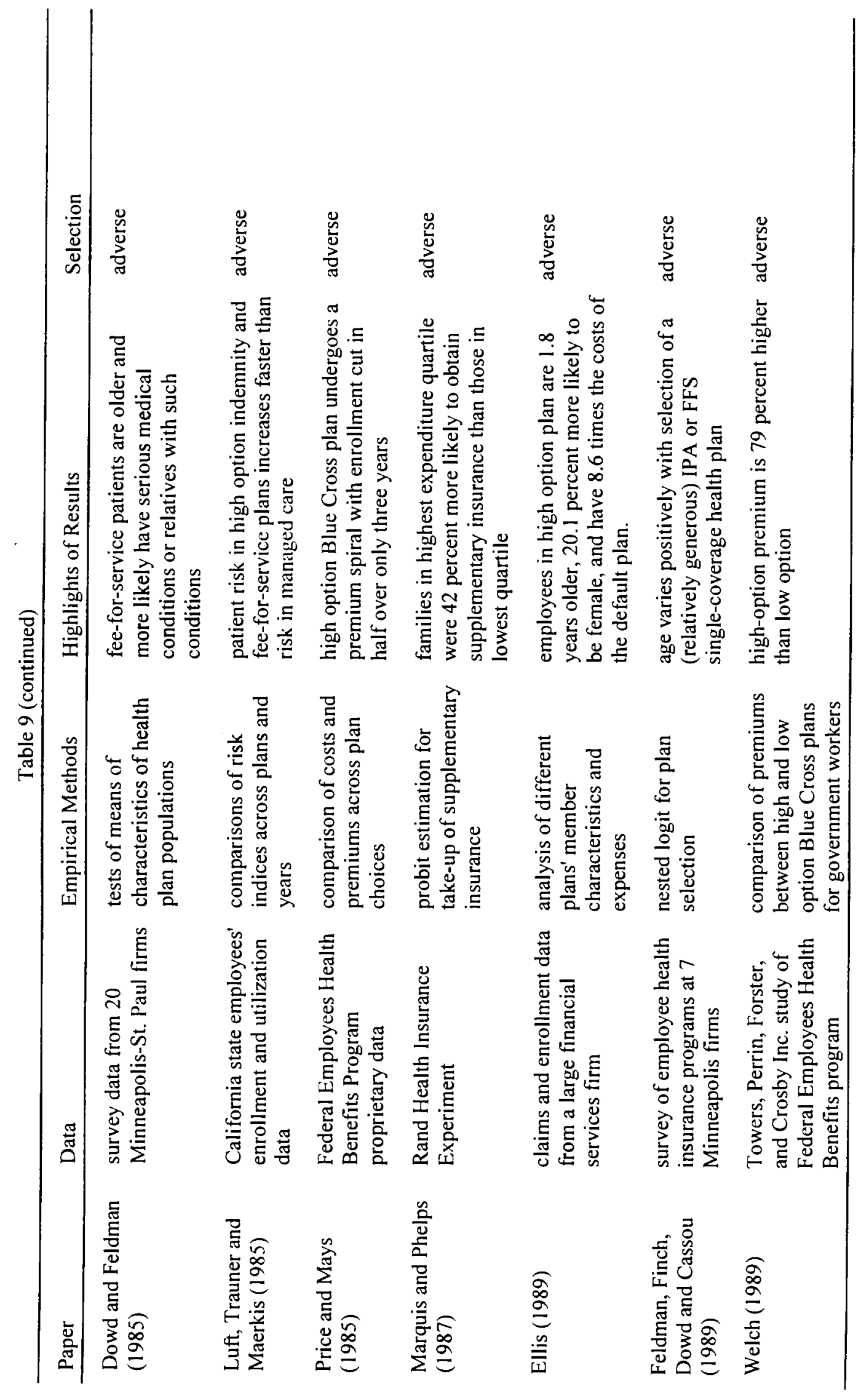




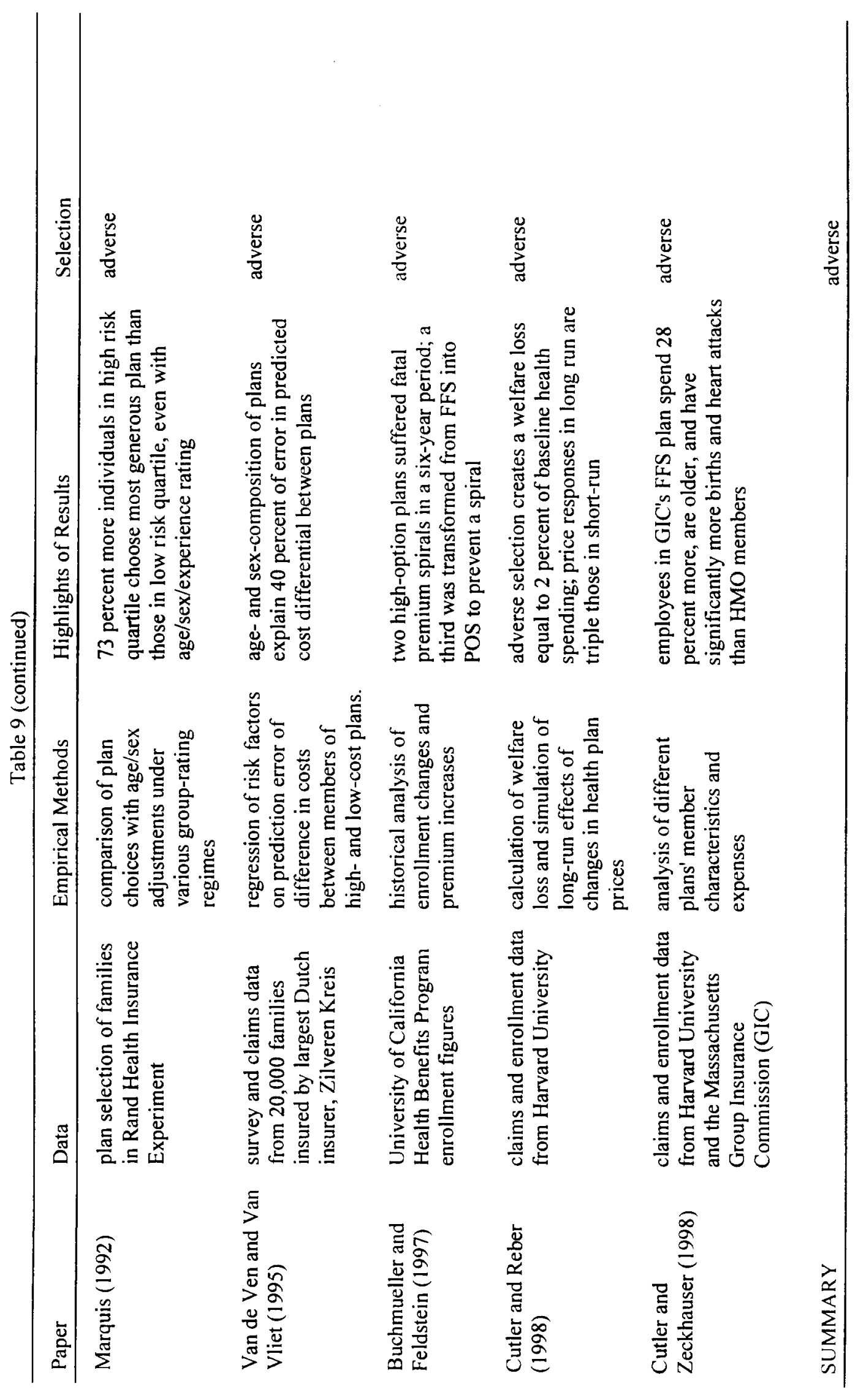


Table 10: Five Central Lessons About Health Insurance

Lesson I: Risk

Spreading versus

Incentives

Lesson 2: Integration of Insurance and Provision

Lesson 3:

Competition and Consumer Identity

Lesson 4: Information and Long-term Insurance

Lesson 5: Health Insurance and Health
Health insurance involves a fundamental tradeoff between risk spreading and appropriate incentives. Increasing the generosity of insurance spreads risk more broadly but also leads to increased losses because individuals choose more care (moral hazard) and providers supply more care (principal-agent problems).

Medical care is unlike other insurance markets in that insurers are often involved in the provision of the good in addition to insuring its cost. The integration of insurance and provision, intended to align incentives, has increased over time. Managed care, where the functions are united, is an extreme version. Under it, doctors have dual loyalties, to the insurer as well as the patient.

When consumer identity affects costs, competition is a mixed blessing. Allowing individuals to choose among competing health insurance plans can allocate people to appropriate plans and provide incentives for efficient provision. But it can also bring with it adverse selection -- the tendency of the sick to prefer the most generous plans. Adverse selection induces people to enroll in less generous plan, so they can be in a healthier pool, and gives plans incentives to distort their offerings to be less generous on care for the sick.

More information about individual risk levels allows for more efficient pricing of risk, but portends a welfare loss from incomplete insurance contracts.

The primary purpose of health insurance and delivery is to improve health. Unfortunately, conclusive results are not in on which insurance and provision arrangements do this most effectively. 


\section{Figure 1: The Medical Care Triad}

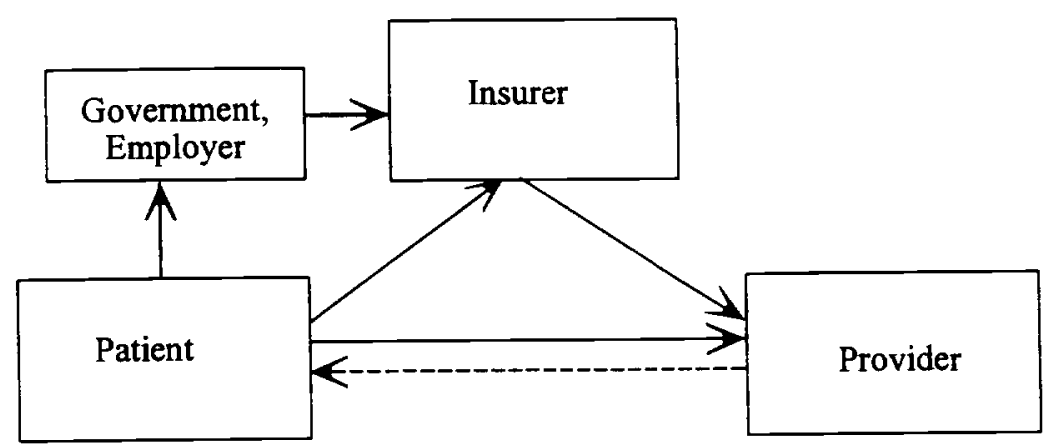

Solid lines represent money flows; the dashed line represents service flows. 
Figure 2: The Welfare Gains from Health Insurance

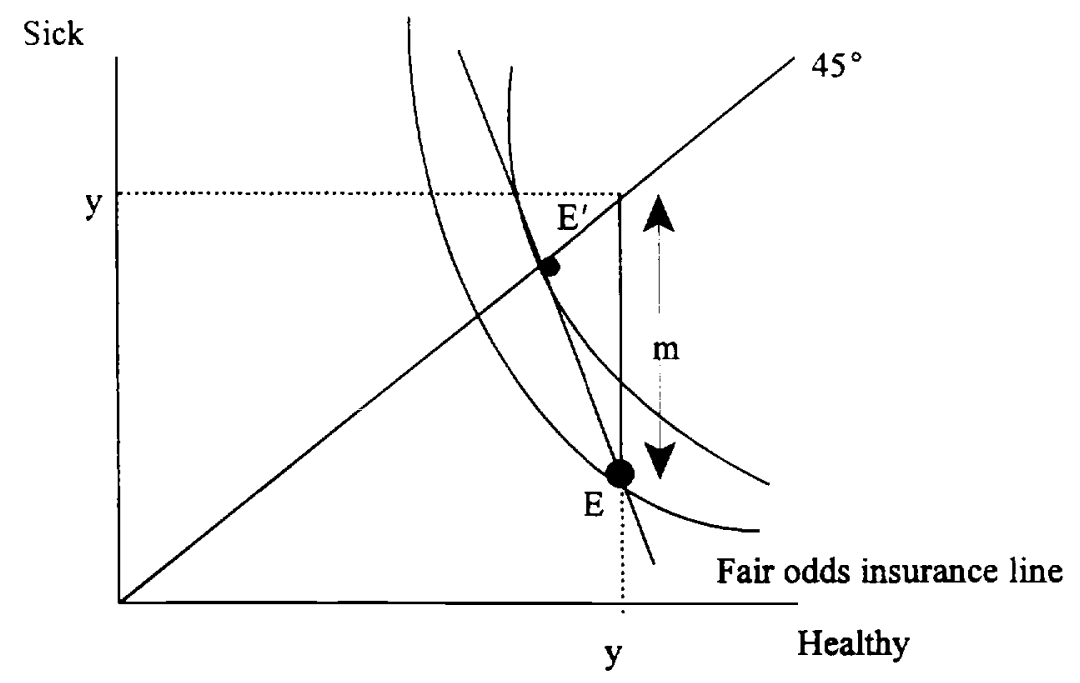


Figure 3: Cost Sharing Under Indemnity Insurance

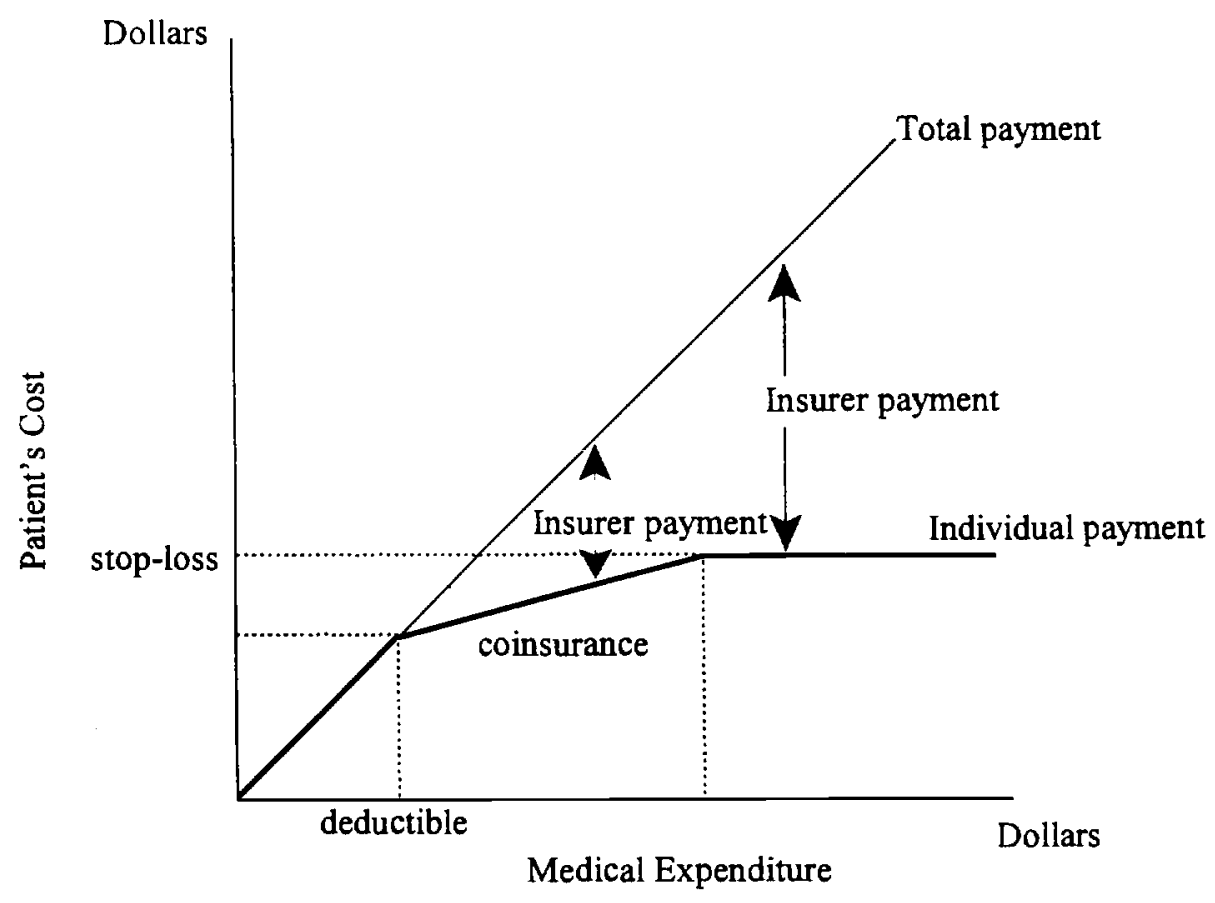




\section{Figure 4: Changes in Health Plan Enrollments}

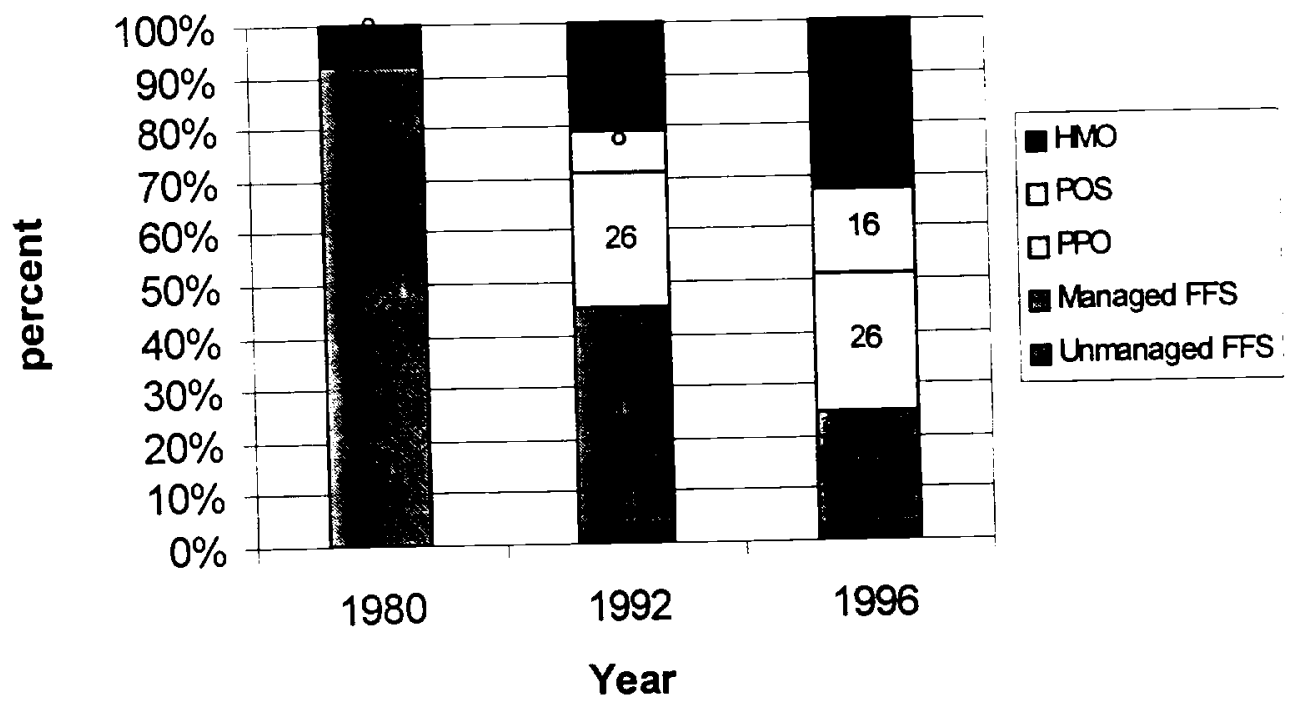

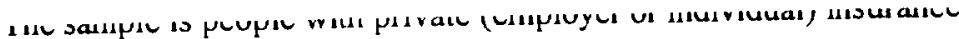
Source: Data are from Lewin-VHI. 
Figure 5: Conflict in Quantities Desired Between Providers and Patients

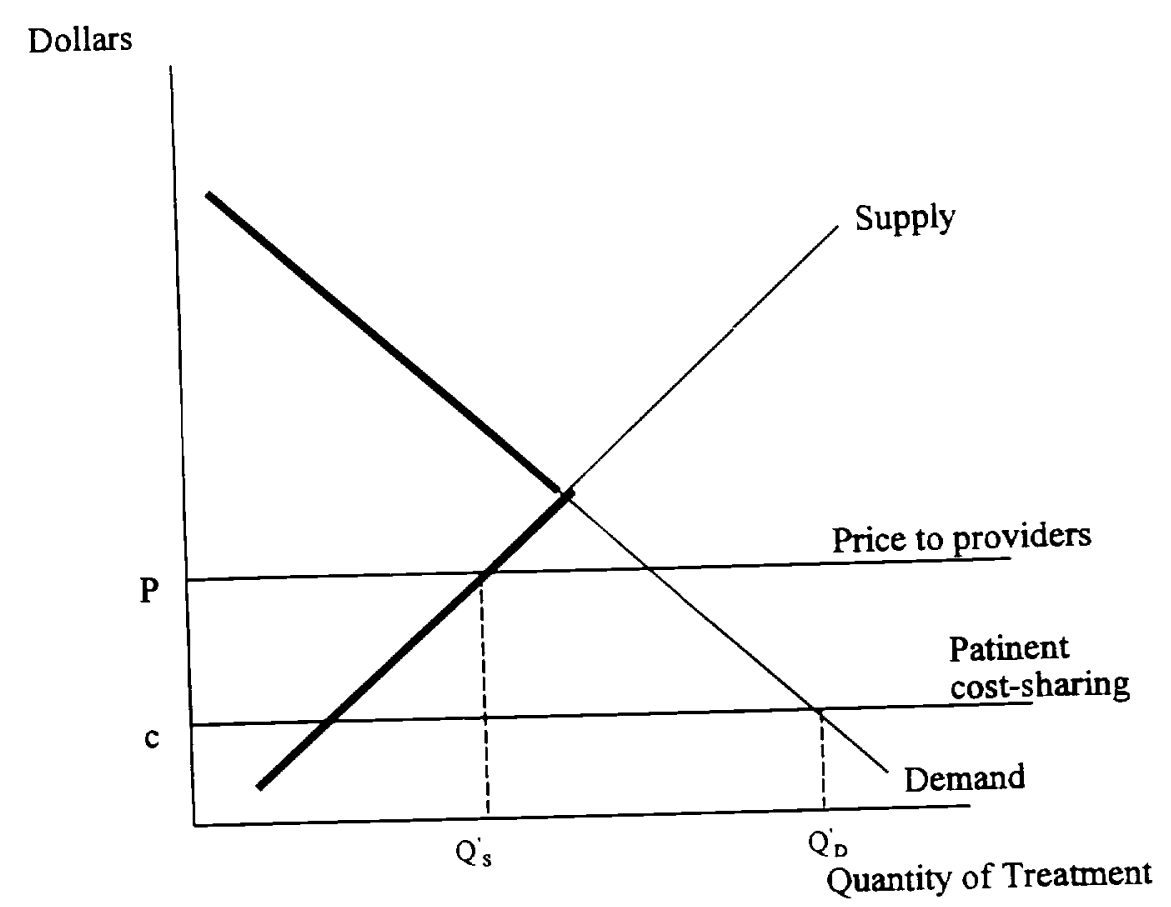


Figure 6: Demand and Supply Side Expenditure Controls

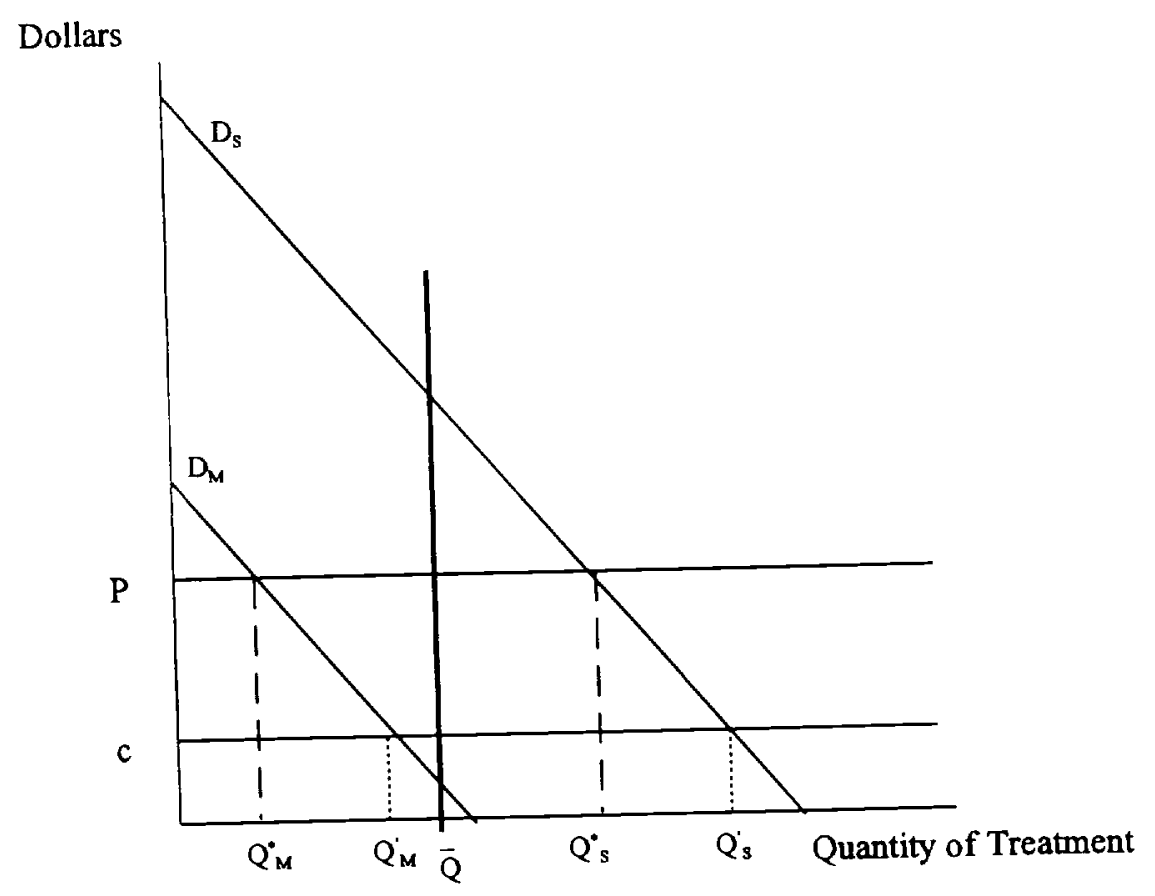


Figure 7: Reduction in Insurance to Separate High and Low (a) Stable Separating Equilibrium

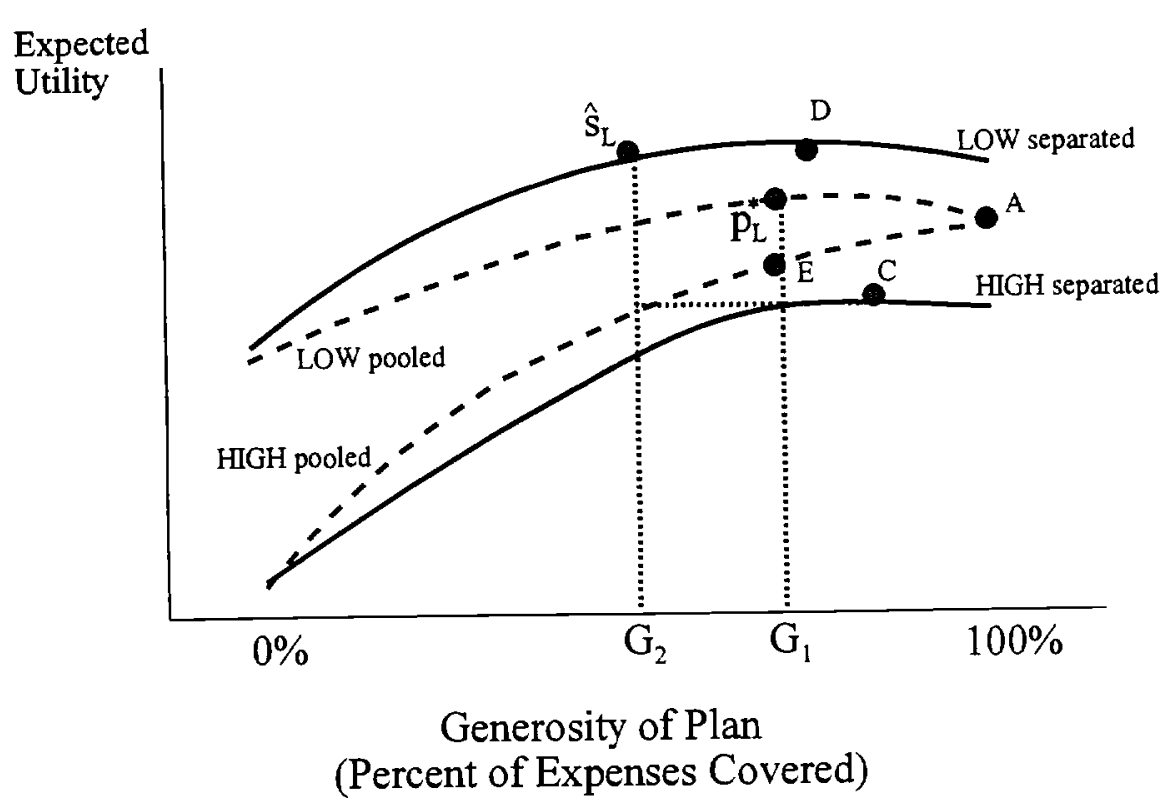

Figure 7: Reduction in Insurance to Separate High and Low

(b) Unstable Separating and Pooling Equilibria

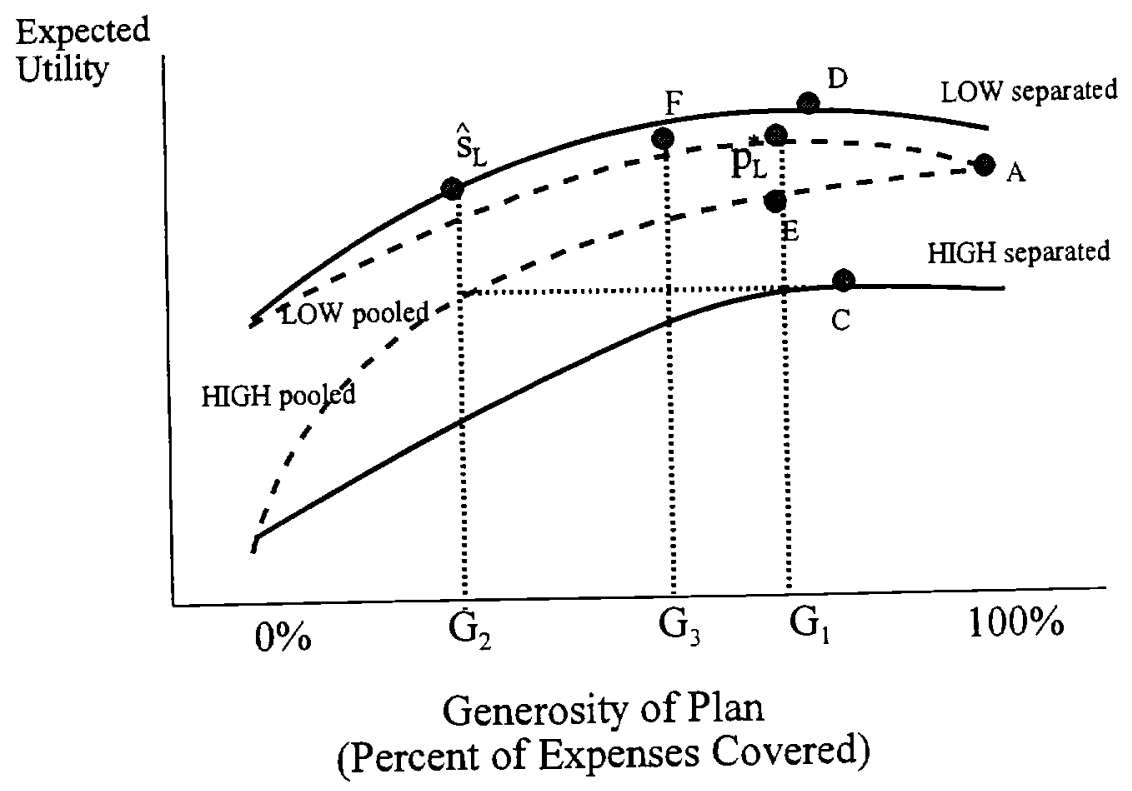




\section{Figure 8: Hybrid Equilibria with Adverse Selection}

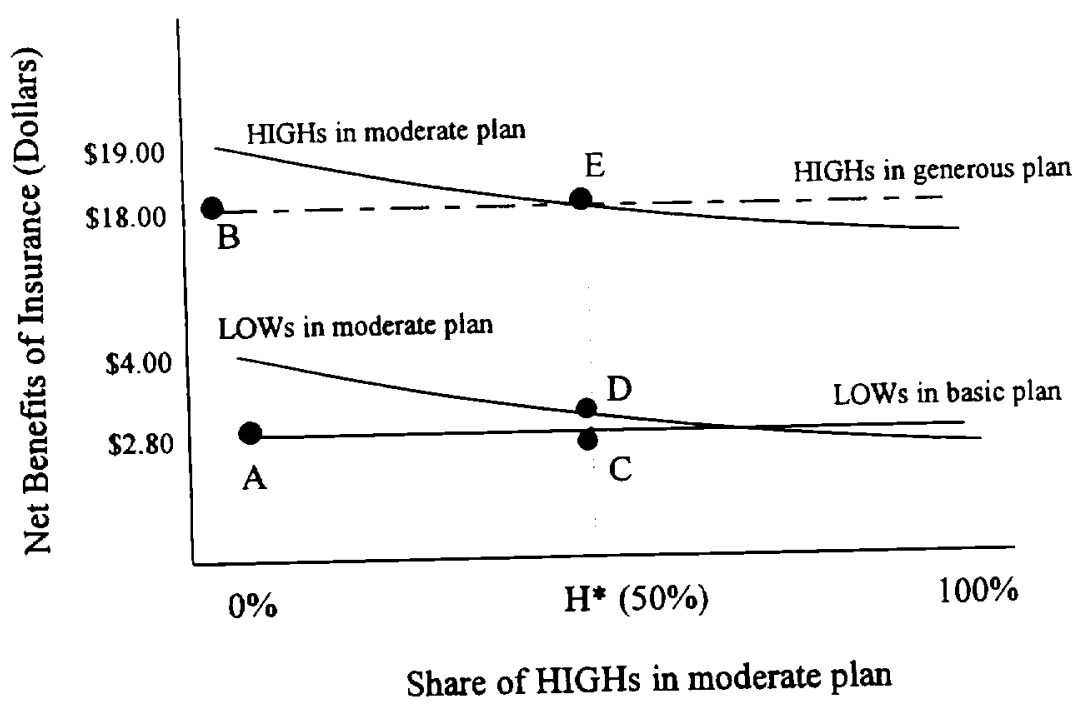

Note: Dashed lines assume all LOWs choose moderate plan. The figure uses the values in Table 9, assuming the benefits to the HIGH risks in the generous plan is $\$ 34$ instead of $\$ 33$. 
Figure 9: Enrollment Consequences of Adverse Selection

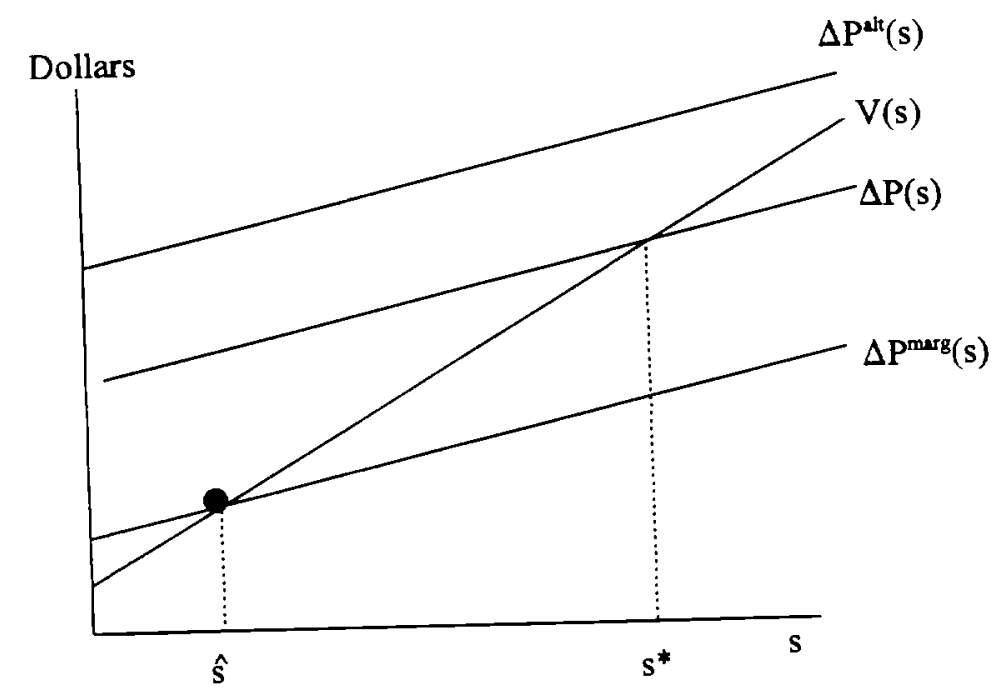



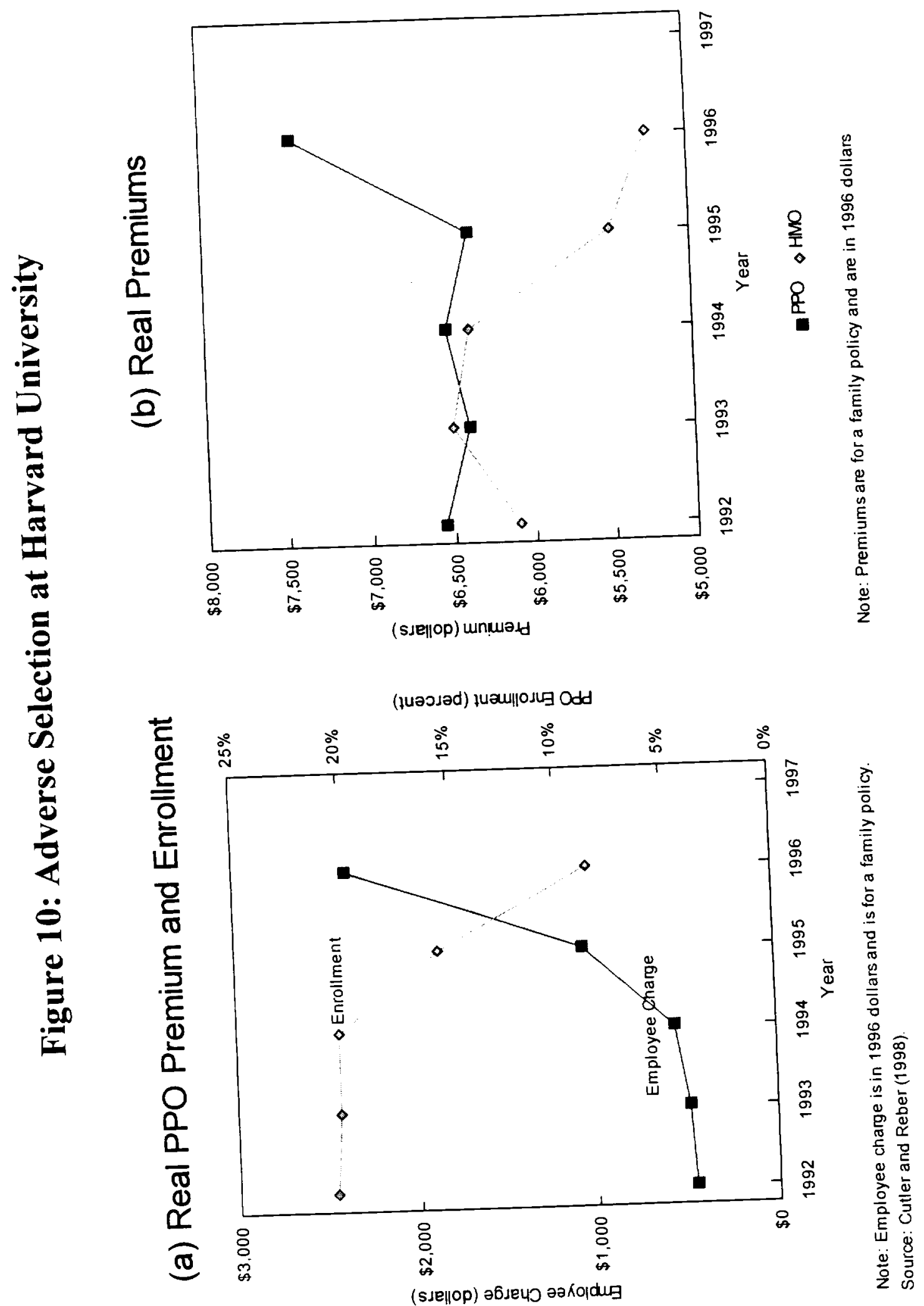


\section{Figure A: Adverse Selection and Plan Manipulation}

\section{(1) Indifference Curves}

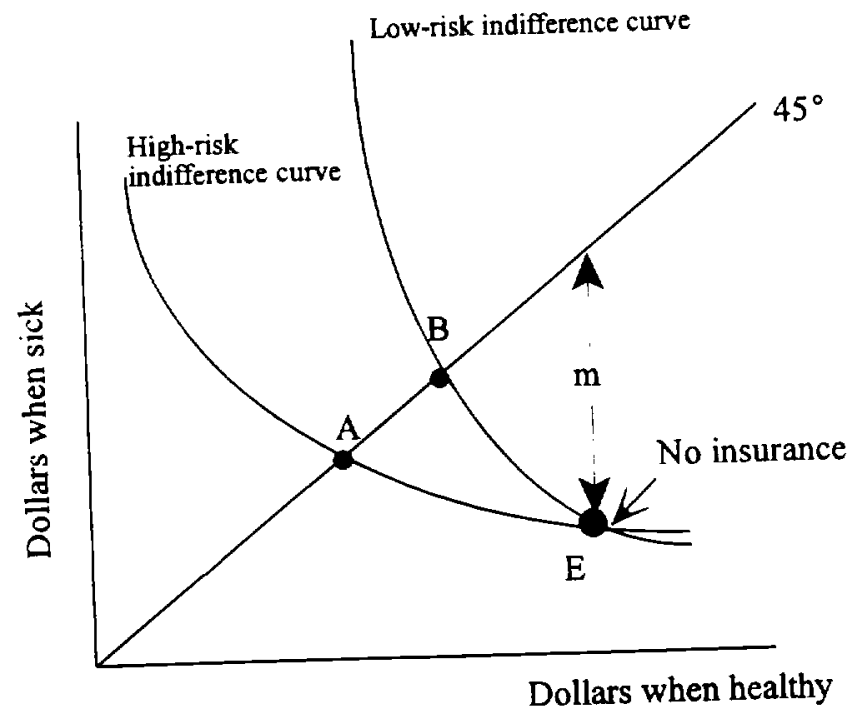

(2) Pooling Equilibrium

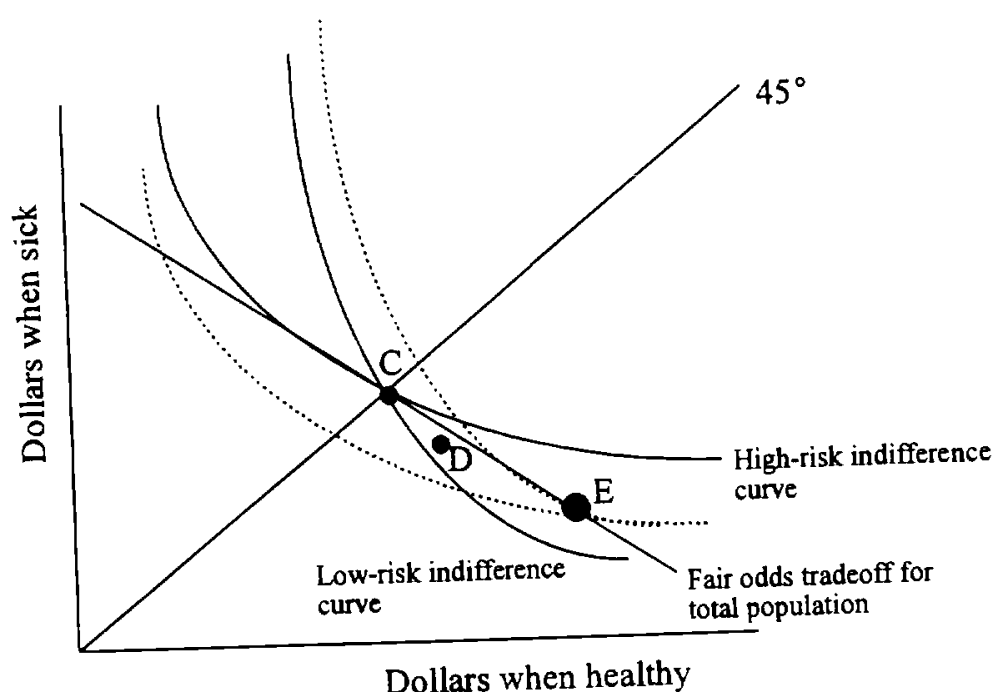

Dashed lines are indifference curves with no insurance. 


\section{(3) Separating Equilibrium}

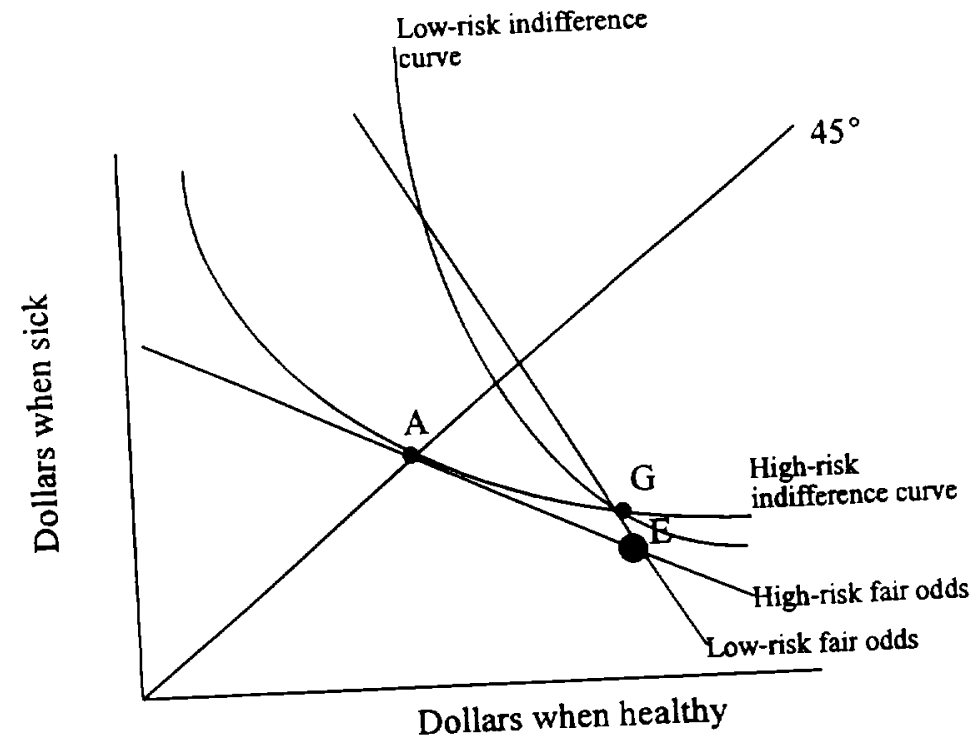

(4) Potential Non-Existence of Separating Equilibrium

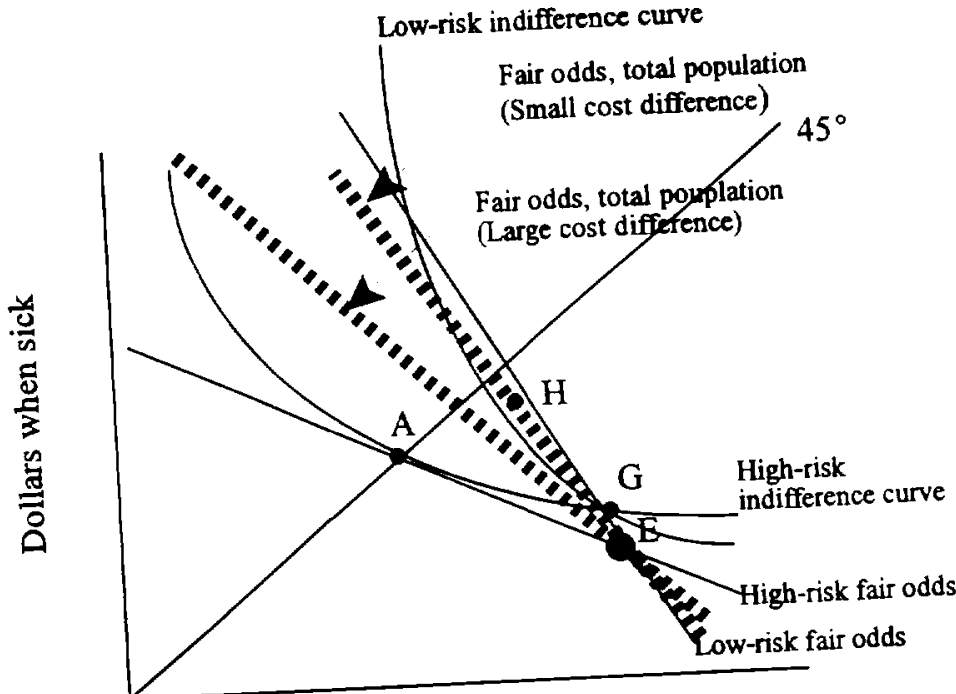

Dollars when healthy 